Portland State University

PDXScholar

3-17-2020

\title{
Tending the Fire: Wildfire Risk Management at the Interface
}

Cody Randolph Evers

Portland State University

Follow this and additional works at: https://pdxscholar.library.pdx.edu/open_access_etds

Part of the Environmental Sciences Commons

Let us know how access to this document benefits you.

\section{Recommended Citation}

Evers, Cody Randolph, "Tending the Fire: Wildfire Risk Management at the Interface" (2020). Dissertations and Theses. Paper 5416.

https://doi.org/10.15760/etd.7289

This Dissertation is brought to you for free and open access. It has been accepted for inclusion in Dissertations and Theses by an authorized administrator of PDXScholar. Please contact us if we can make this document more accessible: pdxscholar@pdx.edu. 
Tending the Fire:

Wildfire Risk Management at the Interface

by

Cody Randolph Evers

A dissertation submitted in partial fulfillment of the requirements for the degree of

Doctor of Philosophy

in

Earth, Environment and Society

Dissertation Committee:

Max Nielsen-Pincus, Chair

Alan Ager

Andres Holz

Vivek Shandas

Antonie Jetter

Portland State University

2020 
(C) 2020 Cody Randolph Evers 


\begin{abstract}
Escalating loss from wildfire in the American West has made clear the need to rethink wildfire risk, including how such risks result from the unique interaction of social and natural dynamics within the wildland urban interface. Unfortunately, techniques for studying these interactions remain limited. The intent of this research is to address this gap. In each of four chapters, I examine different aspects of wildfire risk management through a coupled human-natural lens. I document how wildfire activity has shifted over three decades across forest and shrubland systems in the western US and connect these changes to the simultaneous growth in development within fire-prone wildlands. Using wildfire models, I then examine the transmission of wildfire risk from public land into nearby communities to quantify both the magnitude and geographic extent of wildfire exposure across the American West. These results show how community exposure has become geographically concentrated within several dozen regional hotspots, each featuring a distinct mix of exposure conditions. The dissertation then shifts its focuses to wildfire management within one specific hotspot, North Central Washington. Here I map where wildfire risk management crosses ownership boundaries to address risk and how the resulting organizational diversity appears to shape the roles that different organizations play. Finally, I look at the network structure of relationships among those managing wildfire risk and show that geographic proximity and shared risk lead to collaboration. Together, this work represents a cohesive body of research that expands coupled social and biophysical knowledge of wildfire risk management.
\end{abstract}




\section{Dedication}

To my parents for their unconditional support

To my wife for her courage and perseverance

To my daughter for a love I never imagined 


\section{Acknowledgments}

The research presented in this dissertation would not have been possible without the guidance and support of many. A special thanks goes to Max Nielsen-Pincus, the chair of my dissertation committee, for his reliably, timely, and sage advice. The work of Alan Ager provided the foundation for much of this research. I deeply appreciate his drive and curiosity. Thanks goes to Andres Holz for inspiring the work in Chapter 1 and for the intellectual engagement and honesty that he applies to all of his work. I thank Vivek Shandas for our early conversations on community resiliency and ecosystem services. His enthusiasm and creativity always inspired. The Rocky Mountain Research Station of the USDA Forest Service provided financial support for much of this research. I also wish to acknowledge the training and support provided by the National Science Foundation Integrated Graduate Research and Education Traineeship (IGERT) program. A dissertation is a long journey influenced by many colleagues and friends. Thanks goes to numerous classmates and colleagues at Portland State University, Oregon State University and University of Oregon. 


\section{Table of Contents}

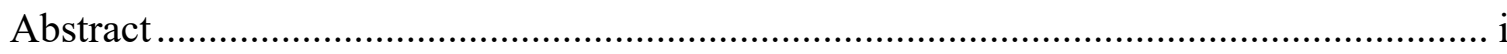

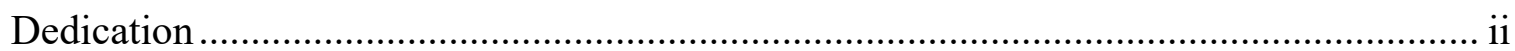

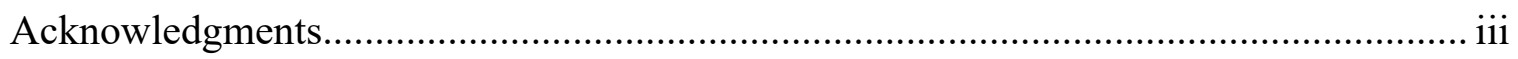

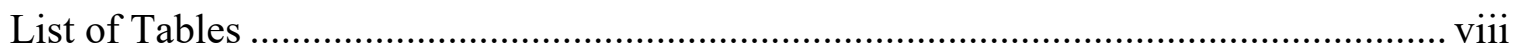

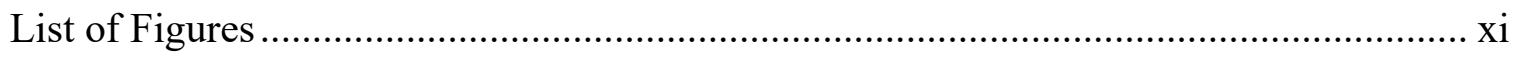

Introduction: Wildfire Risk Management at the Interface ...........................................

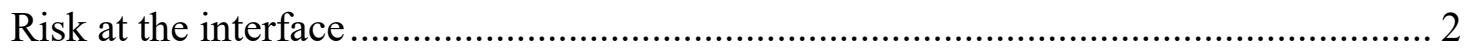

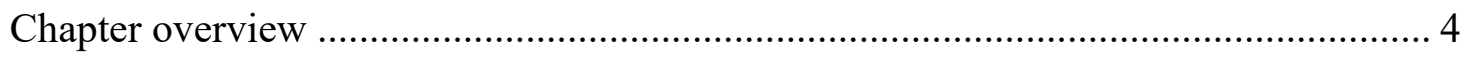

Chapter 1: Shifting Fire Regimes in the American West .........................................

1. Shifting Fire Regimes in the American West.................................................... 11

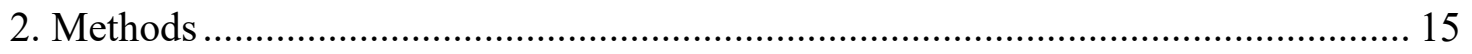

2.1. Classifying vegetation and fire regimes ............................................................ 16

2.2. Classifying social dimensions of fire activity ……................................................

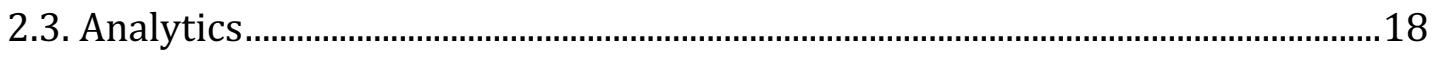

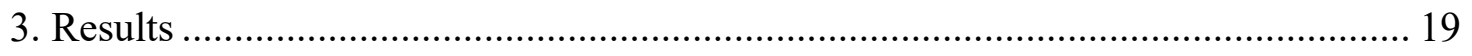

3.1. Shifts in fire activity among vegetation systems ..............................................19

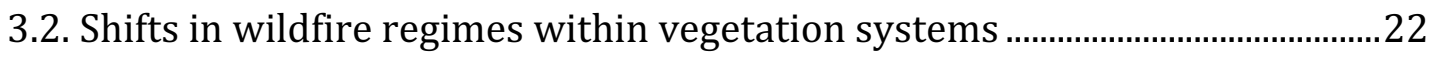

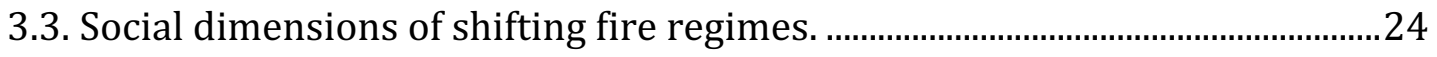

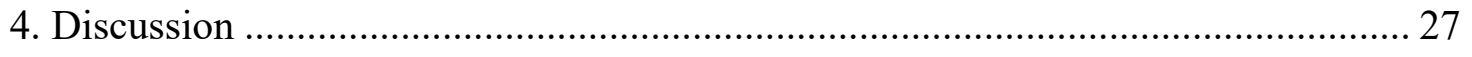

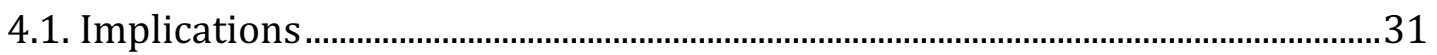




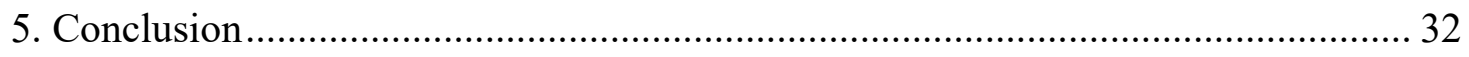

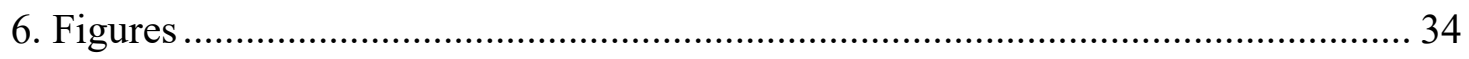

Chapter 2: Archetypes of Community Wildfire Exposure ...............................................44

1. Archetypes of Community Wildfire Exposure …………………......................... 46

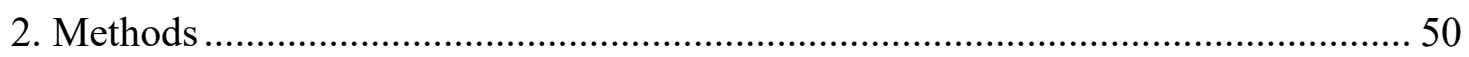

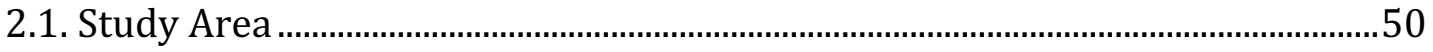

2.2. Simulation exposure to communities................................................................5

2.3. Characterizing wildfire exposure..............................................................................53

2.4. Gradient and cluster analysis of wildfire exposure.............................................55

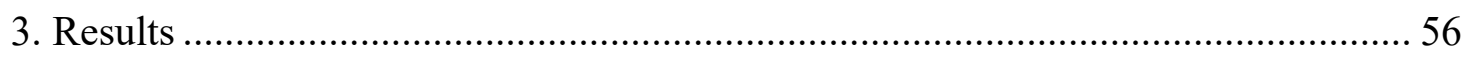

3.1. Community exposure to wildfire originating from national forests.................56

3.1. Variation in conditions among highly exposed communities.............................58

3.2. Archetypes of community wildfire exposure..........................................................59

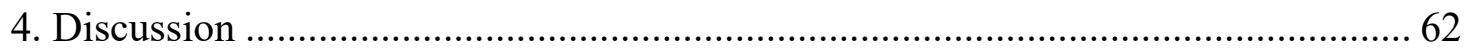

4.1. National forest sources areas .............................................................................6

4.2. Community exposure areas ......................................................................................6

4.3. Connecting multiple scales of exposure ..............................................................66

4.4. Limitations and Future Research...........................................................................67

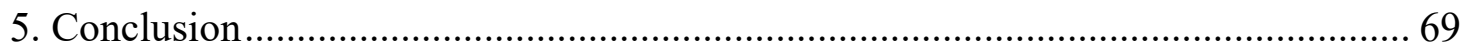

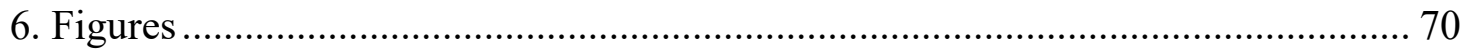

7. Tables ………

Chapter 3: Organizational Geography of Wildfire Risk Management ...............................81 
1. Organizational Geography of Wildfire Risk Management .................................. 82

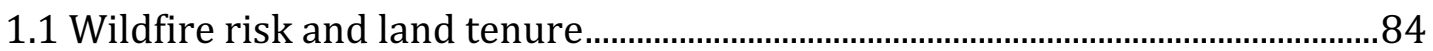

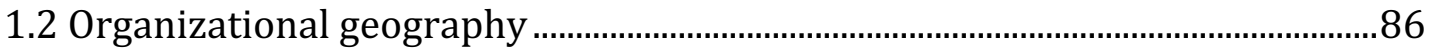

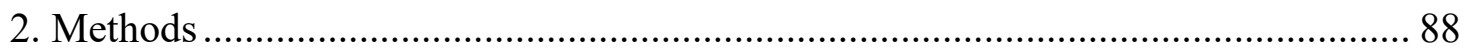

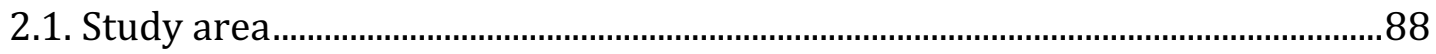

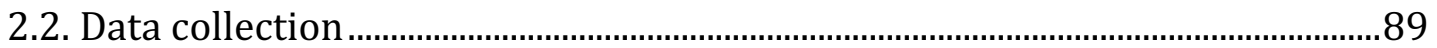

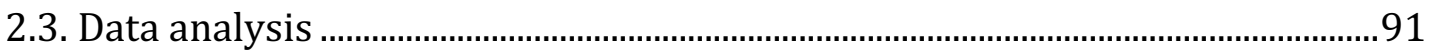

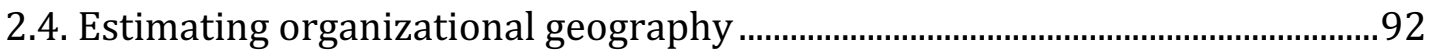

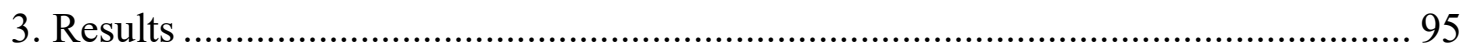

3.1. Organizational groups and roles .............................................................................95

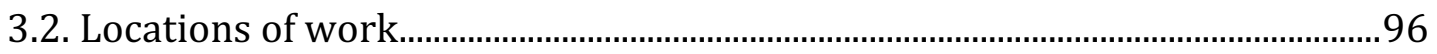

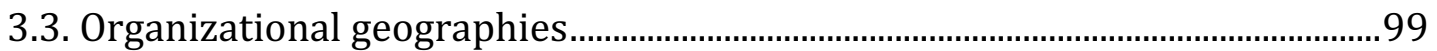

3.5. Organizational diversity and role specificity ..................................................... 100

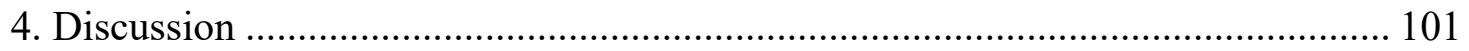

4.1 Organizations involved in addressing wildfire risk ........................................101

4.2. Organizational geographies of wildfire risk management...............................102

4.3. Organizational diversity and role specificity .................................................... 104

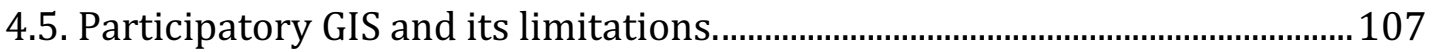

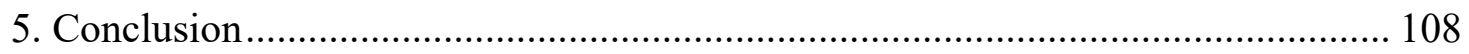

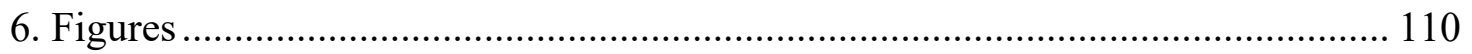

Chapter 4: Collaboration in the Wildfire Risk Management System ............................114

1. Collaboration in the Wildfire Risk Management System ................................. 115 


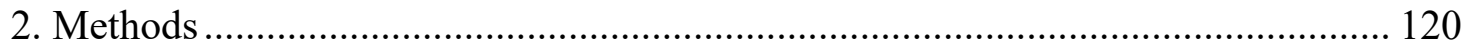

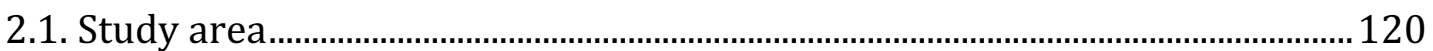

2.2. Wildfire risk management system (WRMS) survey .........................................121

2.3. Relational analysis using exponential random graph models (ERGM) .......122

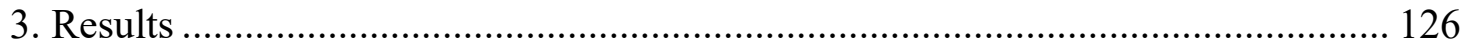

3.1. Wildfire risk management community............................................................126

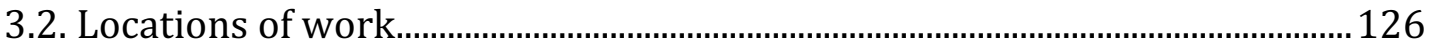

3.3. Predictors of work relationships..........................................................................127

3.4. Spatial influence on work relationships..............................................................130

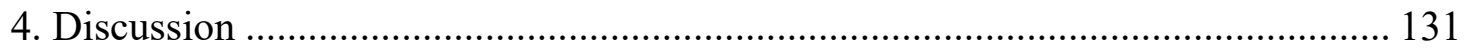

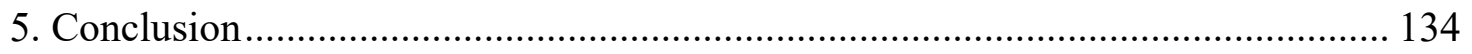

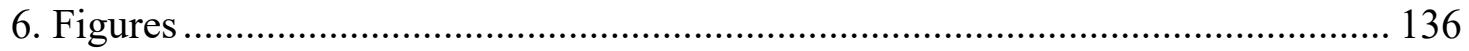

Conclusion: Wildfire Risk Management at the Interface ................................................140

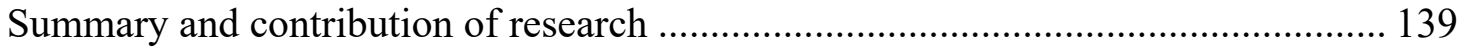

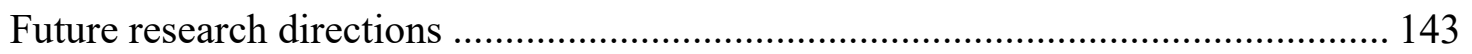

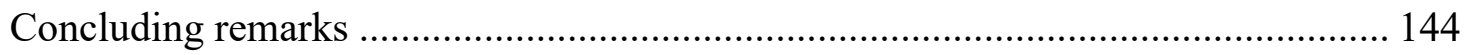

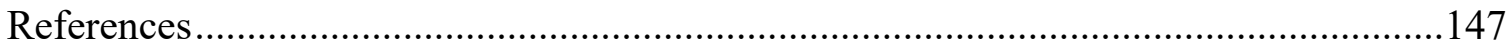




\section{List of Tables}

\section{Chapter 1}

Table 1. LANDFIRE fire regime groups for the western US (Rollins et al., 2009)....

Table 2. Cross-tabulation between vegetation potential and fire regime group. Marginal totals are shown in bold (data source: LANDFIRE).

Table 3. Change in annual area burned (AAB) among fire regimes groups for forest and shrubland systems. Changes are reported as an absolute value, percent, and as a proportional share of the overall change

Table 4. Change in the wildland urban interface between 1990 and 2010 by vegetation potential and fire regime group. Changes are reported both as area and structure count in terms of absolute change, growth, and the proportional share of growth. $\mathrm{IM}=$ intermixed WUI; IF = interface WUI. Shr $=$ share of WUI structure and area as of 2010

\section{Chapter 2}

Table 1. Variables used to distinguish the nature of wildfire exposure among threated communities. Variables reflect conditions found within the national forest source

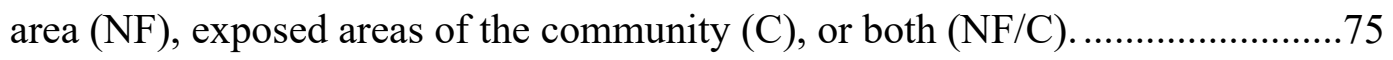

Table 2. Descriptive statistics of wildfire exposure among highly exposed communities $(n=516)$. The reference values represent the average conditions among western national forests and western communities (WUI and non-WUI). 
Table 3. Loadings of exposure variables on the 8 components (F1-F8) used to distinguish community archetypes. Components are ordered by the variance explained. Loadings greater than 0.5 are shown in bold while loadings less than 0.1 are omitted. .78

Table 4. Descriptive statistics show differences in the character of exposure among 5 community archetypes, represented as mean values and standard deviations

\section{Chapter 3}

Table 1. Roles related to addressing wildfire risk. Roles capture roles related to wildfire risk before, during, and after wildfires.

Table 2. Geographic context variables used to predict the distribution of work of organizational groups, along with a brief description and source for each. All reference data were processed at a 270-m spatial resolution.

Table 3. Number of responses by organizational group along with the number of work locations reported in the five-year period prior to 2018

Table 4. Role participation by organization type (i.e., \% of respondents that reported role). Cells marked with $+/$ - had higher/lower role participation than the average (based on $95 \%$ confidence interval).

Table 5. Organizational geographies (\%) based on underlying land ownership. Cells marked with +/- were more/less common than expected based on chi-squared tests. 
Table 6. Portion of work locations reported inside the WUI or within 1-mile, 2.5-miles, or 5-miles of the WUI, grouped by primary organizational groups.

Table 7. Importance of environmental covariates in determining the working geography of each organizational group.

\section{Chapter 4}

Table 1. Estimated coefficients from the complete ERGM model. Positive estimates reflect factors promote working relationships among actors while negative estimates dissuade ties. Effects are additive. 


\section{List of Figures}

\section{Chapter 1}

Figure 1. (A) Large wildfires occurring in the western US between 1984 and 2015 priorand post-2000. (B) Environmental site potential alongside WUI and non-WUI developed areas.

Figure 2. (A) Map of forest systems colored by fire regime (103.5 M ha, 23\% of area shown). (B) Map of shrubland systems colored by fire regime (124.6 M ha, 28\% of area shown). Other cover types (primarily grasslands and barren) are shown in light grey (data source: LANDFIRE).

Figure 3. (A) Annual area burned (AAB) colored by vegetation system (forest, shrubland, grass, other). (B). Annual values prior- and post-2000 with significance (p-values less than 0.05 highlighted in red). (C/D) Same as above but reported as an annual

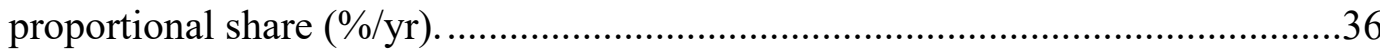

Figure 4. (A) Annual burn ratio between forest- and shrub-systems by year (bars colored by vegetation potential; green = forest; brown = shrub). (B) Annual burn-ratio compared to overall annual area burned. Differences between periods in the distributions of $\mathrm{AAB}$ and burn-ratio are shown above and to the right. In both panels, the 1:1 ratio is shown as a horizontal solid line. Significance labeled for

trends in each panel.

Figure 5. Percent of wildfire burn area $(n=9228)$ within forest system (compared to other vegetation types) colored by dominant vegetation system. Point color reflects 
dominant vegetation potential. Green $=$ forest; Orange $=$ shrubland; Purple $=$ grassland.

Figure 6. Variation in annual area burned by dominant fire regime within forest (A) and shrubland (B) systems, divided prior- and post-2000 (Wilcox p-values less than 0.05 are in bold). (C/D) Same as above but transformed to annual proportional share $(\%)$. Fire regimes: FRG1 $=$ frequent and low-severity, FRG2 = frequent and severe; FRG3 = intermittent and mixed-severity; FRG4 = intermittent and severe; FRG5 = infrequent with variable severity.

Figure 7. Pairwise comparison of annual burn ratios among forest wildfire regimes and annual area burned. Panels are equivalent to that shown in Figure 4A. Significance of the trend (dashed line) is labeled (trend) along with correlation with the total annual area burned (AAB; equivalent to Figure 4B). Significant values are highlighted. Fire regimes: FRG1 = frequent and low-severity, FRG2 = frequent and severe; FRG3 = intermittent and mixed-severity; FRG4 = intermittent and severe; FRG5 = infrequent with variable severity.....

Figure 8. Pairwise comparison of the trends in burn-ratios among shrubland wildfire regimes. Significance of the trend (dashed line) is labeled (trend) along with correlation with the total annual area burned (AAB; equivalent to Figure 4B). Significant values are highlighted. Fire regimes: FRG1 = frequent and lowseverity, FRG2 = frequent and severe; FRG3 = intermittent and mixed-severity; FRG4 = intermittent and severe; FRG5 = infrequent with variable severity 
Figure 9. Proportion and trends (dashed line) of annual area burned partitioned by land ownership and protection status (all vegetation types; panels ordered by overall proportional share of fire; note differences in y-axes). Trends lines over period are shown as dashed lines. Y-axes are freely scaled so note labeled values. FSM/P = National forest managed/protected; PRM/P = Private managed/protected; BLM/P $=$ Bureau of Land Management managed $/$ protected; STM $/ \mathrm{P}=$ State managed/protected.

Figure 10. Change in fire activity (median AAB) and WUI (ha and structure count). Arrows labeled by vegetation potential, fire regime group, and WUI type: $\mathrm{F}=$ forest; $\mathrm{S}=$ shrub; $1-5=$ fire regime group; $\mathrm{M}=$ mixed WUI; $\mathrm{F}=$ interface WUI. The top row represents WUI change as area. The bottom row represents WUI change as structure count.

\section{Chapter 2}

Figure 1. Community wildfire exposure was determined using the area where wildfire and development intersect (red-hashed area). The archetype of community exposure was based on conditions within both the source area where wildfire ignited (yellow-hashed area) and the exposed area of the community (red hashed). Conditions for both areas were averaged for the entire community based on thousands of possible wildfires.

Figure 2. Community wildfire exposure was grouped into 5 exposure archetypes based on 8 components. The number of components $(\mathrm{f}=8)$ was determined using parallel 
analysis (left). The number of clusters $(\mathrm{k}=5)$ was chosen based on the change in the area under the curve (right) for successive cumulative density functions (middle)

Figure 3. Map of the western US shows the 516 communities that account for $80 \%$ of the wildfire exposure originating in the national forest. Areas of the national forest that contribute the most exposure are shown in orange and the most exposed areas within communities are shown in magenta

Figure 4. Exposure patterns for highly exposed communities divided into five archetypes, as shown in the dendrogram and consensus plot above and in the map below. Differences in the height of branches in the dendrogram reflect differences within and among clusters. Branches of the dendrogram dominated by a single color in the consensus plot represent greater homogeneity among communities within archetypes (e.g., C2 open-interface), while branches containing a mixture of colors represent groupings that are less distinct.

Figure 5. Community archetypes reflect different priorities for managing wildfire risk. Vegetation management, for instance, is effective in only half of highly exposed communities (i.e., $\mathrm{C} 3$ mixed-interface and $\mathrm{C} 4$ forested-intermix communities). Differences in prioritization also indicate different needs for cross-boundary coordination and which actors are involved. 


\section{Chapter 3}

Figure 1. The study area is located in North Central Washington on the east side of the Cascade Mountains (50 miles east of Seattle). More than 380,000 people reside in the region. Major communities are labeled. For reference, the study area is broken into six drainages: 1) Methow, 2) Okanogan, 3) Chelan, 4) Wenatchee, 5) East of the Columbia, and 6) Yakima.

Figure 2. Organizational geographies for six major organization groups involved in wildfire risk management. Highlighted locations represent those areas predicted by the work distribution models that had similar environmental attributes to actual work locations.

Figure 3. Relationship between organizational diversity (derived from the overlap of all organizational geographies) and role diversity (derived from the total number of reported roles) grouped by organizational group.

\section{Chapter 4}

Figure 1. Transformation in the wildfire risk management system as risk becomes more complex. Three transformations are illustrated: risk interdependency; spatial externalities, and; coordinated management.

Figure 2. (A) Principal land cover North Central Washington study area shows a mixture of forest and shrubland systems. (B) Fire frequencies vary between 30 and 500 years with the most flammable areas occurring at the transition zone from dryland-forest to open desert-steppe. (C) Land ownership represents a mixture of private and public lands with developed areas occupying valley bottomlands. .137 
Figure 3. Relationship between the social network and reported work location. Actor-toactor collaborative work-ties (A) are superimposed over ties that connect the actor to the location of work (B). Social distance in A is implied by the relative distance between actor nodes........ 138 


\section{Introduction:}

\section{Wildfire Risk Management at the Interface}

Risks from wildfire have continued to escalate despite substantial efforts to protect people and property. The dynamics underlying this trend center on the area where human and natural communities meet - the wildland urban interface. Nationwide, the wildland urban interface (WUI) contains more than 40 million structures, of which a substantial portion are found in areas prone to frequent wildfire. A recent insurance report estimated as many as 800,000 homes are built in areas of extreme fire risk, which collectively represent more than $\$ 220$ billion dollars at risk. The magnitude of this estimate has been brought into sharp relief in recent years as home losses from fires in California in 2017 and 2018 totaled more than $\$ 33$ billion dollars, led to hundreds of deaths, and forced one of the nation's largest utilities to file bankruptcy over the resulting liability.

Given increased hazard and surging suppression costs, government agencies are under intense pressure to improve risk governance. To do this, agencies have increasingly turned to risk-based decision making, which proponents argue allows for improved efficiency, proactive management of risk, and improved capacity for achieving management objectives. Yet, traditional definitions of risk focus on events that are relatively well understood, have a known frequency of occurrence, and have a clear direct relationship between the event and its impact. Wildfire risks violate many of these assumptions, which leads to the uncertainty, complexity, and ambiguity surrounding 
wildfire. No one agency or stakeholder owns complete responsibility for the event and wildfire risk management increasingly requires multiple actors to coordinate their actions. Risks are not evenly distributed in the landscape, nor do they mean the same thing for all the different parties, which can make it unclear who should do what and why they should do it. This ambiguity compounds uncertainty since different people react to the same risk in different ways and depending on how that risk is framed. Further, various social and biophysical feedbacks lead to a litany of seemingly paradoxical outcomes. When wildfires are suppressed, fuels accumulate, which promotes the size and severity of the future fire, ultimately making suppression more difficult. Such feedbacks are also seen among social actors. For instance, by treating wildfire risk as an environmental hazard, rather than one linked to social behaviors, governments effectively subsidize the cost of developing in fire-prone areas, which in turn promotes more development in high-risk areas and increased risk exposure over time.

\section{Risk at the interface}

Viewing wildfire as an event that occurs at an interface provides some insights into these dynamics. An interface reflects a place at which independent and somewhat unrelated systems meet and act on each other. In the simplest sense, fire is a chemical reaction that occurs at the interface between oxygen and fuel. At larger scales, wildfire activity occurs at the interface between weather and fuels. In order to propagate, fire depends on the gaseous byproducts produced as fuels are heated and organic matter begins to disassociate. Water, which is present in both living and dead fuels, serves to counteract this process by absorbing heat and dampening the reaction. Thus, fire activity 
occurs at a global interface where fuels are available to burn and conditions are sufficiently dry for fire to propagate.

The risk from wildfire is also found at the interface. Representing the possibility of loss, wildfire risk is technically found where wildfire threatens directly threatens something of value. Geographically, this interface is found where communities and wildland meet. Here, wildlands capable of burning carry fire towards and through communities, creating the possibility of catastrophic loss. Much of this development occurred during a period in the twentieth century when wildfire was relatively quiescent, due in large part to long-standing policies of aggressive fire suppression. This, in turn, resulted in communities acutely ill-adapted to deal wildfire. Even to this day, many zoning rules in many threatened communities encourage homeowners to build and landscape using flammable materials and vegetation.

Social and biophysical characteristics within and surrounding WUI largely determine how and the degree to which communities are affected, how wildfire can be accommodated, and the type of institutional changes in wildfire risk governance that need to be made. Yet the reciprocal nature of these social and biophysical feedbacks can lead both communities and surrounding ecosystems to fall into undesirable states that resist easy fixes while risk continues to mount. Some of these problems can emerge when social institutions become misaligned with the ecological processes they intend to manage, including when wildfire and wildfire risk spills across jurisdictional boundaries. In such cases, affected social actors must coordinate their actions, each working in 
distinct geographies and/or function at different scales (e.g., individual, local, state, federal). These changes require time, investments, and foresight.

Despite advances in the conceptual framing of wildfire risk as a coupled human and natural system, empirical research on coupled wildfire risk remains lacking. My dissertation speaks to this gap by approaching the topic of wildfire risk as a coupled social and natural system. As a result, I approach this topic from several disciplinary angles - fire ecology, geography, and social science - and combine a variety of research techniques, including remote sensing, wildfire simulation, social surveys, network analysis, and participatory GIS mapping. The research is organized into four chapters, each written as an individual paper with its own set of research questions, results, and conclusions. This differs from the traditional dissertation monograph, yet my intention is that, taken together, the chapters create a cohesive body of work. The theme of the interface is present throughout this work. This research suggests that the reason that wildfire risk has expanded so rapidly in the wildland urban interface is the result of a diverse set of both social and biophysical processes operating on multiple scales. The interaction of society and the surrounding environment has resulted in a diversity of contexts under which risk must be managed and a spectrum of adaptive responses that need to be documented and learned from. What follows is a brief overview of each chapter.

\section{Chapter overview}

Chapter 1 examines the social and biophysical changes in wildfire activity in the western US over three decades. Beginning near the turn of the century, these changes 
resulted in a series of national policies and programs designed to address elevated wildfire activity. Most of these efforts were designed targeted at restoring historical fire regimes, which describe the frequency and severity of disturbance that shaped landscapes prior to Euro-American settlement of the West. Still, fire regimes are a dynamic property of ecosystems resulting from the interaction of ignition sources, vegetation, and climate trends and patterns. What is more, the human footprint on fire regimes can be marked, both by changing the timing, frequency, and locations of ignitions, but also in terms of suppressing naturally occurring fires. Therefore, the possibility exists that the very standards used to guide national fire management programs have become obsolete and that wildfire activity has and will continue to evolve in directions in which current research and management practices are ill-suited.

Chapter 2 focuses on wildfire exposure to communities resulting from fires igniting in nearby national forests. Given its historical role managing wildfire, much of the attention on increased wildfires have been directed towards the US Forest Service (USFS), due in part to massive amenity value that national forests and public lands have come to have on nearby communities. Besides leading the USFS to increasingly frame its management mission in terms of ecosystems services and recreation opportunities, the slow encroachment of homes created the conditions that allow massive wildfires in public lands to threaten nearby communities. The agency has begun to address this threat through a spectrum of strategic initiatives, but rarely are all tools appropriate to all contexts. Chapter 2 examines wildfire transmission from national forests into communities to determine the scale and diversity of this exposure. It relies on wildfire 
simulation to estimate risk and builds from previous work using network approaches to describing wildfire risk. Looking at wildfire risk in the Western US reveals how much development, and therefore risk, is clustered into several dozen geographic clusters. These include areas like the Wasatch Front in Utah, the Front Range of Colorado, and North Central Washington. While labeling any one of these areas as a problem would come as no surprise, these areas also represent a deep library of learned experience as people and organizations within these regions have prepared for, experienced, and recovered from wildfire. Taking this perspective, there is much that can be learned from each region, and an urgent need to be able to apply that knowledge to other regions also experiencing elevated fire risk.

The following chapters switch scales to look at wildfire risk management in North Central Washington, one of the several dozen national risk hotspots discussed above. These chapters focus on the wildfire risk management system, a term meant to describe the spectrum of social actors involved in addressing wildfire risk in the region given that no one actor has the authority or capacity to coordinate all aspects of this endeavor. Framing wildfire risk management in terms of a network of interconnected individuals, organizations, and agencies is a novel aspect of this work, particularly given its quantitative focus. Given its novelty, I frame these chapters around a series of relatively basic questions: Who is involved in wildfire risk management? What do they do? Where do they work? How do different actors work together?

My interest in Chapter 3 lies in understanding where different organizations involved in wildfire risk management actually work. For agencies that manage public 
lands or fire districts associated with certain jurisdictions, this may seem rather obvious. Yet, when it comes to risk mitigation, fire response, and fire recovery, there an extensive set of organizations working outside their particular boundaries. Other organizations lack any specific ownership or special access to land yet play a critical role in managing wildfire risk. Further, as fires increased in size and intensity, there is a greater reason for individuals and organizations to be considered with risk in adjacent lands, and this is especially true in a mixed ownership landscape that characterizes much of the WUI. I examine differences in where organizational groups work using a term called risk management tenure. That tenure reflects, at least in part, some area of the landscape in which the organization maintains some interest or responsibility in managing wildfire risk. This notion is akin to the habitat range for a given species. Organizations, much like organisms, operate within specific geographies, which can be likened to the habitats of individuals groups of organisms. The extent of these geographies is tied to some extent on those of other organizational groups. Much like ecologists use the sightings of organisms to estimate their geographic home ranges, I employ similar techniques to map the 'habitats' of different organizational groups with interests in wildfire. The analogy can be extended further to that of organizational diversity, which like biodiversity, reflects those areas of the landscape where risk tenures overlap. This overlap provides new opportunities for collaboration, but also new challenges and constraints for planning and implementing projects. Thus, another question raised in this chapter is how organizational diversity affects how other organizations operate. Do organizations 
become narrower in their mission? Or do they expand their mission to support a greater number of roles?

Finally, Chapter 4 looks at the social structure of collaboration among the risk management professionals surveyed above. Collaboration arises when two individuals or organizations are able to accomplish together what would be more difficult or impossible to do alone. Yet, organizations must also be careful in allocating their time given the amount of energy that initiating and sustaining collaboration takes. Over time, such partnerships naturally form, and taken as a whole, can be described as a network. In principle, the structure of this network thus reflects where benefits of collaboration outweigh costs, while the absence of ties can indicate the opposite. The entire network can then be decomposed into a small set of building blocks and using a new branch of network statistics, identify those patterns that are likely the result of some set of social processes, rules, or institutions. Given the increased emphasis on cross-boundary planning and management, I am particularly interested in how geography, fire activity, and ownership influence the relationships that form. 


\title{
Chapter 1:
}

\section{Shifting Fire Regimes in the American West}

\begin{abstract}
Fire regimes provide a critical reference for management and restoration programs seeking to move disturbed ecosystems closer towards historical ranges of variability. Yet, the 21 st century has marked a drastic shift in wildfire activity within many areas of the world including the western US, southern Australia, and Mediterranean Europe. This chapter looks at trends in large wildfire activity in the western US in relation to mapped historical wildfire regimes. Primarily, I ask whether a greater share of the wildfire area burned over the past 30 years has occurred within areas historically characterized by mixed to high-severity wildfire events. In addition, as land ownership in many fire-prone regions in the US becomes increasingly fragmented and as large fires grow in size, fire regimes have taken on critical social dimensions as well. Thus, I secondarily ask how wildfire activity has shifted with respect to the social landscape, and specifically with regards to land ownership. Finally, I look at the shift in the social and biophysical complexity of these regimes. I report a number of significant changes in fire activity during the era of mega-fire. Despite substantial increases in both shrub and forest cover, wildfire has accelerated more quickly among forest systems. Within forest systems, a greater proportion of wildfire is occurring in mixed and high-severity regimes over the period surveyed. These changes have also shifted wildfire activity from BLM and private land tenures into the national forest. These results illustrate that while fire
\end{abstract}


regimes continue to be a useful frame for understanding fire activity and wildfire risk in the landscape, their utility becomes increasingly contingent upon trajectories of both climate and development.

\section{Keywords}

Fire regimes; Wildfire management; Environmental change

\section{Research Highlights}

- An acute shift in wildfire behavior around the year 2000 coincided with a series of management programs and actions aimed at stemming its increase.

- Fire activity has increased in most fire regimes within the western US, although it is especially prominent in forested systems.

- Within forested systems, increases in annual burn area are particularly pronounced in forests where fires historically occurred intermittently.

- The significance of these shifts is amplified by the broadscale expansion of the wildland urban interface into both forest and shrub wildland.

- Risk management policy targeting low and mixed fire regime forestland remains relevant, although rapid changes in other regimes suggest the need for expanded policy options. 


\section{Shifting Fire Regimes in the American West}

Fire regimes translate highly stochastic wildfire events into meaningful ecological benchmarks. By characterizing ecosystem processes at the scale of decades to centuries, these regimes produce relatively stable estimates of burn frequency and severity. Fire regimes function as more than ecological descriptors; they also serve as a critical policy tool in contemporary planning and management regimes (Keane et al. 2009). Based on the management principle that ecosystems should be maintained within their historical range of variability in order to restore and maintain resilience, fire regimes are critical for quantifying ecological departure, expected fire behavior, and risk exposure estimates (Seidl et al. 2016), which are subsequently used to prioritize management actions. Tracing at least to the 2000 US National Fire Plan, land managers have routinely utilized fire regimes in the planning and implementation of management programs at both project and landscape scales. Indeed, these requirements were codified in the 2003 Healthy Forest Restoration Act (USFS 2003), and all subsequent Farm Bills and omnibus spending bills identify fire regimes where hazardous forest reduction projects are prioritized (Taylor 2019). Federal and state programs and planning documents have relied on this legal framework for land management decisions for decades, which, in turn, has shaped the investment of tens of billions of dollars used to conduct fuel treatments over millions of hectares (Valliant \& Reinhardt 2017).

The increase in wildfire activity is well documented for the western US (Littell et al. 2009), as well as many other fire-prone areas around the globe (Krawchuk et al. 2009). Yet the overall increase in recorded wildfire activity may mask relative changes 
among different types of fire regimes and vegetation types. Thus, there is a need to look at changes in fire activity across all vegetation in an integral way to report proportional changes over time in fire. While the annual area burned will vary by fire regime due to different return intervals, the ratio of area burned between any two fire regimes should remain constant over time, assuming social and environmental constraints on fire activity remain constant. Changes in climate, vegetation, ignition-patterns, suppression, and landscape-response affect these constraints, thus creating novel conditions under which fire regimes begin to change, which are likely to manifest as altered burn-ratios over time. For example, longer and hotter fire seasons unlocks fuels where wildfire activity was historically constrained by the lack of flammable conditions, including in forests characterized by mixed and high-severity fire regimes (Reilly et al. 2017, Holafsky et al. 2018). Human actions have also shaped extant fire regimes. Human ignitions of wildfire have vastly altered the timing of wildfire as well as expanded the spatial scale over which they occur (Balch et al. 2017). Aggressive fire suppression has been central to wildfire management for most of the twentieth century, and the resultant fuel loads have shifted fire behavior from frequent low-severity towards present-day high-severity megafires in many forests across the western US (Hessburg 2015).

Fire regimes are shaped by bottom-up and top-down constraints, which Krawchuk and Moritz (2011) posit vary along a wet-to-dry gradient. On the wetter extreme, fuels are abundant and fuel moisture acts as the primary constraint to fire. In these conditions, hotter and drier weather will result in more fire. On the drier extreme, flammable conditions are persistent and fuel abundance acts as the dominant constraint on fire 
activity. In these environs, antecedent precipitation is critical in building fine fuels. McKenzie and Littell (2016) demonstrate how differences within annual burn area among western US ecoregions vary both with regards to aridity in addition to moisture conditions in the growing season prior to the fire. At the ecoregional scale, they report a loose negative relationship between year-of and year-prior precipitation, such that prior year moisture conditions tend to be less correlated with area burnt in regions where the area burnt is correlated with fire weather (McKenzie and Littell 2016).

Differential shifts in fire activity suggest that the operation window where land managers have the greatest leverage may be shifting towards forests where the effectiveness of fuel reduction efforts is not well understood or where such actions may push the forest further outside of historic structure and composition (Schoennagel et al. 2018). For instance, thinning and prescribed burns are often appropriate in dry forests where land management and fire suppression have shifted historically open, park-like forests into the denser even-aged forest of today. On the other hand, this typical dry forest strategy so dominates both the literature and policy papers in the western US that few adaptation options have been described for other forest types, especially those in which disturbances are driven less by forest structure and fuels, and more by climate and weather (Schoenagel et al. 2004; Perry et al. 2011; Halofsky et al. 2018). There thus exists the risk that warming-mediated patterns in fire activity will evolve in directions for which existing policy and science are ill-prepared, especially given the degree to which mapped fire regimes dictate the implementation of many of the programs. 
As fire activity shifts, so too does the relationship between fire activity and underlying ownership, planning, and management regimes. Regions were fire activity had been relatively quiescent during much of the 20th century are now confronting wildfire at frequencies and intensities that make established programs and protocols inefficient if not entirely ineffective (Moritz et al. 2014). In particular, the management of wildfire risk has been profoundly reshaped development within the wildland urban interface (WUI). Radeloff et al. report that between 1990 and 2010, the wildland urban interface increased in terms of land use by $30 \%$, representing the most rapid change in land use during the period. They further find that development within the wildfire perimeters occurred at roughly double the national growth rate in houses, exacerbating the adverse relationship between development and wildfire.

These factors further separate the backward-looking dimension of fire regimes as a historical reference from the forward-looking dimension of fire regimes as a management-heuristic. This separation may be contributing to the emergence of 'megadisturbances' in temperate forests (Millar and Stephenson 2015). The scale of these disturbances continues to far outmatch the capacities of federal and state land managers (North et al. 2015; Moritz et al. 2017; Schoennagel et al. 2018) yet continue to generate intense political pressure to accelerate the rate and scale of mitigation efforts that were developed under drastically different conditions. This chapter seeks to compare recent fire trends within and among established fire regimes to evaluate how wildfire activity has changed over time, with a particular interest in the years following 2000 that have been increasingly referred to as the age of megafires. I address the following questions: 
How has annual area burned changed with respect to established fire regime types, and do these changes differ among major vegetation types? Has the proportional share of fire among vegetation systems and fire regimes shifted over time? How are these shifts distributed within the wildland urban interface and among different land ownerships?

\section{Methods}

The western USA, defined here as the area west of the $100^{\text {th }}$ meridian in the conterminous US, is a geographically diverse region composed of forest ecosystems (27\%) and lowland shrublands and deserts (39\%; Figure 1). Compared to fire-prone areas globally, fires are relatively infrequent, large in size, and intense (Archibald et al. 2013). Most fires occur between May and October (Westerling 2003), with timing dependent primarily on latitude and secondarily on elevation. Three decades of large fires (1984 to 2015) were assessed using perimeters recorded by the Monitoring Trends in Burn Severity program $(\mathrm{n}=8956$, MTBS 2018). Perimeters were intersected with several geographic layers in order to measure changes in wildfire patterns during that period. Reference data were resampled to a $270 \mathrm{~m}$ grid based on majority coverage. Fire perimeters were grouped as prior- and post-2000 (i.e., 1984-1999, 2000-2015) based on (a) previous climate-fire trends (Abatzoglou et al. 2017), and (b) the development of the US National Fire Plan circa 2000. Burn perimeters range from 500 ha to more than $1,000,000$ ha in size.

Figure 1. (A) Large wildfires occurring in the western US between 1984 and 2015 prior-and post-2000. (B) Environmental site potential alongside WUI and nonWUI developed areas. 


\subsection{Classifying vegetation and fire regimes}

Landscapes were classified in terms of vegetation potential and historical fire regimes. Vegetation potentials (ESP; Rollins et al. 2009, Holsinger et al. 2006) describe the climate-constrained late-stage successional communities in the absence of disturbances (e.g., wildfire, human activities, etc.), which makes it is more appropriate for longer time-series analyses. Similar to Abatzoglou and Kolden (2013), vegetation potential was aggregated into forest systems (upland forest and woodland, 27\%), shrubland systems (39\%), grassland systems (14\%), and other natural systems (e.g., sparse vegetation, wetlands, undetermined; 17\%). Fire regimes were described according to the frequency and severity of wildfire disturbance using five Fire Regime Groups (FRG) described by LANDFIRE (Table 1). FRGs were assigned for the entire US based on historical (pre-European) fire return interval and first-order fire effects with regards to the dominant overstory (see Rollins et al., 2009). LANDFIRE measures fire severity in terms of mortality within the dominant overstory. Severe fire regimes tend to result in more than $75 \%$ mortality within the dominant overstory, while mortality in those lowseverity regimes tends to be less than $25 \%$. Such measures are clearly scale-dependent. Severity is generally unspecified in FRG5 fire regime due to its long return interval and bimodal distribution between fuel-limited (e.g., low desert shrubland) and moisturelimited systems (e.g., high subalpine). It is important to note that fire regimes describe typical fire behavior and not the actual severity of the wildfires that occurred. Fire regimes are strongly associated with vegetation potential (Table 2). Forest systems have historically experienced frequent low-severity (34\%) or infrequent low-to-mixed severity 
fire regimes (39\%) while shrublands often exhibited higher severity regimes with longer fire return (frequent $=12 \%$, intermittent $=32 \%$, rare $=27 \%$ ). Grass systems - typically defined by frequent high-severity fires - represent less than $20 \%$ of the region and an even smaller share of its fire. As a result, this work focuses primarily on fire regimes in forest and shrubland systems (Figure 2).

Table 1. LANDFIRE fire regime groups for the western US (Rollins et al., 2009).

\begin{tabular}{llll} 
Group & Fire return & Severity & Veg potential* \\
\hline FRG1 & Frequent (0-35 years) & Low (occasionally mixed) & Forestland \\
FRG2 & Frequent (0-35 years) & Replacement & Grassland \\
FRG3 & Intermittent (30-200 years) & Mixed (occasionally low) & Forest / shrub \\
FRG4 & Intermittent (30-200 years) & Replacement & Shrubland \\
FRG5 & Rare (200+ years) & Any severity (often severe) & Forest / shrub \\
* dominant vegetation physiognomy as a product of both climate and disturbance
\end{tabular}

\subsection{Classifying social dimensions of fire activity}

Landownership was constructed from the USGS Protected Areas Database (PAD 2016). Public land covers more than half the western US. Major land-tenure tenures were divided into protected and non-protected lands according to PAD. As a general rule, the USFS manages lands at higher elevations that have heavier fuel while the Bureau of Land Management (BLM) manages lands with finer fuels such as grasses and shrubs. All land not covered by the PAD data were assumed private and were further divided into developed and undeveloped areas. Developed areas contained structure density greater than 6.1 structures per hectare and were further divided into non-WUI, interface-WUI 
(development abutting wildland) and intermix-WUI (development within wildlands)

using definitions and WUI descriptions developed by Radeloff et al. (2006).

Table 2. Cross-tabulation between vegetation potential and fire regime group. Marginal totals are shown in bold (data source: LANDFIRE).

Vegetation potential (LANDFIRE ESP)

\begin{tabular}{lrrrr} 
Fire regime (LANDFIRE FRG) & Forest & Shrub & Grass & \\
\hline Frequent-low severity (FRG1) & $34 \%$ & $10 \%$ & $5 \%$ & $18 \%$ \\
Infrequent-mixed severity (FRG3) & $39 \%$ & $17 \%$ & $4 \%$ & $22 \%$ \\
Frequent-severe (FRG2) & $1 \%$ & $13 \%$ & $81 \%$ & $21 \%$ \\
Infrequent-severe (FRG4) & $15 \%$ & $32 \%$ & $7 \%$ & $22 \%$ \\
Rare-variable severity (FRG5) & $11 \%$ & $27 \%$ & $3 \%$ & $17 \%$ \\
& $34 \%$ & $49 \%$ & $18 \%$ & $100 \%$
\end{tabular}

Figure 2. (A) Map of forest systems colored by fire regime (103.5 M ha, 23\% of area shown). (B) Map of shrubland systems colored by fire regime (124.6 M ha, $28 \%$ of area shown). Other cover types (primarily grasslands and barren) are shown in light grey (data source: LANDFIRE).

\subsection{Analytics}

MTBS fire perimeters were intersected against underlying raster stacks containing the above-mentioned layers for vegetation potential, FRG, and PAD ownership then summarized for each fire in terms of area burned. Trends in fire activity were assessed both as annual area burned (AAB) and as a proportional share within a given year. I group values prior- and post-2000, although I considered other breakpoints by examining the absolute difference in median $\mathrm{AAB}$ across a range of breakpoint values. Differences between periods were assessed using the non-parametric Wilcoxon signed-rank test. To assess changes in relative burn frequency over time, I compare annual burn ratios, which 
measure the extent of area burned within one fire regime group with respect to another. Under static climate conditions, the burn ratio should be constant. All burn ratios were log-transformed to address their bounded nature. Trends in burn-ratios were assessed using the Mann-Kendall test. Finally, burn-ratios were compared to overall AAB, and this relationship was tested as a standard linear regression.

\section{Results}

\subsection{Shifts in fire activity among vegetation systems}

AAB increased substantially between 1984 and 2015. While various breakpoints were considered, the difference in AAB between periods was greatest from 1999 and 2001 (see Figure 3A). Thus, AAB is divided into two periods for the remainder of the results: 1984-1999 and 2000-2015. Median AAB increased 164\% (0.76 M ha/yr) from

$0.47 \mathrm{M} \mathrm{ha} / \mathrm{yr}$ prior to $2000(\mathrm{SD}=0.48 \mathrm{M} \mathrm{ha} / \mathrm{yr})$ to $1.23 \mathrm{M} \mathrm{ha} / \mathrm{yr}$ after to $2000(\mathrm{SD}=0.79$ $\mathrm{M}$ ha/yr). Most large wildfires during the period burned in either forests or shrublands $(83 \%)$, yet the rate of increase differed between the two vegetation types. The median forest $\mathrm{AAB}$ increased from $0.16 \mathrm{M}$ ha to $0.62 \mathrm{M}$ ha $(385 \%$ increase, Wilcox p-value $<$ $0.001)$ while the median shrubland $\mathrm{AAB}$ increased from $0.27 \mathrm{M}$ ha to $0.44 \mathrm{M}$ ha $(162 \%$ increase, $\mathrm{p}$-value $<0.001)$. Despite increases in both systems, forest AAB saw a greater proportional increase such that forest fires became the dominant wildfire activity. Between 1984-1999, forest wildfires accounted for $31 \%$ of the total area burned, which rose to $44 \%$ between 2000-2016, reflecting a three-fold increase in forestlands AAB. By contrast, fire activity within shrublands proportionally dropped from $52 \%$ to $43 \%$ after 2000, despite a 2-fold increase in shrubland AAB. 
Figure 3. (A) Annual area burned (AAB) colored by vegetation system (forest, shrubland, grass, other). (B). Annual values prior- and post-2000 with significance (p-values less than 0.05 highlighted in red). (C/D) Same as above but reported as an annual proportional share (\%/yr).

Table 3. Change in annual area burned $(A A B)$ among fire regimes groups for forest and shrubland systems. Changes are reported as an absolute value, percent, and as a proportional share of the overall change. Historical mean fire return intervals (MFRI) derived from LANDFIRE.

\begin{tabular}{lrrrrrrr}
$\begin{array}{l}\text { Vegetation } \\
\text { potential }\end{array}$ & $\begin{array}{r}\text { Fire } \\
\text { regime }\end{array}$ & $\begin{array}{r}\text { Historical } \\
\text { MFRI } \\
(\text { ha/yr })\end{array}$ & $\begin{array}{r}\text { AAB } \\
84-99 \\
(\text { ha/yr })\end{array}$ & $\begin{array}{r}\text { AAB } \\
\text { (ha/yr })\end{array}$ & $\Delta($ ha $)$ & $\Delta(\%)$ & $\Delta$ (share) \\
\hline Forest & FRG1 & $1,372,678$ & 82,565 & 338,179 & 255,614 & $310 \%$ & $37 \%$ \\
& FRG2 & 49,665 & 2,185 & 5,019 & 2,834 & $130 \%$ & $0 \%$ \\
& FRG3 & 383,104 & 27,874 & 184,960 & 157,086 & $564 \%$ & $23 \%$ \\
& FRG4 & 125,525 & 18,590 & 71,195 & 52,605 & $283 \%$ & $8 \%$ \\
\hline \multirow{2}{*}{ Shrub } & FRG5 & 22,088 & 1,066 & 20,734 & 19,669 & $1845 \%$ & $3 \%$ \\
& FRG1 & 291,824 & 21,650 & 53,617 & 31,966 & $148 \%$ & $5 \%$ \\
& FRG2 & 903,918 & 12,444 & 22,899 & 10,455 & $84 \%$ & $2 \%$ \\
& FRG3 & 236,968 & 46,851 & 104,821 & 57,970 & $124 \%$ & $8 \%$ \\
& FRG4 & 438,209 & 119,403 & 247,165 & 127,762 & $107 \%$ & $18 \%$ \\
& FRG5 & 63,752 & 47,116 & 27,098 & $-20,018$ & $-42 \%$ & $-3 \%$
\end{tabular}

Reflected as an annual burn ratio between forest and shrubland, forest $\mathrm{AAB}$ exceeded shrubland AAB in 9 out of 16 years post-2000, compared to 2 of 16 years prior2000 (Figure 4A). The overall trend is positive and significant (Mann-Kendall statistic = $0.288, \mathrm{p}=0.019)$. This trend is correlated with the overall increase in AAB. Figure 4B shows the ratio between forest and shrubland $\mathrm{AAB}$ against overall $\mathrm{AAB}$ (i.e., regardless of the vegetation system), with each point representing a single year. The figure shows a significant positive relationship between total $\mathrm{AAB}$ and the proportion of that area 
occurring within forest systems. The margin distribution curves show significant differences in both dimensions, suggesting substantial shifts in both AAB post-2000 in addition to the proportional share of fires occurring in forested systems.

Figure 4. (A) Annual burn ratio between forest- and shrub-systems by year (bars colored by vegetation potential; green $=$ forest; brown $=$ shrub). $(B)$ Annual burn-ratio compared to overall annual area burned. Differences between periods in the distributions of $A A B$ and burn-ratio are shown above and to the right. In both panels, the 1:1 ratio is shown as a horizontal solid line. Significance labeled for trends in each panel.

I also examined the vegetation systems involved at the level of individual fires to determine whether the increase in forest $\mathrm{AAB}$ may be the result of interactions between shrub and forest systems. Because of the lack of cover, open shrubland fires can grow rapidly in size, so I examined the degree to which expansion of forest fires may have been the result of fires expanding rapidly under open conditions. Figure 5 shows the proportion of a given fire that occurred within forested systems for all MTBS fires $(\mathrm{n}=9228)$ over time. While the trend line shows a greater portion of forest-dominant fires over time, the perimeter of individual fires continued to bifurcate between shrub- and forest-systems. Most individual fires $(90 \%)$ occurred exclusively in either shrub or forest systems while relatively few fires spanned both shrub and forest sites. This bifurcation possibly reflects the divergent environmental constraints that define fire activity within each environment.

Figure 5. Percent of wildfire burn area (n=9228) within forest system (compared to other vegetation types) colored by dominant vegetation system. Point color reflects dominant vegetation potential. Green $=$ forest; Orange $=$ shrubland; Purple $=$ grassland . 


\subsection{Shifts in wildfire regimes within vegetation systems}

Differences in fire activity varied among fire regimes within both forest and shrubland systems. Figure 6 shows the annual area burned (millions of hectares) by forest (left) and shrubland systems (right). Among forests, wildfire AAB significantly increased in 4 out of 5 fire regimes: FRG1 from $0.08 \mathrm{M} \mathrm{ha} / \mathrm{yr}$ to $0.33 \mathrm{M} \mathrm{ha} / \mathrm{yr}(415 \%$, Wilcox $\mathrm{p}<$ 0.001); FRG3 from $0.03 \mathrm{M}$ ha/yr to $0.15 \mathrm{M} \mathrm{ha} / \mathrm{yr}(500 \%$, Wilcox $\mathrm{p}<0.001)$; FRG4 from $0.02 \mathrm{M}$ ha/yr to $0.07 \mathrm{M} \mathrm{ha} / \mathrm{yr}(390 \%$, Wilcox p-value $<0.001)$, and; FRG5 from 1070 to $20100 \mathrm{ha} / \mathrm{yr}(2000 \%$, Wilcox p < 0.001). While wildfire in low-severity FRG1 forest systems remained dominant in most years, it dropped its annual share from $60 \%$ to $55 \%$. This change was reflected in the proportional gains in FRG3 and FRG5. Changes in fire activity within shrubland systems were subtler. Overall AAB increased in 3 out of 5 fire regimes: FRG1 from 0.02 to $0.05 \mathrm{M}$ ha/yr (240\% increase); FRG2 from 0.01 to $0.02 \mathrm{M}$ ha/yr (200\% increase), and; FRG4 from 0.12 to $0.25 \mathrm{M}$ ha/yr (208\% increase). The proportional split among shrubland fire regimes has remained steady.

Figure 6. Variation in annual area burned by dominant fire regime within forest (A) and shrubland (B) systems, divided prior- and post-2000 (Wilcox p-values less than 0.05 are in bold). (C/D) Same as above but transformed to annual proportional share (\%). Fire regimes: FRG1 = frequent and low-severity, FRG2 = frequent and severe; FRG3 = intermittent and mixed-severity; FRG4 = intermittent and severe; FRG5 = infrequent with variable severity.

Change in the proportional share of wildfire activity among different fire regimes reflected a differential acceleration in some fire regimes. Figure 7 depicts changes in annual burn ratios between all pairwise fire regime combinations in forest systems. For each pair, the significance of the trend is reported (Mann-Kendall test) in addition to the 
correlation between the ratio and $\mathrm{AAB}$. Changes in annual burn ratios were most notable among FRG5 forests, where fire activity has accelerated faster than in all other forest regimes. For instance, in 1990, AAB in forests characterized by low-severity fire regimes (FRG1) was approximately 100-times more common than fire activity in FRG5 forests, although by 2010 this ratio was an order of magnitude less. This trend was similar, although slightly more muted, with regards to mixed-severity regimes (FRG3). The relationships were highly correlated with overall AAB.

Figure 7. Pairwise comparison of annual burn ratios among forest wildfire regimes and annual area burned. Panels are equivalent to that shown in Figure 4A. Significance of the trend (dashed line) is labeled (trend) along with correlation with the total annual area burned (AAB; equivalent to Figure $4 B$ ). Significant values are highlighted. Fire regimes: $F R G 1=$ frequent and lowseverity, $F R G 2=$ frequent and severe; FRG3 = intermittent and mixed-severity; $F R G 4=$ intermittent and severe; FRG5 = infrequent with variable severity.

While wildfire activity shifted towards higher severity regimes within forest systems, trends in shrublands were more complex. Further, while some shrub fire regimes show a relationship between annual burn activity and where that activity occurs, there does not appear to be a significant difference pre- and post-2000. Specifically, the correlation between overall $\mathrm{AAB}$ and annual burn ratios were statistically significant for comparisons between FRG1/FRG3, FRG1/FRG5, and FRG3/FRG4. In general, wildfire activity has shifted towards low-severity shrub regimes (FRG1 \& FRG3) and moved away from high-severity regimes (FRG2, FRG3, \& FRG5). Despite the overall increase in shrubland fire activity, no pairing showed significantly differential acceleration among fire-regimes. 
Figure 8. Pairwise comparison of the trends in burn-ratios among shrubland wildfire regimes. Significance of the trend (dashed line) is labeled (trend) along with correlation with the total annual area burned (AAB; equivalent to Figure $4 B$ ). Significant values are highlighted. Fire regimes: $F R G 1=$ frequent and lowseverity, $F R G 2=$ frequent and severe; $F R G 3=$ intermittent and mixed-severity; $F R G 4=$ intermittent and severe; FRG5 = infrequent with variable severity.

\subsection{Social dimensions of shifting fire regimes.}

Figure 9 shows proportional changes in area burned by land ownership over time (both forest and shrublands). The area burned by large fires has increased significantly in USFS and declined in BLM and private lands, both of which tend to occupy drier ecosystems at lower elevations. Trends in USFS managed lands are particularly notable. These lands occur at lower elevations relative to protected wilderness and roadless areas.

Figure 9. Proportion and trends (dashed line) of annual area burned partitioned by land ownership and protection status (all vegetation types; panels ordered by overall proportional share of fire; note differences in y-axes). Trends lines over period are shown as dashed lines. Y-axes are freely scaled so note labeled values. $F S M / P=$ National forest managed/protected; $P R M / P=$ Private managed/protected; BLM/P = Bureau of Land Management managed/protected; $S T M / P=$ State managed/protected .

Even though the actual degree of intersection between fire and development remains limited, wildfires pose risks to communities well before reaching developed areas. Allocation suppression resources are often proportional to the potential for loss. Expansion of development within the fire-prone wildland urban interface increases the chance that fire threatens life and property. Still, it remains unclear how this expansion has varied with respect to both vegetation type and fire regime given that most definitions of WUI do not distinguish between shrub or forest wildlands, much less the particular fire regime present in each. Intermixed WUI in forested areas continued to be the most 
expansive form, although it expanded at a slower rate than shrubland intermix and interface WUI. While intermixed WUI in FRG1 forestlands continued to be the most prevalent both in terms of area covered and the number of structures, it expanded at a slower rate than almost any other WUI class. Nonetheless, in 2010, there were nearly a half million structures in FRG1 forests. Table 4 shows that expansion of the WUIstructures was particularly notable within the shrubland interface, with growth well above $300 \%$, and in the case of shrubland FRG5, well beyond $1000 \%$. The expansion of forestWUI was particularly notable in FRG3 and FRG4 fire regimes. Expansion of the shrubland-interface WUI was particularly notable in the FRG4 and FRG5 fire regimes.

Figure 10 plots change of the WUI against $\mathrm{AAB}$ across vegetation potential and fire regime as a single vector. The butt of the arrow reflects the earlier value (i.e., 1990) while the head of the arrow shows the latter (i.e., 2010). Arrows in the diagonal represent the change in both domains, vertical arrows highlight changes primarily in the growth of WUI, while horizontal arrows show change primarily in AAB. The expansion of the WUI is described both in terms of total area and number of structures. Most WUI structures are located in forests in FRG1, FRG3, and FRG5 while shrubland WUI was most extensive in FRG4 and FRG5.

Figure 10. Change in fire activity (median AAB) and WUI (ha and structure count). Arrows labeled by vegetation potential, fire regime group, and WUI type: $F=$ forest; $S=$ shrub; $1-5=$ fire regime group; $M=$ mixed $W U I ; F=$ interface WUI. The top row represents WUI change as area. The bottom row represents WUI change as structure count. 
Table 4. Change in the wildland urban interface between 1990 and 2010 by vegetation potential and fire regime group. Changes are reported both as area and structure count in terms of absolute change, growth, and the proportional share of growth. IM = intermixed WUI; IF = interface WUI. Shr = share of WUI structure and area as of 2010.

\begin{tabular}{|c|c|c|c|c|c|c|c|c|c|c|c|c|}
\hline \multirow[b]{2}{*}{ Veg } & \multirow[b]{2}{*}{ FRG } & \multirow[b]{2}{*}{ WUI } & \multicolumn{5}{|c|}{ WUI structures (thousand) } & \multicolumn{5}{|c|}{ WUI area (thousand ha) } \\
\hline & & & 1990 & 2010 & $\Delta$ & $\% \Delta$ & $\%$ & 1990 & 2010 & $\Delta$ & $\% \Delta$ & $\%$ \\
\hline & 1 & IM & 288.5 & 424.3 & 135.8 & 47 & 12 & 140.1 & 192.7 & 52.6 & 38 & 21 \\
\hline & & IF & 46.5 & 71.4 & 24.9 & 54 & 2 & 4.4 & 6.1 & 1.7 & 39 & 1 \\
\hline & 2 & IM & 3.1 & 5.9 & 2.7 & 89 & 0 & 1.9 & 3.1 & 1.2 & 64 & 0 \\
\hline & & IF & 0.8 & 1.5 & 0.7 & 94 & 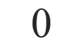 & 0.1 & 0.1 & 0.0 & 59 & 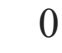 \\
\hline & 3 & IM & 160.9 & 277.1 & 116.2 & 72 & 10 & 82.2 & 125.1 & 42.9 & 52 & 17 \\
\hline & & IF & 18.3 & 42.5 & 24.3 & 133 & 2 & 3.3 & 5.0 & 1.7 & 53 & 1 \\
\hline & 4 & IM & 25.0 & 46.0 & 20.9 & 84 & 2 & 12.4 & 21.4 & 9.0 & 73 & 4 \\
\hline & & IF & 5.0 & 10.7 & 5.6 & 111 & 0 & 0.7 & 1.3 & 0.5 & 77 & 0 \\
\hline & 5 & IM & 91.0 & 142.3 & 51.3 & 56 & 5 & 52.1 & 67.0 & 14.9 & 29 & 6 \\
\hline & & IF & 14.0 & 39.0 & 24.9 & 178 & 2 & 3.0 & 4.6 & 1.6 & 55 & 1 \\
\hline & 1 & IM & 71.6 & 118.0 & 46.4 & 65 & 4 & 35.2 & 50.8 & 15.6 & 44 & 6 \\
\hline & & IF & 11.0 & 41.0 & 30.3 & 276 & 3 & 2.2 & 4.0 & 1.8 & 85 & 1 \\
\hline & 2 & IM & 37.8 & 56.9 & 19.1 & 51 & 2 & 17.8 & 26.8 & 9.1 & 51 & 4 \\
\hline & & IF & 6.6 & 26.9 & 20.3 & 308 & 2 & 1.3 & 2.6 & 1.3 & 101 & 1 \\
\hline & 3 & IM & 36.4 & 72.0 & 35.7 & 98 & 3 & 21.6 & 37.0 & 15.4 & 72 & 6 \\
\hline & & IF & 6.1 & 26.9 & 20.8 & 340 & 2 & 1.6 & 3.2 & 1.6 & 95 & 1 \\
\hline & 4 & IM & 113.8 & 216.1 & 102.3 & 90 & 9 & 58.2 & 92.1 & 33.9 & 58 & 14 \\
\hline & & IF & 26.8 & 127.5 & 100.7 & 376 & 9 & 4.3 & 9.5 & 5.2 & 122 & 2 \\
\hline & 5 & IM & 126.2 & 249.7 & 123.5 & 98 & 11 & 50.0 & 77.3 & 27.2 & 54 & 11 \\
\hline & & IF & 20.6 & 250.7 & 230.0 & 1114 & 20 & 3.1 & 12.2 & 9.0 & 289 & 4 \\
\hline $\mathrm{bt}$ & & & 71.6 & 1110 & 2246 & 102 & & 35.2 & 496 & 742 & 50 & \\
\hline
\end{tabular}




\section{Discussion}

At the outset of this chapter, I asked whether changes in fire activity will alter management landscape such that current programs are poorly suited to match those changes. Fire activity has increased across the western US, although done so at rates that depend on both vegetation potential and fire regimes. Over the period examined, wildfire activity in forest systems expanded at nearly twice the rate of shrublands, such that forest fire has become the dominant fire activity in most years. The fire regime variable constraints hypothesis provides some insight as to why these shifts are occurring. Setting aside suppression, fire activity in most forest systems is constrained by a combination of fuels and moisture, whereas fire in most shrubland systems is primarily constrained by fine fuels. Changes in fire activity suggest shifts in underlying constraints, which in turn has allowed fire to expand more rapidly in certain conditions (Krawchuk et al. 2009).

Given the time needed to accumulate biomass, forests tend to form in conditions that limit fire frequency or severity. In most forests, fuel moisture serves as the primary constraint to fire. Low-severity fire regime forests are somewhat unique since higher temperatures, longer fire seasons, drier fuel conditions of these forests tend to favor fire. Here, availability of fuel historically limited the size and intensity of flames, yet due to an extended fire deficit in during much of the $20^{\text {th }}$ century, due in part to aggressive suppression, has essentially primed these forests for more severe fires (Reilly et al 2017; Haugo et al. 2019). This included sites that had forest potential but were maintained in savannah or open-prairie conditions from frequent burns. Comparing historical photographs from the 1930 s to those taken 80 years later reveals that many sites capable 
of supporting forests historically existed in grassland, shrubland, or open-canopy states (Hessburg et al 2019). Haugo et al. (2019) examined fire activity in the Pacific Northwest during the same period and reported fire deficits in all forests, though specifically in those that historically burned frequently.

Acceleration of forest wildfire activity was particularly acute within mixed to high-severity regime forests. Annual large forest wildfire frequency in mesic and northern forests is significantly correlated with spring and summer temperature with the largest fire years occurring in years with both warm spring and summer temperatures and early-spring snowmelt. For instance, fire seasons average approximately 3 months longer than those found 3 decades earlier (Westering 2016). What is more, over the same period, the average large wildfire burn time grew from nearly six days to over 50 days. The most sensitive forests are ones that historically had a mean snow-free season of just two to four months and high spring and summer evapotranspiration. As wildfire shifts into mixed and high-severity forests, larger-scale landscape patterns become comparatively more important in determining the fire activity. Past burn perimeters can both inhibit fire spread in the period immediately following a fire, as well as enhance its spread once flammable shrubs and grasses have reestablished (Parks et al. 2016; Ager et al. 2017). Fire in mesic conditions is driven by climate as dry and warm conditions deplete fuel moisture, increase evapotranspiration, and widen soil water deficits. Because these conditions are linked to regional fluctuations in climate, fire conditions tend to form across wide swaths of the landscape (Heyerdahl et al. 2008; Liu et al. 2016). 
Given the increase in wildfire across all forest types, there remains substantial debate on the role of management in this transition (Hessburg et al. 2016; Schoennagel et al. 2017). While evidence of the effectiveness of these programs is well-established in lower severity regimes, there is a weaker ecological understanding of the natural range of variability of mixed fire regimes in the western US, and thus managers face greater uncertainty as to what guidelines to follow. These results suggest that an increasingly greater portion of wildfires have been occurring in forests characterized by mixed-to-high fire regimes. Further, fire occurring under extreme conditions tends to become decoupled from previous hazardous fuel reduction efforts. It is increasingly important to critically evaluate the effectiveness and implications of applying strategies conceived for dry forests with low-severity regimes into forests where wildfire has historically been less frequent and more severe (McWethy et al. 2019). Further, there is evidence that in human-dominated landscapes that past actions have simplified forest structure and created the conditions that have amplified the scale of disturbances. For instance, Summerfield et al. 2018 noted that in areas of high disturbance activity (i.e., high severity, prevalence, etc.), disturbance patches were larger and less complex in the human-dominated landscapes outside of protected areas than in protected areas. Even still, large-scale disturbances can override the effect of human land use and dominate landscape patterns in forest ecosystems. Since many of these effects are climate-sensitive, future conditions could produce a more coarse-grained landscape from the increased scale of disturbance (Hessburg et al. 2019). 
While fire in forest systems has increased at a quicker rate in higher-severity regimes with longer fire return intervals, fire in FRG1 forests remains the most extensive in terms of annual area burned. In the examination of fire activity, I did not consider changes in fire severity. Numerous other studies have reported these changes. Reilly et al. (2017) reported a five-fold increase in burn severity in low-severity forests. Combined with poor post-fire recruitment, increased severity may result in substantial and irreversible loss of dry-forests (Kemp et al. 2019; Davis et al. 2019) due to the intervalsqueeze resulting from increasingly frequent disturbance and reduced plant growth (Enright et al. 2015). While fuel management activities have been extensive in lowseverity regime forests, the actual amount of overlap between fires and treated stands is quite low (Barnett et al. 2016). This suggests that management is unlikely to have significantly altered burn area, although these measures may hide indirect effects of such treatments on fire activity. Suppression activity may be more successful in these forest types and climate change may have weakened the antecedent effect of rainfall pulses on the growth of fine fuels. Further, it could be that warming effects on fire size were blunted in these forests due to a relative lack of heavy fuels compared to other fireregime forests.

Most studies on change in fire activity continue to preference forest systems, which has led to a comparative gap in knowledge regarding changes in shrubland systems. Exceptions include ecoregional studies such as McKenzie and Littell (2017) as well as Parks et al. (2015). For example, in examining fire deficits throughout the western US, Parks et al. (2015) note a fire surplus in certain shrubland systems, which they 
attribute to increasing fine fuel loads from invasive grasses. While they note that the increase is particularly acute within shrubland systems marked by frequent and mixedseverity disturbance, the results did show that this activity has increased appreciably compared to that of other fire regimes in the western US over the past three decades. In fact, I note a slight trend away from these shrubland fire regimes. The shift in shrubland fire away from high-severity regimes may reflect a weakening trend in the effect of antecedent rainfall pulses as triggers for high fire years in dry systems due to the drying effect of a 'thirstier atmosphere.'

\subsection{Implications}

Fire activity has accelerated over the past quarter-century, and in particular within forested systems. The rate of increase in particularly notable in forests where fire activity is limited by wet conditions. Earlier snowmelt and longer, hotter, and drying summers have released fire in many of these forests. Long intervals between fires mean that most vegetation in these forests is intolerant to fire and therefore limits management options that are mean to decrease fuel loads that have built up over a century of aggressive fire suppression. Here, reduction in fuels is less warranted from an ecological perspective, but may still be warranted given that these ecosystems will continue to experience elevated fire activity as the climate continues to warm. The effectiveness of active mitigation is relatively unknown in these systems, and even if effective, there remains the possibility that such actions would actually increase ecological departure.

Nonetheless, fire in fuels-limited forests has also grown and remains the dominant forest fire within any given year. While these forests are likely to be the first where fire 
activity is constrained by the lack of fuels, the continued increase is likely the result of the substantial fire deficits that have persisted for more than fifteen years. Despite the increased fire and substantial investments to reduce fuels through thinning and prescribed burns, the current rate of consumption continues to lag behind the historical levels to which these forests are adapted. The variables constraints hypothesis would suggest that fire activity in low-severity forests should reach an upper limit in terms of its response to a warming climate, since fuels remain the dominant constraint. The fact that fire activity has substantially increased in both fuels-limited and climate-limited forests suggests that climate-constraints operates in both cases. It is also true that in low-severity forests, fuels are more likely to become a limiting factor since fire is ultimately a self-limiting process.

\section{Conclusion}

The turn of the millennium marked an inflection point in fire activity, heralding in an era of megafires in the Western US notable both for their size, severity, and increased hazard. This was also the time in the US that wildfire policy, programs, and laws began to rapidly evolve, at each iteration trying to address the perceived causes for escalating fire costs and increased hazard to both vegetation and communities. Owing to their dynamic nature, wildfire has increased as different rates within different environments and social contexts. While fire activity increased substantially in both forest and shrubland systems, that rate of change in greater among forests such that on most years the majority of wildfire now occurs in forest systems. Further, the rate of change among forest fire regimes has also varied, with a marked increase of annual area burned in forests that were historically marked by intermittent high-severity fire. While fire activity 
has also increased in shrubland systems, changes in burn ratios among different fire regime groups are less distinct. Differences in these trajectories extend to the social dimensions of the landscape as well. An increasing share of annual fire activity occurs on national forests, specifically dry mixed-conifer forests that occur at lower elevations and tend to fall outside of protected wilderness or roadless areas. Such shifts are reflected in agency wildfire budgeting, which threatens to overtake all other functions of the agency. An expanding array of funding and policy tools have developed around existing fire regimes, and while their classifications still hold substantial utility, the differential acceleration of fire in forest systems suggests that programs that are too strictly wed to historical definitions of fire regime may be ill-prepared to address changes in future fire risk. What is more, while fire trends are clearly shifting towards forested systems, increases in shrubland systems are also notable. Dynamics that drive fire in both fire and shrubland systems remain distinct, but the increases observed in both systems are a reminder that each requires attention, monitoring, and adaptation to accommodate future fire. 


\section{Figures}

A.

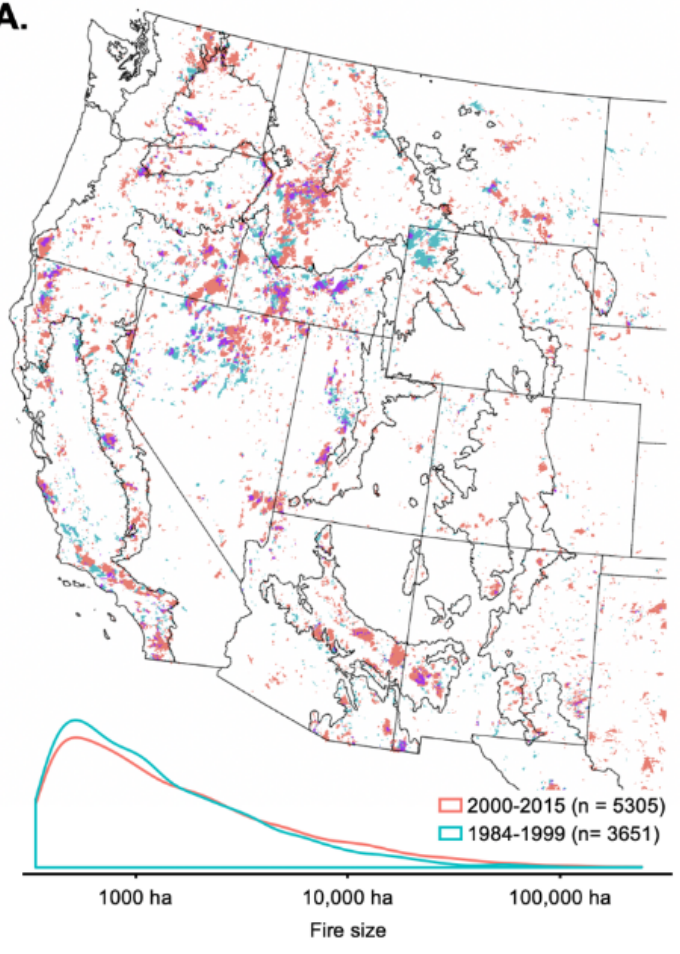

B.

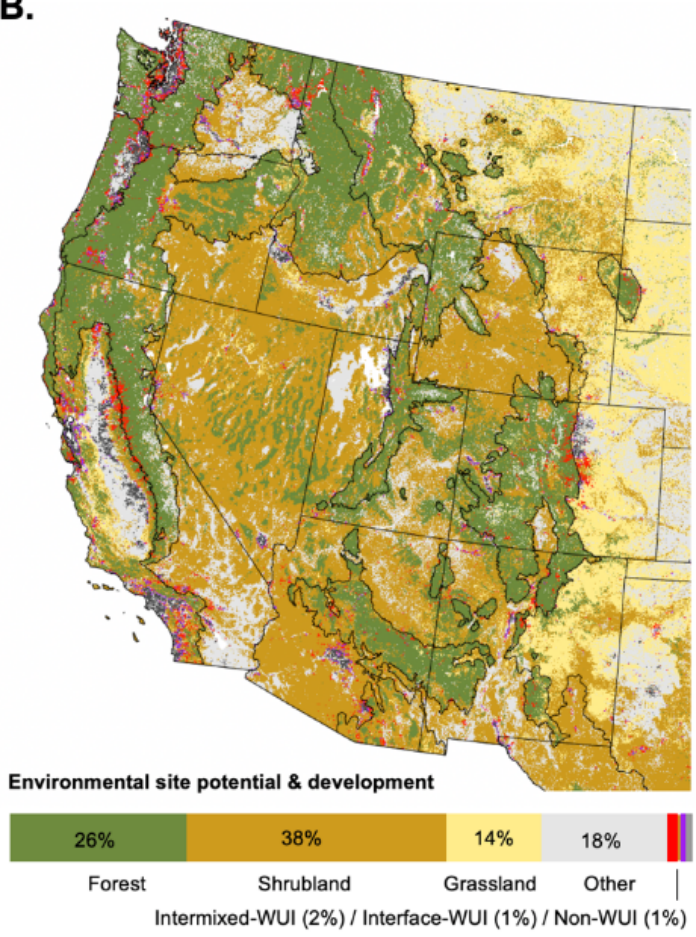

Figure 1. (A) Large wildfires occurring in the western US between 1984 and 2015 prior- and post-2000. (B) Environmental site potential alongside WUI and nonWUI developed areas. 

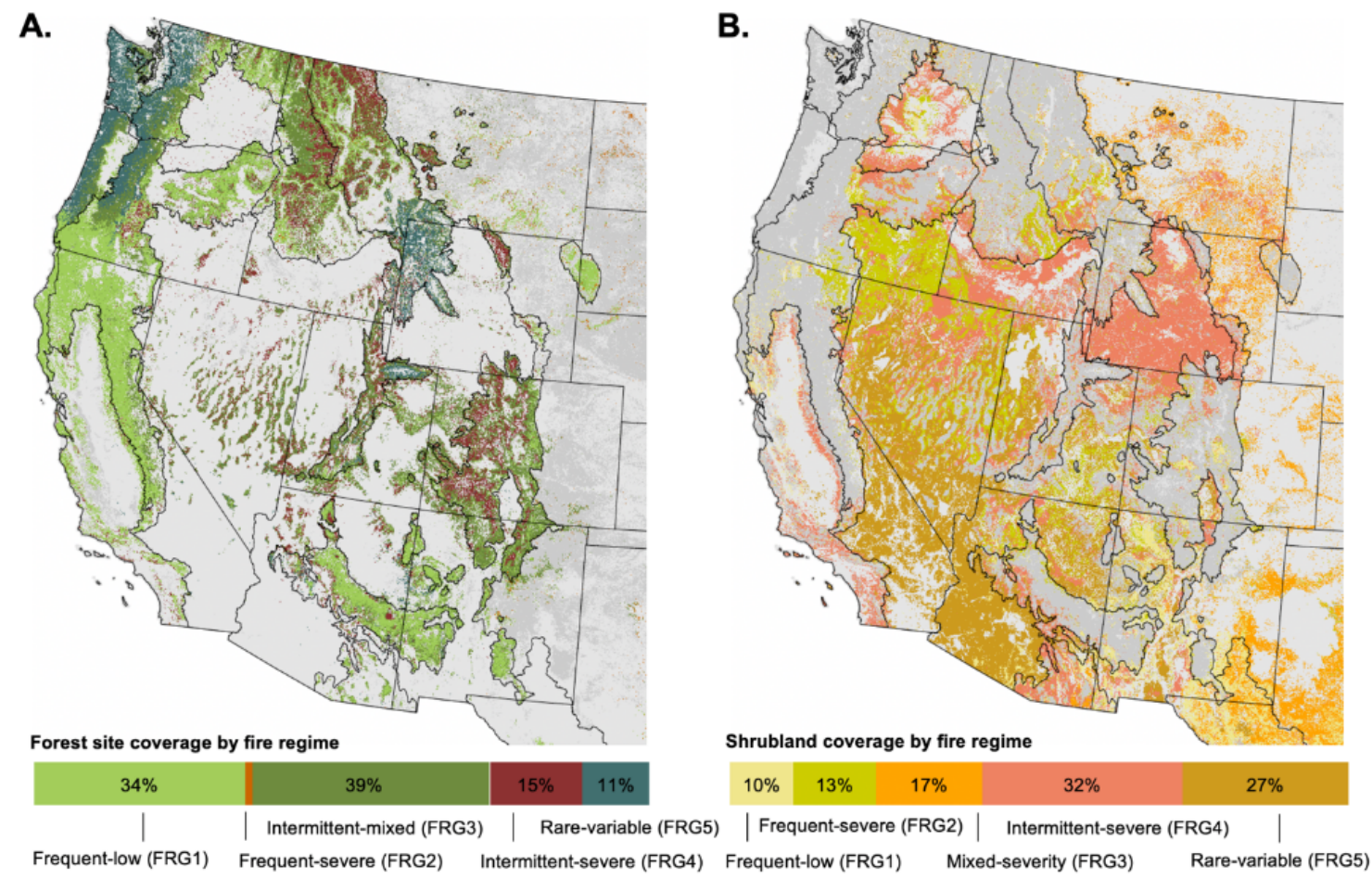

Figure 2. (A) Map of forest systems colored by fire regime (103.5 M ha, 23\% of area shown). (B) Map of shrubland systems colored by fire regime (124.6 M ha, $28 \%$ of area shown). Other cover types (primarily grasslands and barren) are shown in light grey (data source: LANDFIRE). 

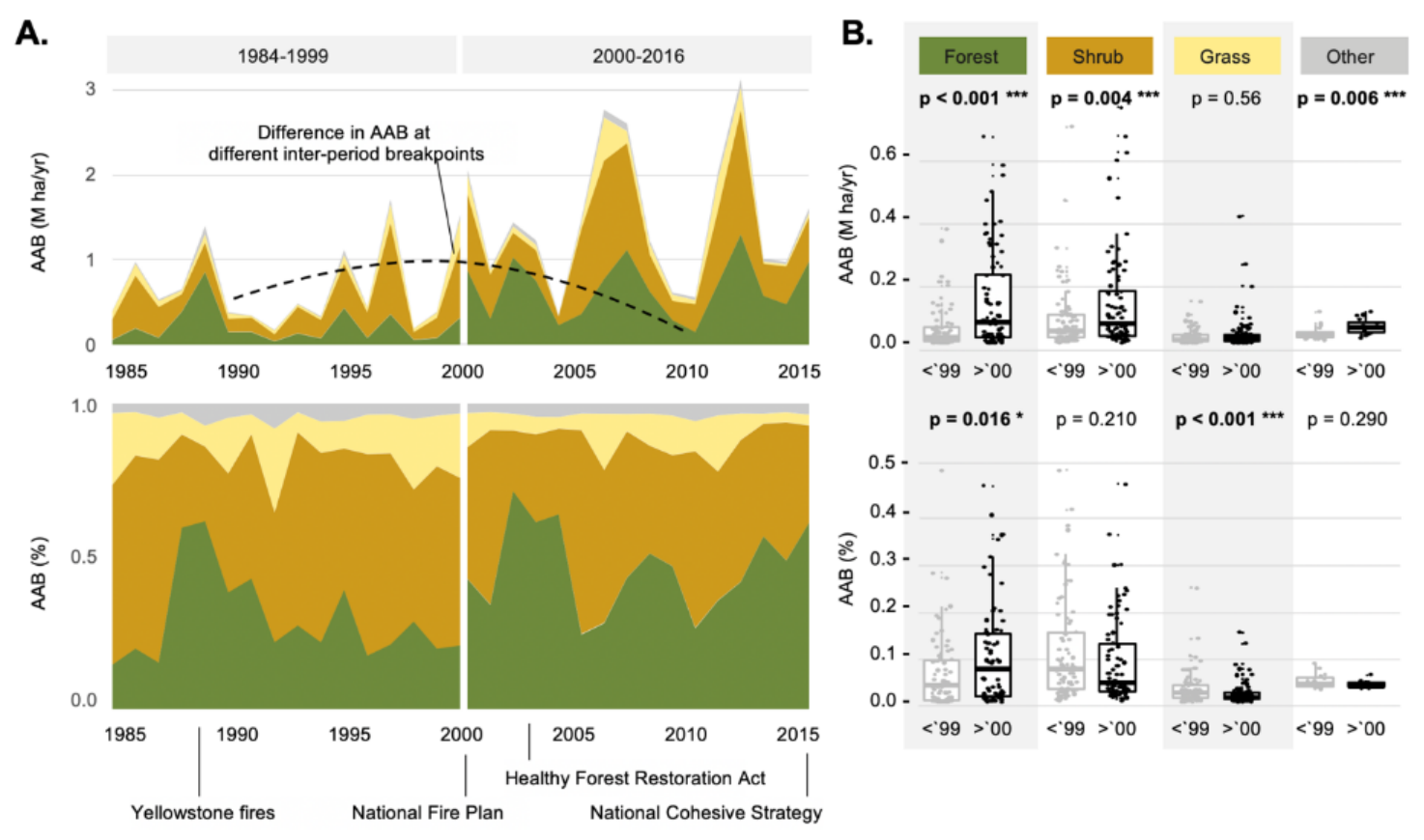

Figure 3. (A) Annual area burned (AAB) colored by vegetation system (forest, shrubland, grass, other). (B). Annual values prior- and post-2000 with significance ( $p$-values less than 0.05 highlighted in red). (C/D) Same as above but reported as an annual proportional share (\%/yr). 
A.

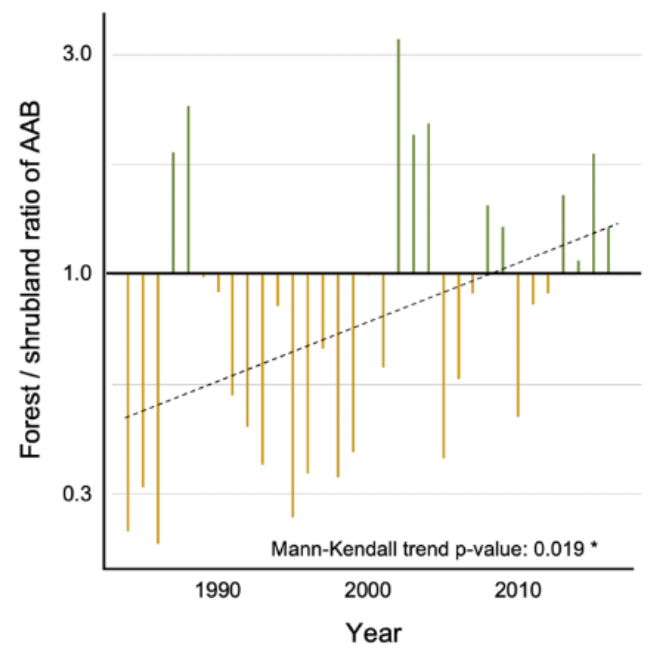

B.

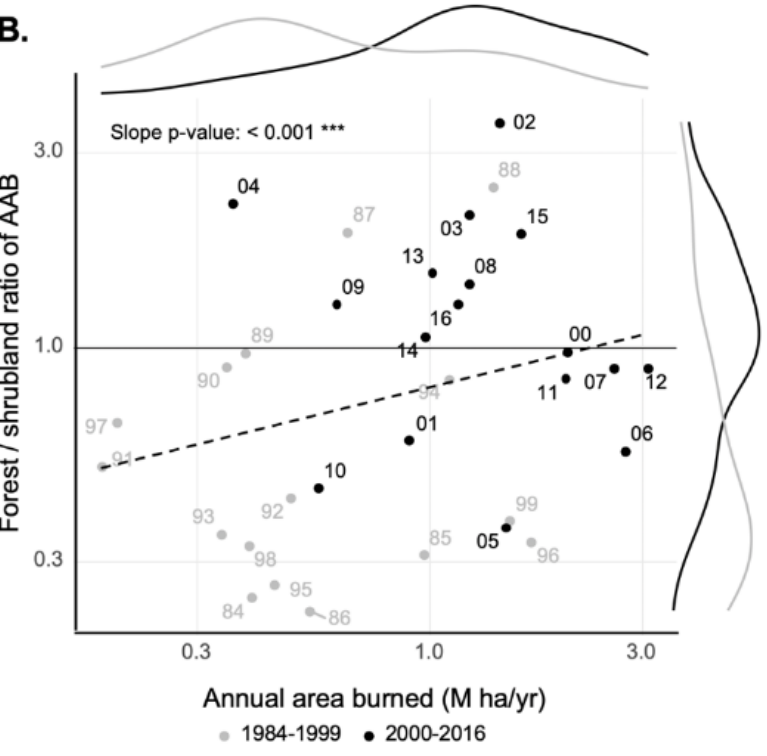

Figure 4. (A) Annual burn ratio between forest- and shrub-systems by year (bars colored by vegetation potential; green = forest; brown = shrub). (B) Annual burn-ratio compared to overall annual area burned. Differences between periods in the distributions of $A A B$ and burn-ratio are shown above and to the right. In both panels, the 1:1 ratio is shown as a horizontal solid line. Significance labeled for trends in each panel. 


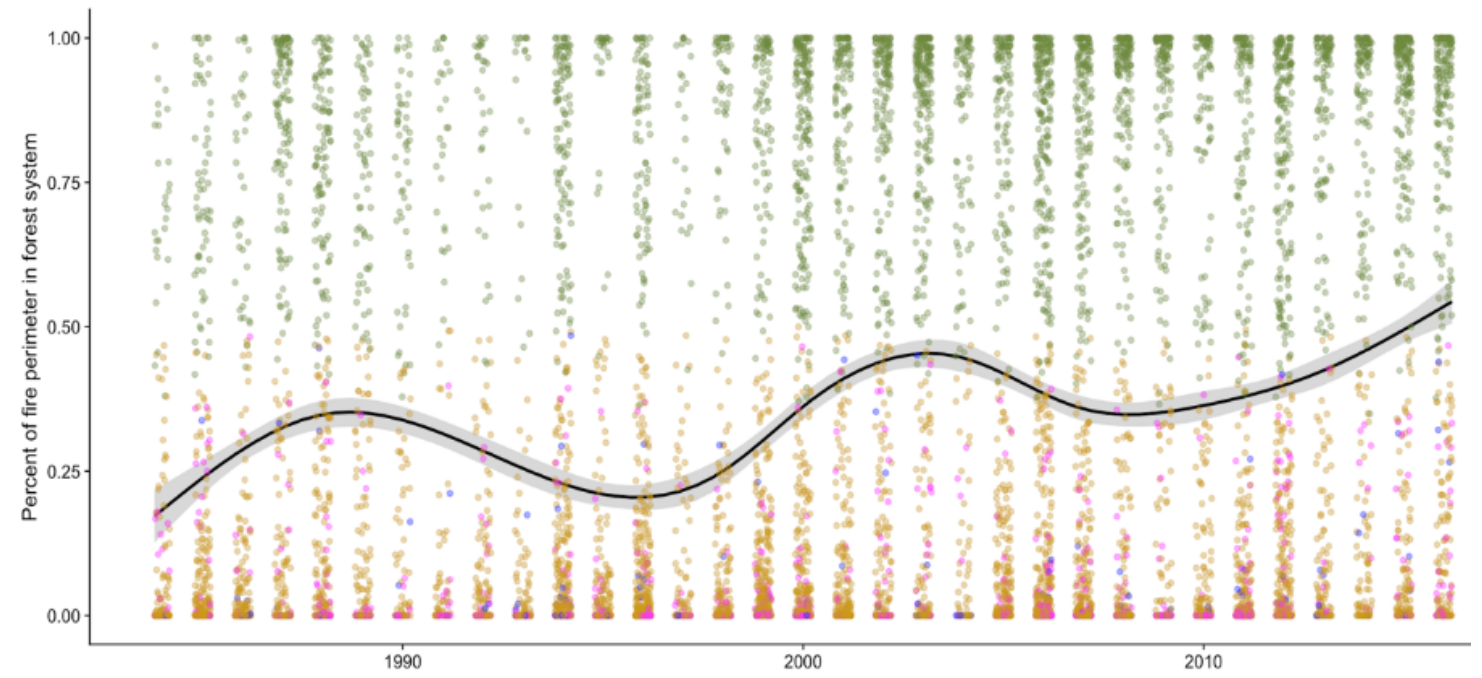

Figure 5. Percent of wildfire burn area $(n=9228)$ within forest system (compared to other vegetation types) colored by dominant vegetation system. Point color reflects dominant vegetation potential. Green $=$ forest; Orange $=$ shrubland; Purple $=$ grassland . 
A.

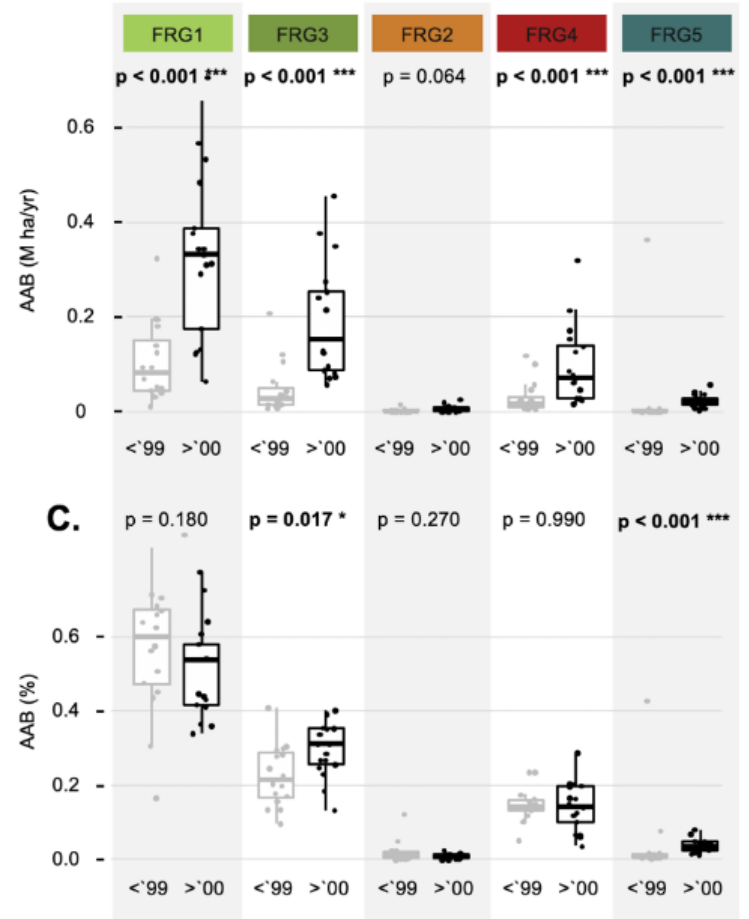

B.

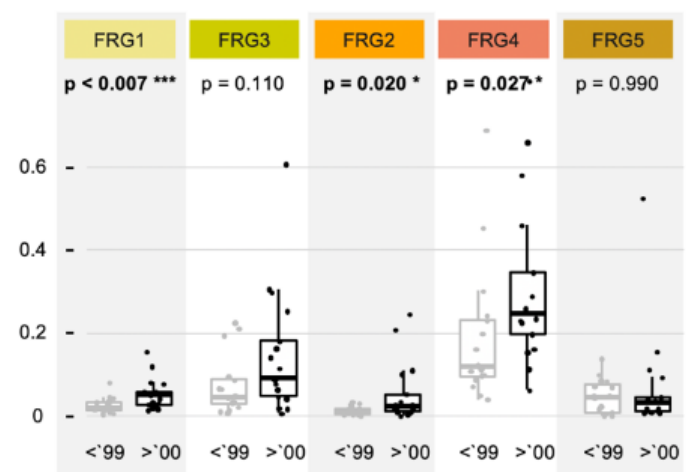

D.

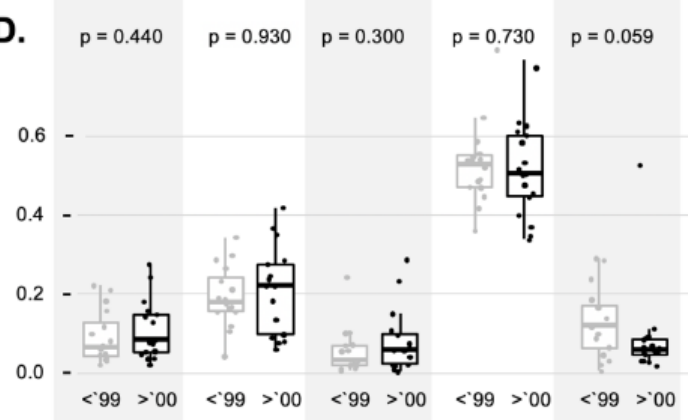

Figure 6. Variation in annual area burned by dominant fire regime within forest (A) and shrubland (B) systems, divided prior-and post-2000 (Wilcox p-values less than 0.05 are in bold). (C/D) Same as above but transformed to annual proportional share (\%). Fire regimes: $F R G 1=$ frequent and low-severity, $F R G 2$ $=$ frequent and severe; $F R G 3=$ intermittent and mixed-severity; $F R G 4=$ intermittent and severe; FRG5 = infrequent with variable severity. 

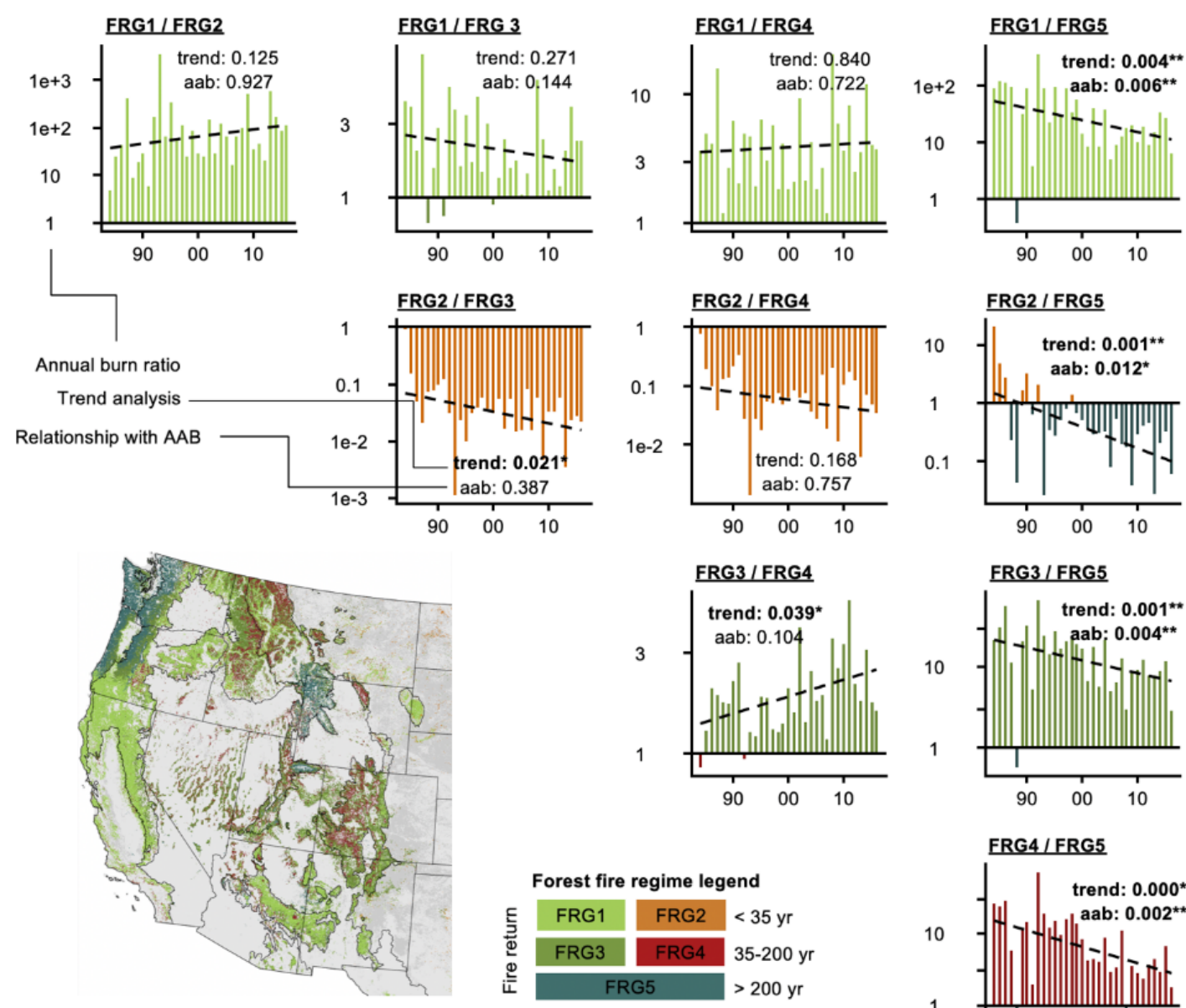

ERG4/FRG5
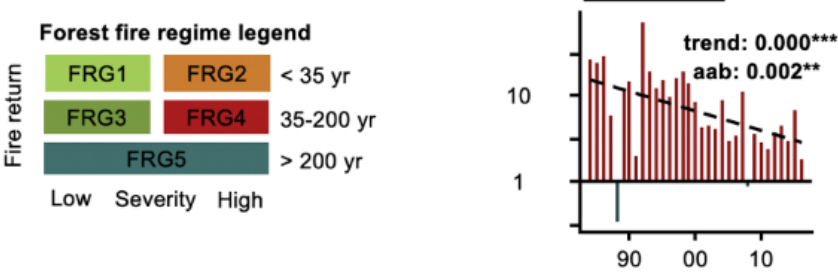

Figure 7. Pairwise comparison of annual burn ratios among forest wildfire regimes and annual area burned. Panels are equivalent to that shown in Figure 4A. Significance of the trend (dashed line) is labeled (trend) along with correlation with the total annual area burned (AAB; equivalent to Figure $4 B$ ). Significant values are highlighted. Fire regimes: $F R G 1=$ frequent and lowseverity, $F R G 2=$ frequent and severe; $F R G 3=$ intermittent and mixed-severity; $F R G 4=$ intermittent and severe; FRG5 = infrequent with variable severity. 

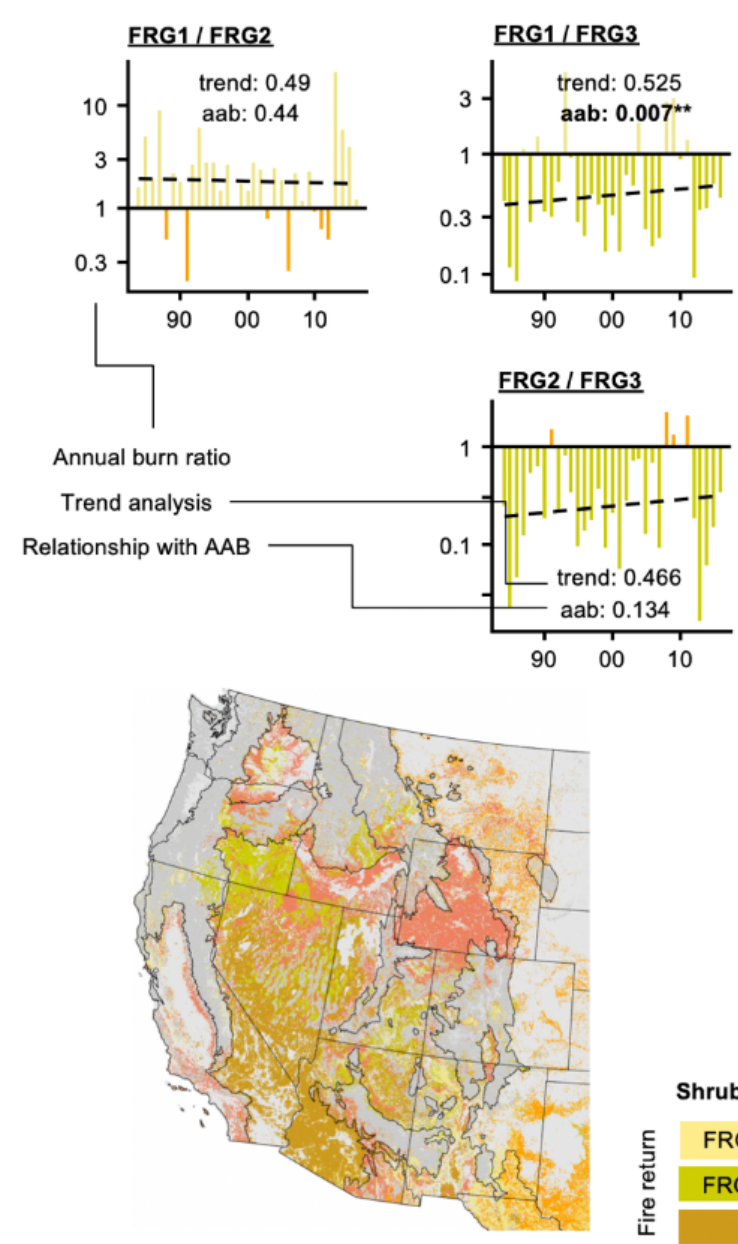
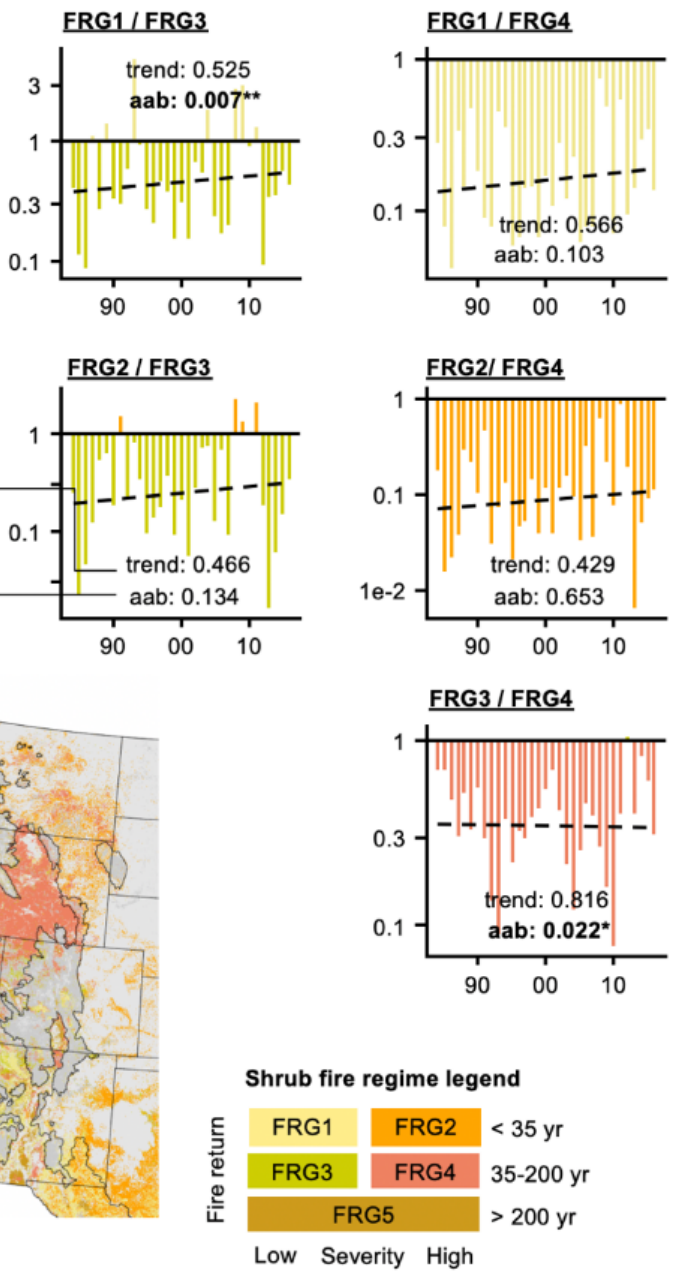
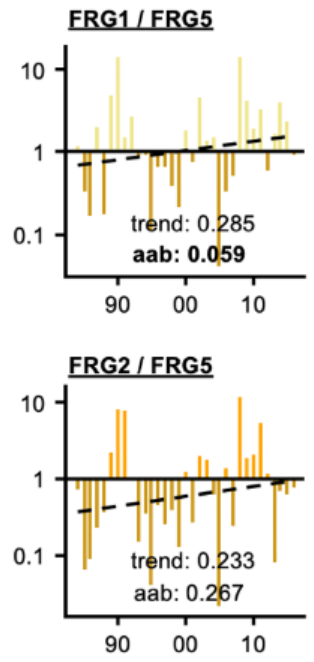

FRG3 / FRG5

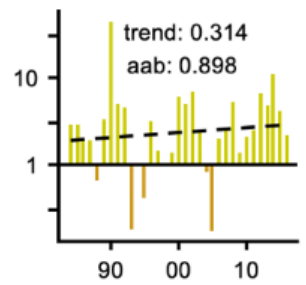

FRG4 / FRG5

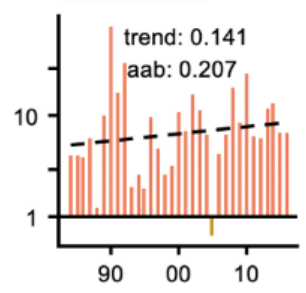

Figure 8. Pairwise comparison of the trends in burn-ratios among shrubland wildfire regimes. Significance of the trend (dashed line) is labeled (trend) along with correlation with the total annual area burned (AAB; equivalent to Figure $4 B$ ). Significant values are highlighted. Fire regimes: $F R G 1=$ frequent and lowseverity, $F R G 2$ = frequent and severe; $F R G 3=$ intermittent and mixed-severity; $F R G 4=$ intermittent and severe; $F R G 5=$ infrequent with variable severity. 

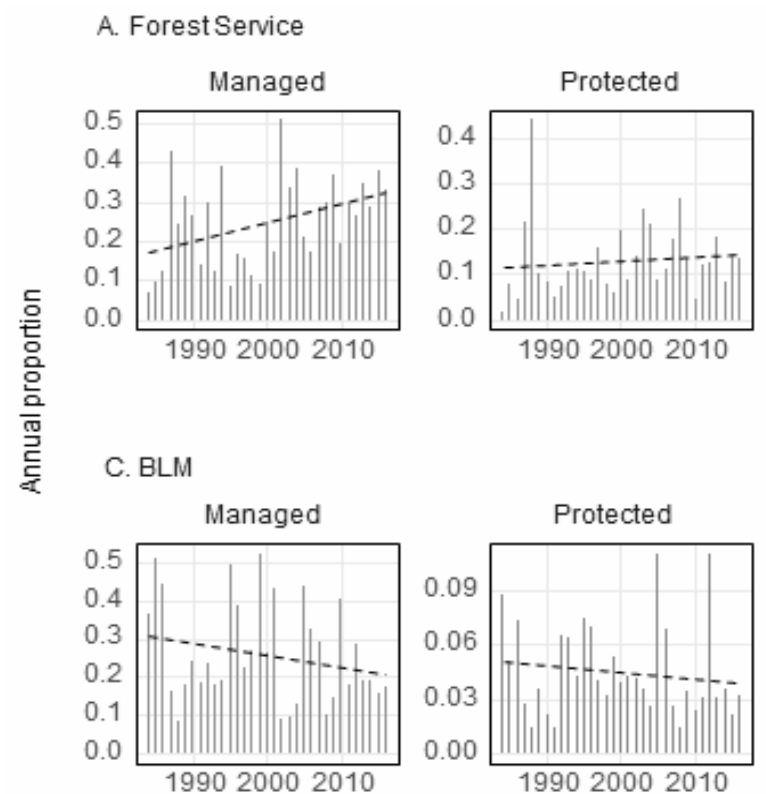

B. Private
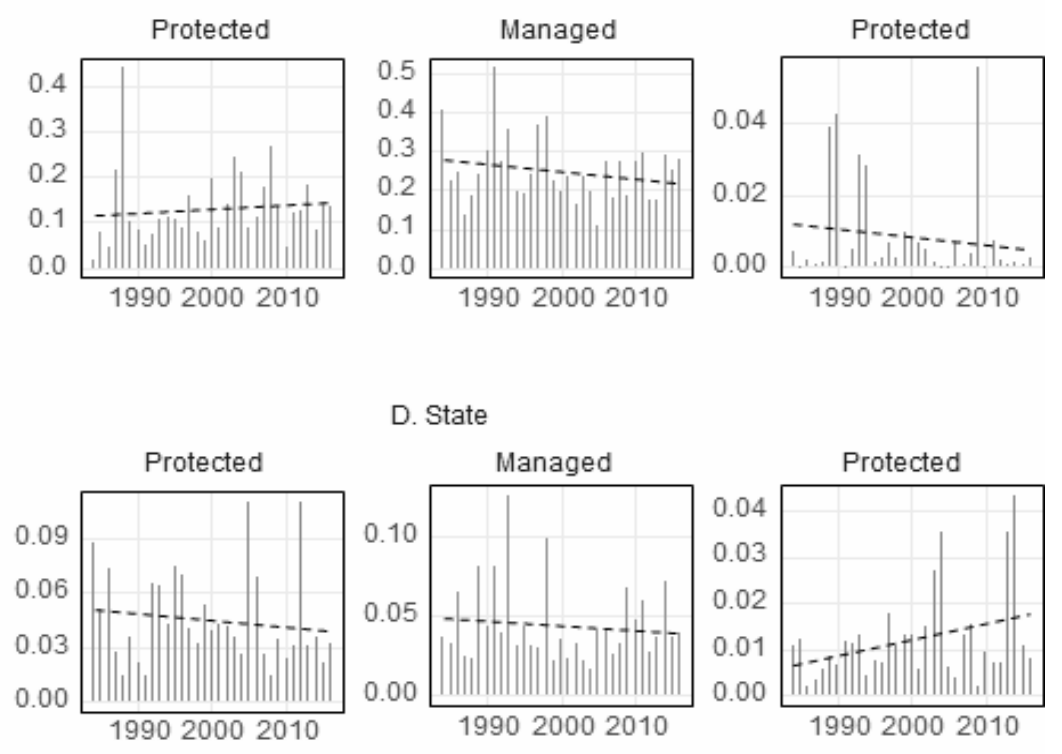

D. State
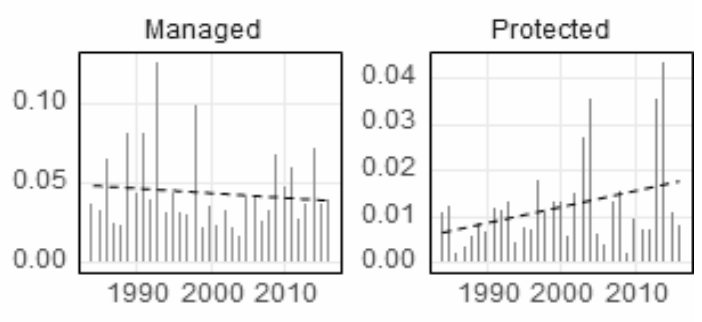

Figure 9. Proportion and trends (dashed line) of annual area burned partitioned by land ownership and protection status (all vegetation types; panels ordered by overall proportional share of fire; note differences in y-axes). Trends lines over period are shown as dashed lines. Y-axes are freely scaled so note labeled values. $F S M / P=$ National forest managed/protected; $P R M / P=$ Private managed/protected; BLM/P = Bureau of Land Management managed/protected; $S T M / P=$ State managed/protected . 

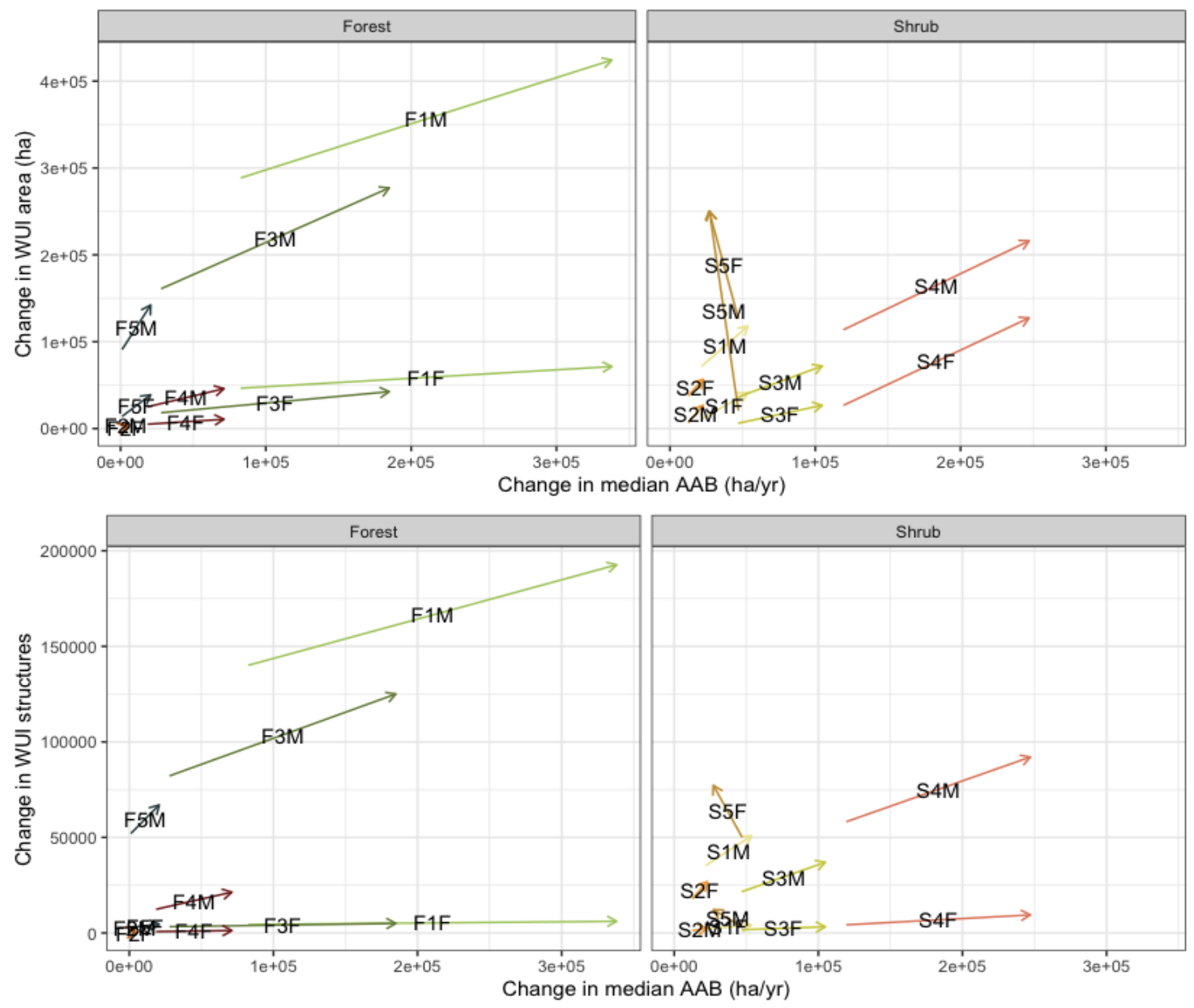

Figure 10. Change in fire activity (median $A A B$ ) and WUI (ha and structure count). Arrows labeled by vegetation potential, fire regime group, and WUI type: $F=$ forest; $S=$ shrub; $1-5=$ fire regime group; $M=$ mixed $W U I ; F=$ interface $W U I$. The top row represents WUI change as area. The bottom row represents WUI change as structure count. 


\title{
Chapter 2:
}

\section{Archetypes of Community Wildfire Exposure}

Previously published in the Journal of Landscape and Urban Planning: Evers, C. R.,

Ager, A. A., Nielsen-Pincus, M., Palaiologou, P., \& Bunzel, K. (2019). Archetypes of community wildfire exposure from national forests of the western US. Landscape and urban planning, 182, 55-66.

\begin{abstract}
Risk management typologies and their resulting archetypes can structure the many social and biophysical drivers of community wildfire risk into a set number of strategies to build community resilience. Existing typologies omit key factors that determine the scale and mechanism by which exposure from large wildfires occur. These factors are particularly important for land managing agencies like the US Forest Service, which must weigh community wildfire exposure against other management priorities. We analyze community wildfire exposure from national forests by associating conditions that affect exposure in the areas where wildfires ignite to conditions where exposure likely occurs. Linking source and exposure areas define the scale at which cross-boundary exposure from large wildfires occurs and the scale at which mitigation actions need to be planned. We find that the vast majority of wildfire exposure from national forests is concentrated among a fraction of communities that are geographically clustered in discrete pockets. Among these communities, exposure varies primarily based on development patterns and vegetation gradients and secondarily based on social and ecological management
\end{abstract}


constraints. We describe five community exposure archetypes along with their associated risk mitigation strategies. Only some archetypes have conditions that support hazardous fuels programs. Others have conditions where managing community exposure through vegetation management is unlikely to suffice. These archetypes reflect the diversity of development patterns, vegetation types, associated fuels, and management constraints that exist in the western US and provide a framework to guide public investments that improve management of wildfire risk within threatened communities and on the public lands that transmit fires to them.

\section{Keywords:}

Risk transmission; WUI; Western US; National Forests; Cohesive strategy

\section{Research Highlights}

- We assessed community exposure based on wildfire transmitted from US national forests

- Highly exposed communities represented a diversity of natural and built environments

- We identified five primary archetypes of community exposure in the western US

- Archetypes link drivers of risk to mitigation factors at the appropriate landscape scale

- Community exposure archetypes can translate national wildfire policy to the local level 


\section{Archetypes of Community Wildfire Exposure}

The increase of wildfire risk in many regions around the world has prompted a wide-ranging discussion of responsible drivers, potential solutions, and how communities and land managing organizations can adapt to these changes (Smith et al., 2016). Existing wildfire risk policy has been to slow these trends. Overly general prescriptions have failed to account for the diversity of social and ecological factors that shape wildfire risk. Typologies are used in natural disaster risk management to match mitigation programs to a diverse set of exposure factors (Mileti, 1999), and in the case of wildfire, biophysical and social dimensions of risk (Steelman, 2016). A typology that combines social and biophysical aspects of wildfire exposure has the potential to improve risk governance systems by highlighting specific priorities and trade-offs among mitigation and adaptation strategies across diverse public and private landscapes (Smith et al., 2016; Spies et al., 2014).

Wildfire is concentrated within the Wildland-Urban Interface (WUI), the area where development and infrastructure are located within or adjacent to wildland vegetation (e.g., forests, shrublands, grasslands). Combined with longer fire seasons, altered ignition patterns, and accumulation of fuels, the growth of the WUI has accelerated suppression costs and wildfire-related losses (Schoennagel et al., 2017). The exact definition of the WUI varies by country and statute. The two classes of WUI most commonly described in the US are intermix WUI, where development is scattered within wildlands, and interface WUI, where development abuts wildlands (USDA and USDI, 2001). Maps depicting the extent of WUI in the US now span more than two decades and 
show that the growth of WUI has surpassed that of any other major land cover class (Radeloff et al., 2018). National maps have also been recently developed for Canada (Johnston \& Flannigan, 2018) and for much of Europe (Modugno, Balzter, Cole, \& Borrelli, 2016). Other examples are region-specific, including the Mediterranean (Alcasena, Evers, \& Vega-Garcia, 2018; Chas-Amil, Touza, \& García-Martínez, 2013; Lampin-Maillet et al., 2010), Australia (Gill, Stephens, \& Cary, 2013; Price \& Bradstock, 2014), and South America (Argañaraz et al., 2017).

General principles for addressing wildfire risk within and around the WUI are well documented (Calkin, Cohen, Finney, \& Thompson, 2014; Schoennagel et al., 2017). Discouraging future development limits future exposure (Alexandre, Stewart, Keuler, et al., 2016; Syphard, Bar Massada, Butsic, \& Keeley, 2013) while planning codes shape the processes by which subdivision and development occur (Headwaters Economics, 2016; Syphard et al., 2013). Hazardous fuel treatments and prescribed burns reduce fuel loads, which in turn changes fire behavior, allowing wildfires to be better managed (North, Stephens, et al., 2015; OIG, 2016), or contained before reaching the WUI (Ager et al. 2006). Removing flammable vegetation surrounding structures and updating building standards decreases the chance of loss when exposure does occur (Cohen, 2000; Gibbons et al., 2012; Syphard, Brennan, \& Keeley, 2014).

The exact suite of viable mitigation actions, however, will vary with community and landscape (Alexandre, Stewart, Mockrin, et al., 2016; Moritz et al., 2014). The effectiveness of fuels reduction programs is questionable in certain vegetation types (e.g., Cohen, 2010) and may be ecologically inappropriate in others (Schoennagel, Veblen, \& 
Romme, 2004). In other situations, effective risk mitigation actions (e.g., fuel breaks, prescribed burns, vegetation removal, etc.) may not be social palatable (Steelman \& Burke, 2007) or cost-effective (e.g., when structure density is low or access is limited). Communities further differ in their tolerance of wildfire risk (McCaffrey, 2004, 2008) and in their trust in formal authorities to coordinate risk mitigation efforts (Paveglio et al., 2015). Many fire protection districts lack the personnel or resources to proactively address exposure at a local level, especially where development is low density or isolated. Steep hillslopes can limit both pre-suppression and suppression activities (North, Brough, et al., 2015).

Mitigation strategies need to address factors linked to community exposure at multiple scales. In the western US, for instance, a substantial portion of community wildfire exposure is linked to public lands surrounding communities, including land managed by the US Forest Service (Ager et al., 2017). For these areas, exposure is tied to large landscape-scale properties such as land ownership, ignition patterns, and fuel conditions distant from the urban interface. At the same time, vegetation and development patterns within the WUI directly shape the conditions under which structures are exposed to fire and wildfire losses are most likely to occur (Alexandre, Stewart, Keuler, et al., 2016; Gibbons et al., 2012; Syphard et al., 2014). Furthermore, most applications of the WUI only examine the spatial relationship between development and wildlands, which fails to account for the specific mechanisms by which the two types of land use relate to each other. This deficiency is particularly striking considering the degree to which wildfire activity can vary by region. Ignoring wildfire transmission can 
lead to management prescriptions that are focused exclusively on the wildland or interface, thereby negating transboundary risk linkages (Sjostedt \& Linnerooth-Bayer, 2001) and contributing to scale mismatches in planning (Cumming, Cumming, \& Redman, 2006) and risk governance (Lidskog, Soneryd, \& Uggla, 2010; Steelman, 2016). Matching risk mitigation to varying contexts and scale requires cohesive planning. This can be seen in the recent US National Wildfire Cohesive Strategy (USDA and USDI, 2018), which emphasizes the need for integration of social and biophysical aspects of risk (Fischer, Spies, et al., 2016; Moritz \& Knowles, 2016) and increased collaboration across boundaries (OIG, 2016; USFS 2018). As the largest bearer of federal costs for both pre-suppression and suppression (Calkin, Thompson, \& Finney, 2015), the US Forest Service (USFS) maintains a pivotal role in implementing the Cohesive Strategy, especially given that wildfire represents one of the agency's most effective tools for restoring and maintaining resilient forests (North, Stephens, et al., 2015; Schoennagel et al., 2017). Systematically characterizing risk at both community and landscape scales allows large land managing agencies like the USFS to accommodate wildfire within diverse transboundary fire regimes (Ager et al., 2017).

In this paper, we characterize community wildfire risk from fires originating on national forests of the western US. We organize community exposure into risk archetypes based on community and forest conditions known to wildfire behavior and constrain mitigation strategies at both community and landscape scales. We improve on existing community wildfire risk typologies by joining 'in-situ' conditions near threated homes (c.f. Lampin-Maillet et al., 2010) with 'ex-situ' conditions where many large wildfires 
originate (Ager et al., 2017). We discuss how community wildfire exposure archetypes advance the development of cross-boundary, socio-ecological frameworks for risk management (e.g., Steelman, 2016) and how such a framework can be used to adapt the national wildfire strategy to local conditions. This work addresses key gaps in current wildfire planning including: (a) inadequate characterization of exposure to large fires; (b) one-size-fits-all approaches to mitigating fire hazard; and (c) definition of scales applicable to the management of socio-ecological fire systems.

\section{Methods}

The following section describes how wildfire exposure was estimated and characterized among communities of the western US. We combined a national dataset of simulated wildfires and a national map of the WUI in the western US to (a) identify areas of national forest that expose communities to wildfire; (b) identify areas of communities where that exposure is greatest, and; (c) classify wildfire exposure of affected communities based on factors known to affect wildfire behavior and constrain management at both community and landscape scale.

\subsection{Study Area}

We examined community exposure to wildfire igniting on national forests within the 11 states of the western US using structure counts derived from 2010 SILVIS WUI data (Radeloff et al., 2005, 2017). Communities were defined using official CensusDesignated Places (CDP), which are designated geographic areas used to identify concentrations of populations for statistical purposes (Bureau of the Census, 2008). 5118 CDPs are found in the western US. Structures outside of CDP boundaries were assigned 
to the nearest CDP based on a 45-minute drive-time. Drive-times were estimated by applying the cost allocation tool in ArcGIS Desktop 10.3 to the North America Detailed Streets dataset (ESRI, 2012). While forty percent of structures (10.8 million) in the dataset were classified as intermix or interface WUI (Radeloff et al., 2005), it is important to note that exposure is still possible in non-WUI classified areas. The median community contained 97 WUI or non-WUI polygons with a median polygon size of 2.4 hectares. California (CA) had the greatest number of communities (30\%), followed by Washington (WA, 12\%), Colorado (CO, 9\%), Arizona (AZ, 9\%) and New Mexico (NM, 9\%), Oregon (OR, 7\%) and Montana (MT, 7\%), Utah (UT, 6\%), Idaho (ID, 5\%), Wyoming (WY, 4\%) and Nevada (NV, 3\%). Communities varied in size from ten structures to more than a half-million (San Diego, CA, Phoenix, AZ, Los Angeles, CA) with a median of 890 .

\subsection{Simulation exposure to communities}

Our analysis relied on a national "library" of possible wildfires developed in 2014 by the USFS Missoula Fire Science Laboratory (Short, Finney, Scott, Gilbertson-Day, \& Grenfell, 2016). The dataset contains several million wildfires representing tens of thousands of hypothetical fire seasons under current conditions. Fire seasons were constructed on the historical relationship between historical fire size, weather conditions, and energy release component (ERC) (Finney, McHugh, Grenfell, Riley, \& Short, 2011). Their simulations were performed on 2012 LANDFIRE data describing topography, fuels and vegetation structure at a 270m resolution (Rollins, 2009). Ignition points were randomly distributed. Fuel moisture levels, ignition density, ignition timing, and wind 
speed were built using streams of weather data pulled from a national network of weather stations. The simulated fire size distributions were validated against observed distributions and were statistically adjusted to account for the effect of fire suppression (Finney, Grenfell, et al., 2011; Finney, McHugh, et al., 2011).

We limited our analysis to those FSIM wildfires that ignited on national forests and burned into western US communities (as defined above), which resulted in a data subset of 367,000 fire perimeters (out of approximately 2 million records). Housing unit (HU) exposure for each fire was calculated using the geometric intersection of fire perimeters with polygons from the SILVIS WUI dataset that contained structures. Figure 1 shows the perimeters of two wildfires that burn into an adjacent community, which is divided into polygons according to development density. The intersection of each fire with the community results in a set of intersected polygons. If $\mathrm{W}_{\mathrm{n}}$ represents the set of polygons for fire $n$, the exposure (HU) resulting from fire is

$$
e_{n}=\sum_{i=1}^{W_{n}} A_{i} d_{i}
$$

where $A_{i}$ is the area (ha) of the intersected polygon and $d_{i}$ is the density of structures $\left(\mathrm{HU} \mathrm{ha}^{-1}\right)$. The combined exposure for the entire community therefore represents the sum of exposure for all fires intersecting the community. Since wildfires represent thousands of potential fire seasons, the annual exposure $\left(\mathrm{HU} \mathrm{yr}^{-1}\right)$ for community $\mathrm{j}$ is

$$
e_{j}=\sum_{n=1}^{F_{j}} \frac{e_{n}}{s}
$$


where $F_{j}$ is the set of exposure values (HU) for community $j$ and $s$ is the number of total number seasons simulated (yr). The annual community exposure $\left(\mathrm{HU} \mathrm{yr}^{-1}\right)$ reflects the average number of structures within a community that is exposed to wildfire from national forests each year.

Figure 1. Community wildfire exposure was determined using the area where wildfire and development intersect (red-hashed area). The archetype of community exposure was based on conditions within both the source area where wildfire ignited (yellow-hashed area) and the exposed area of the community (red hashed). Conditions for both areas were averaged for the entire community based on thousands of possible wildfires.

Initial screening of exposure data indicated that 2,560 communities in the study area received at least some exposure to fire from the national forest. Given the skewed distribution of wildfire exposure among communities, however, we constrained our analysis to the top $20 \%(\mathrm{n}=516)$. The top $20 \%$ of communities collectively accounted for $80 \%$ of the annual structure exposure, and each of these communities had an estimated annual exposure greater than or equal to $1.0 \mathrm{HU} \mathrm{yr}^{-1}$. Selected communities were found in all 11 states of the study area and most densely clustered in southern CA, the northern Sierra of CA, the western valleys of MT, the Wasatch front of UT, and the central plateau in $\mathrm{AZ}$.

\subsection{Characterizing wildfire exposure}

Community exposure was characterized using attributes known to affect potential fire exposure and hazard (Table 1), including development density $\left(\mathrm{HU} \mathrm{ha}^{-1}\right)$, canopy cover (\%), conditional flame length (CFL - m), slope (\%), fuel models (Scott \& Burgan, 2005), restoration potential (i.e., vegetation departure), and management constraints. For 
simplicity, fuel models were grouped into four classes: grass/shrub fuels, shrub fuels, forest fuels, and others. Agricultural lands were included to distinguish fires in natural grass/shrubland from agricultural fields, where fire behavior is mediated by crop management and irrigation. Information on development density and WUI classification was taken from SILVIS WUI attributes and included WUI type (intermix vs. interface) and structure density (low, medium, high). We included the majority fire regime (FRG) to identify fire-adapted ecosystems within the national forest (i.e., FRG1 \& FRG3, see Rollins 2009). Finally, we identified protected areas where access for mechanical fuel treatments is restricted (USGS Gap Analysis Program, 2016).

These variables were used to construct a multivariate description of community exposure based on the characteristics of (a) the 100-hectare area immediately surrounding each ignition point and (b) the area of the WUI intersecting the wildfire perimeter (refer to Figure 1). These variables were then averaged across all fires that reached the community as weighted by the magnitude of $\mathrm{HU}$ exposure. Thus, the exposure-weighted average value for variable $\bar{x}$ of community $j$ is

$$
\bar{x}_{J}=\sum_{n=1}^{F_{j}} e_{n} x_{n} / \sum_{n=1}^{F_{j}} e_{n}
$$

where $x_{n}$ is the fire-specific value for either (a) the areas surrounding the point of ignition within the national forest or (b) the exposed area of the community, and $e_{n}$ represents the magnitude of exposure resulting from that fire. Weighting emphasized the community and landscape conditions where exposure most commonly occurred (e.g., at the periphery of the community or national forests). For example, we found that exposure in Wenatchee, WA, occurred in developed areas where the canopy cover averaged $6 \%$ and 
originated in the national forest where the canopy cover averaged $41 \%$, which differs from the average canopy cover for either the community (less) or the greater national forest (more). The resulting dataset contained 516 rows, where each row described the exposure conditions for a single community using the variables listed in Table 1.

Table 1. Variables used to distinguish the nature of wildfire exposure among threated communities.

\subsection{Gradient and cluster analysis of wildfire exposure}

The community exposure data were first evaluated using principal component analysis (PCA) as implemented in the psych package in R (Revelle, 2016) in order to isolate the principal dimensions of community exposure. Variables were scaled before the PCA, and the resulting components were rotated using varimax rotation to minimize cross-loading of variables and facilitate interpretation (Jolliffe, 2002). We determined the number of components to retain using parallel analysis (O’Connor, 2000). Components were treated as significant when their respective eigenvalues exceeded those generated using a randomly shuffled dataset. Eight components were retained using this criterion, which explained $80.2 \%$ of the variance within the exposure data (Figure $2 \mathrm{~A}$ ).

Archetypes of community exposure were assigned by clustering on component scores using the PAM algorithm as implemented in the cluster package in R (Maechler et al., 2015). Compared to k-means, PAM clusters are less sensitive to outliers and are considered more appropriate for nonparametric data (Kaufman \& Rousseeuw, 1990). Since divisive clustering solutions like PAM are sensitive to the initial starting points, we used consensus aggregation to make final archetypes assignments and to report the 
stability within each archetype (Monti, Tamayo, Mesirov, \& Golub, 2003). This bootstrapping procedure calculates cluster solutions for 100 subsamples constructed using $80 \%$ of observations randomly sampled from the original dataset with replacement (Figure 2B). Communities were grouped according to their most frequent cluster/archetype assignment. The procedure was repeated across a range of clusters numbers and assessed using changes in both cumulative density function curves as well as the change in area under each CDF with each increase of $\mathrm{k}$ (see Monti et al., 2003 for a detailed discussion) (Figure 2C).

Figure 2. Community wildfire exposure was grouped into 5 exposure archetypes based on 8 components. The number of components $(f=8)$ was determined using parallel analysis (left). The number of clusters $(k=5)$ was chosen based on the change in the area under the curve (right) for successive cumulative density functions (middle).

\section{Results}

\subsection{Community exposure to wildfire originating from national forests}

Cross-boundary community wildfire exposure was concentrated within distinct regions found in all 11 states in the western US (Figure 3). The area of the national forest where community exposure originated (i.e., the source area) represented approximately 10.6 million hectares, or $16 \%$ of the total area of all national forests in the western US (66 million hectares). The portion of the national forest that contributed community exposure varied from less than 5\% of the forest area (e.g., Gifford-Pinchot, Medicine Bow, or Mt. Baker-Snoqualmie National Forests) to greater than $80 \%$ (Angeles, San Bernardino, or Cleveland National Forests). As described above, $80 \%$ of wildfire 
exposure was concentrated among $20 \%$ of communities. Within these highly exposed communities, $60 \%$ of the community area accounted for $80 \%$ of the total housing exposure. Exposure varied widely among communities. In extreme instances, $5 \%$ of the developed area of a community resulted in $80 \%$ of house exposure (e.g., where exposure was constrained to specific subdivisions) while in other cases exposure was spread equally across the community. The average distance between ignition points and points of housing exposure was $14.2 \mathrm{~km}$ and varied among communities from a low of $2.8 \mathrm{~km}$ to a high of $50 \mathrm{~km}$.

Figure 3. Map of the western US shows the 516 communities that account for $80 \%$ of the wildfire exposure originating in the national forest. Areas of the national forest that contribute the most exposure are shown in orange and the most exposed areas within communities are shown in magenta.

Table 2 describes conditions related to exposure for both national forest source areas and exposed community areas among the 516 most highly exposed communities in the western US. On average, the simulated wildfires that burned into the WUI burned at moderate intensity (conditional flame length $=1.8 \mathrm{~m}$ ), occurred under open canopy cover (22.5\%), and were carried by a mixture of forest litter (34.8\%), grass (51.7\%) and shrub (13\%) fuels. Fires generally ignited in fire-adapted forests $(63 \%)$ that were not restricted from management based on forest plan standards (85\%). Compared to the non-source areas of the national forest, source areas were more open and had a greater portion of grass and shrub fuels. High frequency, low-severity (FRG1) and high frequency, highseverity (FRG4) were more common in source areas, while mixed-severity (FRG3) and infrequent fire regimes (FRG5) were less common. Compared to national forest source 
areas, exposed portions of the community were much more open (canopy cover $=7.4 \%$ ), had small amounts of forest and shrub fuels (11.1\% and 9\% respectively), and had slightly lower fire hazard (conditional flame length $=1.45 \mathrm{~m}$ ). Compared to the entire community, exposed areas were much more likely to be classified as WUI (either intermix or interface), and tended to occur in areas where housing density was lower, and as a result, had a greater portion of wildland fuels (predominantly grass). 
Table 2. Descriptive statistics of wildfire exposure among highly exposed communities $(n=516)$. The reference values represent the average conditions among western national forests

\subsection{Variation in conditions among highly exposed communities}

Components retained from the principal component analysis (labeled F1-F8) explained $80 \%$ of the differences in the character of wildfire exposure among communities (Table 3). Reflecting on the diversity of cross-boundary exposure among communities, variance was widely distributed across the eight components, and no component explained more than $18 \%$ of the total variance. Component F1 (18\% of variance) related canopy cover to the ratio of forested fuels and grass fuels. Component F2 (17\% variance) described the ratio of exposure in communities resulting from intermixed compared to interface development. F2 loadings also showed that interface communities had higher development density with a greater proportion of unburnable fuels while intermix communities had lower density and higher conditional flame length. Component F3 (12\% variance) described the correlation between the percentage of shrub fuels and fire hazard. The relative independence in variance between F1 and F2 revealed how vegetation conditions vary widely among WUI classes in different communities. For instance, some communities where a preponderance of exposure occurred in interface WUI were still characterized by the denser and closed vegetation typically associated with intermix WUI.

The remaining five components characterized a smaller degree of differences among exposed communities. Component F4 (9\% variance) described management opportunities and constraints in addition to the correlation between vegetation departure 
from historical conditions and the percent of manageable lands within the national forest. Component F5 (8\% variance) showed a relationship between higher slope, canopy cover, forested fuels and absence of grass fuels. Component F6 (7\% variance) described lowdensity exposure coinciding with agricultural/grazing lands with limited forest cover. The final two components described differences in fire regimes within the national forest source area. Component F7 (6\% variance) described the communities exposed to fire originated from low-severity or mixed-severity fire regimes. Component F8 (5\% variance), by contrast, identified community exposure from low-frequency, high severity fire regimes constrained either by lack of fuels or flammability.

Table 3. Loadings of exposure variables on the 8 components (F1-F8) used to distinguish community archetypes. Components are ordered by the variance explained. Loadings $>0.5$ are bolded; loadings $<0.1$ are omitted.

\subsection{Archetypes of community wildfire exposure}

Community exposure archetypes (labeled C1-C5) represent groups of communities with similar wildfire exposure characteristics (Figure 4). Archetypes C2 and C4 were most common ( $\mathrm{n}=147$ and $\mathrm{n}=153$ respectively) while $\mathrm{C} 1$ and $\mathrm{C} 5$ were least common ( $\mathrm{n}=49$ and $\mathrm{n}=58$ respectively). Archetypes generally fell along a continuum from low canopy cover dominated by grassy fuels ( $\mathrm{C} 1$ and $\mathrm{C} 2)$ to closed canopy cover dominated by forested fuels ( $\mathrm{C} 3, \mathrm{C} 4$, and C5). The consensus plot in Figure 4 shows the portion of times that each of the 516 communities was assigned to each cluster. The final cluster assignment was based on the plurality value. The within-group consensus was highest for archetypes $\mathrm{C} 1, \mathrm{C} 2$ and $\mathrm{C} 5$ and lowest for $\mathrm{C} 3$ and $\mathrm{C} 4$. The dendrogram at the top of Figure 4 reveals subgroups within each cluster, which are most notable in clusters 
$\mathrm{C} 3$ and $\mathrm{C} 4$. Table 4 describes the mean values and standard deviations for the exposure characteristics within each archetype. A brief description of the five primary community exposure archetypes follows.

Figure 4. Exposure patterns for highly exposed communities divided into five archetypes, as shown in the dendrogram and consensus plot above and in the map below. Differences in the height of branches in the dendrogram reflect differences within and among clusters. Branches of the dendrogram dominated by a single color in the consensus plot represent greater homogeneity among communities within archetypes (e.g., C2 open-interface), while branches containing a mixture of colors represent groupings that are less distinct.

C1: Infrequent-exposure communities $(n=49)$. Archetype C1 communities were defined by low frequency, high severity fires limited by either fuels or flammability. Development in these communities was characterized by low-density and low-slope. Fuels were grass-dominated. The cluster included two distinct geographic pockets: the desert southwest with desert scrub and Mogollon chaparral and interior lodgepole pine and subalpine spruce-fir forests. Communities typifying the former included those surrounding the Phoenix metro area, AZ, while the latter included communities of Big Sky, MT, and Jackson Hole, WY.

C2: Open-interface communities ( $n=147)$. Archetype C2 was most commonly associated with communities in southern California. Exposure in these communities commonly tended to occur in high-density interface development in hilly areas, steep slopes, and open forest cover. Fuels represented a mixture of grass and shrubs fuels, including chaparral shrubland. Nearby national forest was open, departed from historical conditions, and frequently management limited. Vegetation in the national forest included 
chaparral and grassland historically shaped by frequent high severity fires. Communities include Las Angeles, CA, Sedona, AZ, and Boise, ID.

C3: Mixed-interface communities $(n=109)$. Archetype $\mathrm{C} 3$ was the most varied of the five archetypes described. Vegetation contained a mixture of forested, grass and shrub fuels. Communities were largely unforested, while source areas contained open canopy mixed-conifer forests (ponderosa pine, pinyon-juniper, Douglas-fir). The exposure type was common throughout the western US, including moderate elevation communities of the SW and Great Basin regions. Typical communities included Bend, OR, Reno, NV, Flagstaff, AZ, and Santa Fe, NM. Some communities in Cluster C3 were similar to those in $\mathrm{C} 2$ and $\mathrm{C} 4$.

C4: Forested-intermix communities $(n=153)$. Archetype $\mathrm{C} 4$ described communities with low-density development, intermixed within a matrix of forest and agricultural lands; national forest source areas had high canopy cover and were adapted to historically low or mixed-severity fire. The archetype was common to the Northern Rockies, and communities on the east side of the Cascade/Sierra ranges and higher mountainous areas of the SW. Communities of $\mathrm{C} 4$ had the lowest-density development and the highest community canopy cover of all archetypes. National forests were predominately Douglas-fir and ponderosa pine and to a lesser extent shrubland steppe. Typical communities included Colorado Springs, CO, Leavenworth, WA, Lolo, MT, Squaw Valley, CA, and Ruidoso, NM. Some C4 communities were similar to C3.

C5: Shrub-interface communities ( $n=58)$. Archetype C5 was found primarily in 
communities along the Wasatch Front where moderate density interface development often occurred in areas with steep slopes. Forests had a mixture of low canopy-height trees and shrubs growing under conditions of wet springs and hot, dry summers. National forests contained pinyon-juniper woodland, Bigtooth Maple, Douglas and Grand-fir, and aspen forests. The combination of fuels and topography led to more common higher intensity burns. Example communities included Salt Lake City, UT, Bountiful, UT, and Elko, NV.

Table 4. Differences in the character of exposure among 5 community archetypes, represented as mean values.

\section{Discussion}

We have shown how conditions pertaining to community wildfire exposure differed markedly among communities in the western US, primarily with respect to forest cover, fuels, and development patterns, and secondarily with respect to conditions that either facilitate or hinder mitigation actions. While federal wildland fire policy in the US fosters a diversified approach to managing wildfire risk (e.g., promoting fire-adapted communities, restoring fire-resilient landscapes, and ensuring safe and effective wildfire response), it provides only limited guidance on how these policy goals can be translated into a set of contextually-relevant strategies (Wildland Fire Leadership Council, 2014). The five archetypes of community exposure that we identified illustrate the need to match risk mitigation strategies to specific conditions that characterize a spectrum of transboundary risk contexts (Figure 5). For example, expanding hazardous fuel treatments and prescribed burns are more likely to be effective and ecologically 
appropriate in exposure archetype C3 and C4 (North, Stephens, et al., 2015; OIG, 2016).

In other cases, such as exposure archetype $\mathrm{C} 2$ and $\mathrm{C} 5$, mitigation efforts should focus more on the areas within and nearby development, which includes restricting development in fire-prone wildlands (Headwaters Economics, 2016) and reducing flammable vegetation surrounding homes (Gibbons et al., 2012). Improving communitybased disaster planning and response (Calkin et al., 2014) may be particularly important in exposure archetype C5 due to shrub fuels, steep slopes, and high flame lengths, as observed both within the national forest source areas and exposed areas of the community.

Figure 5. Community archetypes reflect different priorities for managing wildfire risk. Vegetation management, for instance, is effective in only half of highly exposed communities (i.e., C3 mixed-interface and C4 forested-intermix communities). Differences in prioritization also indicate different needs for crossboundary coordination.

\subsection{National forest sources areas}

Most federal wildfire risk mitigation actions fall on publicly managed lands outside of designated WUIs (Schoennagel, Nelson, Theobald, Carnwath, \& Chapman, 2009). While extensive, the source of community wildfire exposure typically represented only between $10 \%$ to $30 \%$ of most national forests (although some forests in southern California exceed 50\%). Many of the highly-exposed communities that we examined received fires from areas of the national forest where mechanical thinning, slash removal, and prescribed fires are suited to reduce wildfire size and severity (Stephens et al., 2012) and improve the capacity of managers to contain or suppress fires when needed. Despite valid concerns regarding the ecological impact of fuel reduction programs in some forest 
types (e.g., Schoennagel \& Nelson, 2011), our results suggest that the areas of the national forest most likely to threaten communities tend to be lower-elevation, drier, open-structure mixed-conifer forests (Table 2). Such conditions tend to support fuel treatments that restore forest structure at the same time as reducing fire hazard to communities. On the other hand, as much as a third of community exposure originated in parts of the national forest where thinning and prescribed burns are less viable. This includes community exposure from sparsely forested or non-forested lands where fire is carried either by fine-fuels dependent on inter-annual fluctuations in precipitation (Littell, Mckenzie, Peterson, \& Westerling, 2009) or where fire ecology is characterized by highseverity and rapid regeneration of fuels (Keeley, Syphard, \& Fotheringham, 2008). We further found that while community wildfire exposure typically came from areas with relatively frequent fire return intervals, $10 \%$ of highly-exposed communities were notable for the longer wildfire return intervals constrained by either lack of fuels (e.g., Mogollon foothills in AZ) or climatic conditions that typically limit flammability (e.g., the greater Yellowstone ecoregion of WY and MT). We found surprisingly little difference among communities regarding manageability (generally high) and vegetation departure from historical condition (generally moderate) in national forest source areas. Compared to the national forest as a whole, source areas were less likely to be protected and more likely to be ecologically departed from historical conditions.

\subsection{Community exposure areas}

Our results confirm that community exposure to wildfire differs markedly with development patterns (Hammer, Stewart, \& Radeloff, 2009). Half of the estimated 
exposure occurred in low to moderate density intermixed development, much of which has likely occurred in jurisdictions that lack strong controls on development (Burby, 2006). These fire-prone regions often find themselves in a vexing mitigation paradox where the threat of wildfire exposure to low-density development is at odds with economic incentives to promote growth (Moritz et al., 2014; Steelman, 2008). The extent of exposure within intermixed WUI lends to the scale mismatches that challenge existing systems for wildfire risk governance (Burby, 2006; Cumming et al., 2006; Steelman, 2016). Nonetheless, land-use planning remains key to limiting wildfire exposure trends over time (Moritz et al., 2014; Nielsen-Pincus et al., 2010; Syphard, Keeley, Massada, Brennan, \& Radeloff, 2012) and a growing number of fire-prone areas are implementing WUI-specific building and land subdivision codes (Headwaters Economics, 2016). Mitigating exposure of transboundary wildfire risk requires collaborative engagement among both organizations responsible for managing wildfire risk and others that may influence the behavior of actors on either side of the risk transmission boundary (Jakes et al., 2011; Williams et al., 2012). Without coordination, risk mitigation is less likely to address shared priorities and more likely to be rendered ineffective due to indirect spillover effects (Abrams et al., 2015; Fischer \& Jasny, 2017). Many fire-prone regions in the western US are pioneering adaptive approaches to risk mitigation through wildfire learning networks, which provides a forum for communities to share and discuss local risk mitigation actions (Goldstein, Butler, \& Hull, 2010) and Fire Adapted Communities programs that connect wildfire education, planning, and action with comprehensive resources (Fire Adapted Communities Coalition, 2014). The community exposure 
archetypes described in this article support these networks by identifying communities that face similar challenges and can draw on similar resources to become fire-adapted.

\subsection{Connecting multiple scales of exposure}

Our work contributes a spatial planning framework for transboundary wildfire risk mitigation that defines specific geography encapsulating where people live, the local and ex-situ risk drivers, and the multi-party cooperation needed to manage the problem, all of which contribute to community and wildland resilience. Existing schemes for classifying wildfire risk rely solely on structure location and patterns of surrounding vegetation cover (e.g., Bar-Massada, Stewart, Hammer, Mockrin, \& Radeloff, 2013; Chas-Amil et al., 2013; Lampin-Maillet et al., 2010). Focusing exclusively on conditions within the WUI ignores the scale of wildfire risk transmission (Ager et al., 2017), which is important both because of the larger landscape context and contrasting organizational stances towards wildfire risk (Steelman, 2016). By defining the WUI according to both the biophysical and built factors of communities and their surrounding landscape, we have provided an expanded definition of WUI that supports efforts to link the biophysical and social factors that underlie wildfire risk exposure (Ager, Kline, \& Fischer, 2015; Moritz et al., 2014; Spies et al., 2014). Our results make clear that aspects of exposure vary greatly both within and among communities. From the perspective of federal land managing agencies, this expanded definition provides specific guidance over where and how federal dollars are best spent, and points to opportunities for drafting agreements between communities, private landowners, and state or federal land managers that can better leverage their mutual interests (Figure 5). 


\subsection{Limitations and Future Research}

Geographic inventories of development and infrastructure fail to address the institutional and social dimensions of communities that define their capacity to anticipate, prepare for, and mitigate wildfire hazards (Fischer, Vance-Borland, Jasny, Grimm, \& Charnley, 2016; Spies et al., 2014). Individual communities are likely to establish different strategies for planning, mitigating, and recovering from wildfire (Paveglio et al., 2015), and many of these will be tied to their geographic and social context, their understanding of ecosystems processes, and their relationship with federal agencies (Paveglio, Carroll, Stasiewicz, Williams, \& Becker, 2018). Additional data on community willingness and capabilities to mitigate wildfire risk need to be brought into the process of adapting to wildfire (Fischer, Spies, et al., 2016; Nielsen-pincus, Ribe, \& Johnson, 2015). Combining biophysical and social archetypes is an important next step in future research in addition to the integrated management of fire systems (Ager et al., 2015)

The scope of this analysis was limited to national forests to address the immediate policy void concerning expanded fuels funding appropriated to the USFS, but as a result, excludes exposure originating outside of the national forest system, such as fires igniting within community boundaries, or on other private, state, or other federally managed lands. The risk of community wildfire exposure is limited for most national forests, and focusing management on source areas where wildfire exposure originates will have the greatest impact on reducing community wildfire risk. Still, wildfire transmission from national forests into communities represents only a portion of the total fire exchanged 
among the land tenures most common to the western US (Ager et al., 2017). For instance, highly exposed communities were notably absent from Colorado within our study, which indicates that community risk in the state is more likely to come from other land tenures. An expansion of our analysis to all lands is necessary to understand the nature of wildfire exposure in all communities in the western US. As a final point, the scale at which we examined community exposure (i.e., for the entire western US) meant that we did not describe the mapped extent of source and exposure areas in detail. This is likely to be a task better suited for smaller scales of study, such as in those regions where community wildfire exposure was spatially concentrated. Defining the specific spatial extent of source and exposure areas within these regional exposure 'hotspots' is a clear direction for future work.

While this analysis was specific to the western US, the implications of our work are germane to other fire-prone regions globally. As more fire-prone regions incorporate detailed maps of the WUI into wildfire risk mitigation programs (e.g., Bowman et al., 2011; Lampin-Maillet et al., 2010), it is important that those mitigation programs be implemented in a way that does not artificially "flatten" the complex social and biophysical context that underlies wildfire risk. The diversity of conditions we reported is likely true for other contexts globally, and since the increased risk of wildfire found in many fire-prone regions will likely outstrip available resources, it is critical that mitigation actions be tied to a cohesive risk management strategy that accommodates diversity and scale. 


\section{Conclusion}

The risk planning problem faced by land and fire management agencies across the globe involves a diversity of local contexts. Given the scale of the wildland urban interface in the western US, along with changes in fire activity expected from a changing climate, the need to establish and justify the efficacy of mitigation actions at a national level is critical. Hazardous fuel investments can be rendered ineffective given the convoluted process of appropriating funds, distributing money, tying investments to existing programs and planning efforts, and implementing them on the ground. Community exposure archetypes constructed on an expanded definition of the WUI that explicitly considers the scale and process of wildfire exposure can help match national wildfire policy to the diversity of local community contexts. 


\section{Figures}

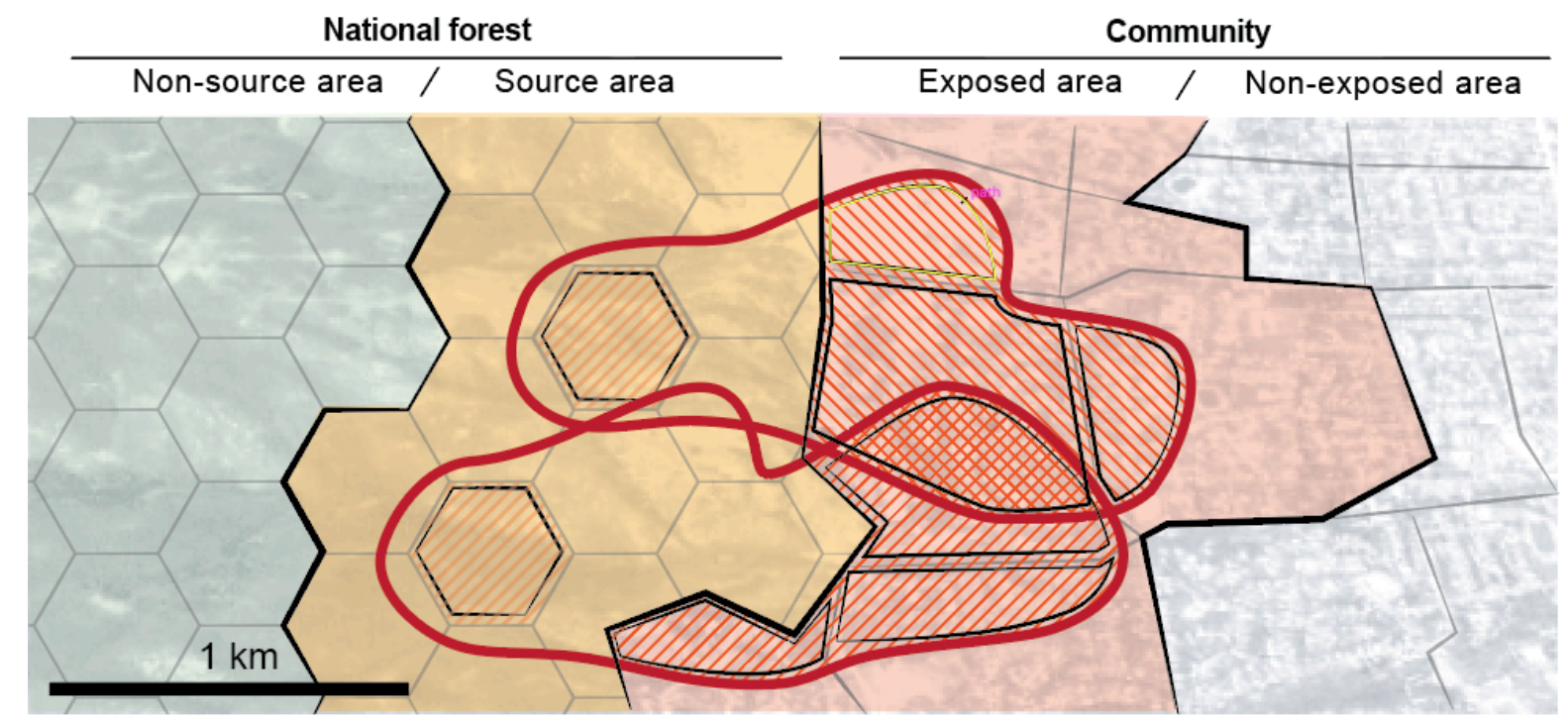

Figure 1. Community wildfire exposure was determined using the area where wildfire and development intersect (red-hashed area). The archetype of community exposure was based on conditions within both the source area where wildfire ignited (yellow-hashed area) and the exposed area of the community (red hashed). Conditions for both areas were averaged for the entire community based on thousands of possible wildfires. 

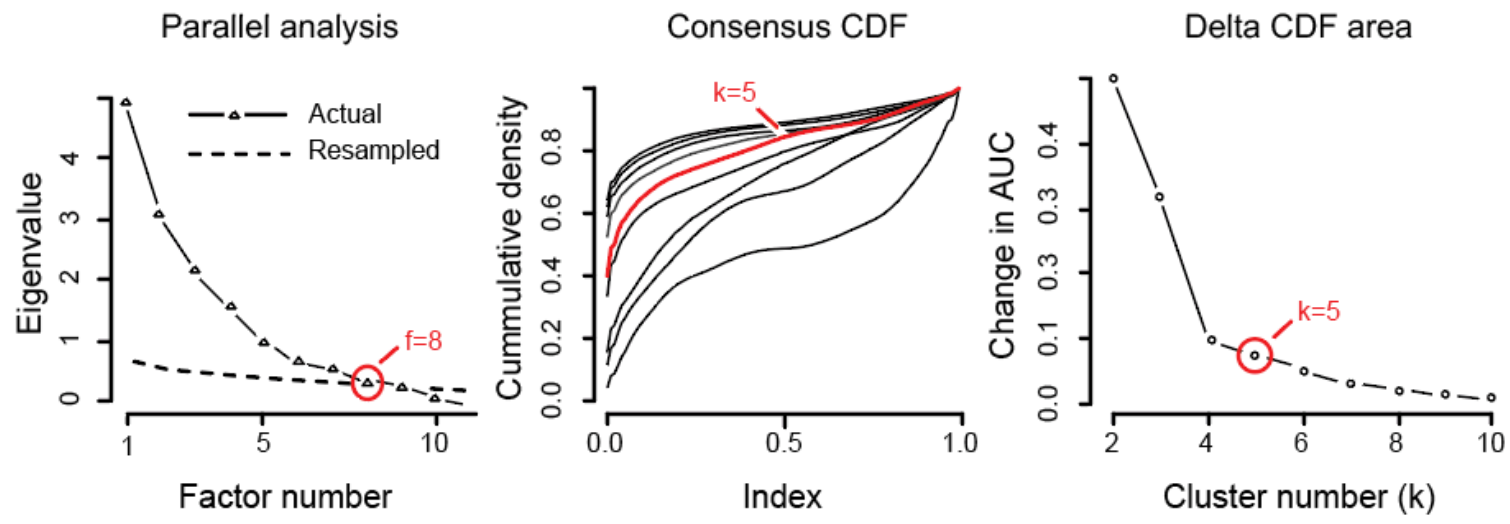

Figure 2. Community wildfire exposure was grouped into 5 exposure archetypes based on 8 components. The number of components $(f=8)$ was determined using parallel analysis (left). The number of clusters $(k=5)$ was chosen based on the change in the area under the curve (right) for successive cumulative density functions (middle). 


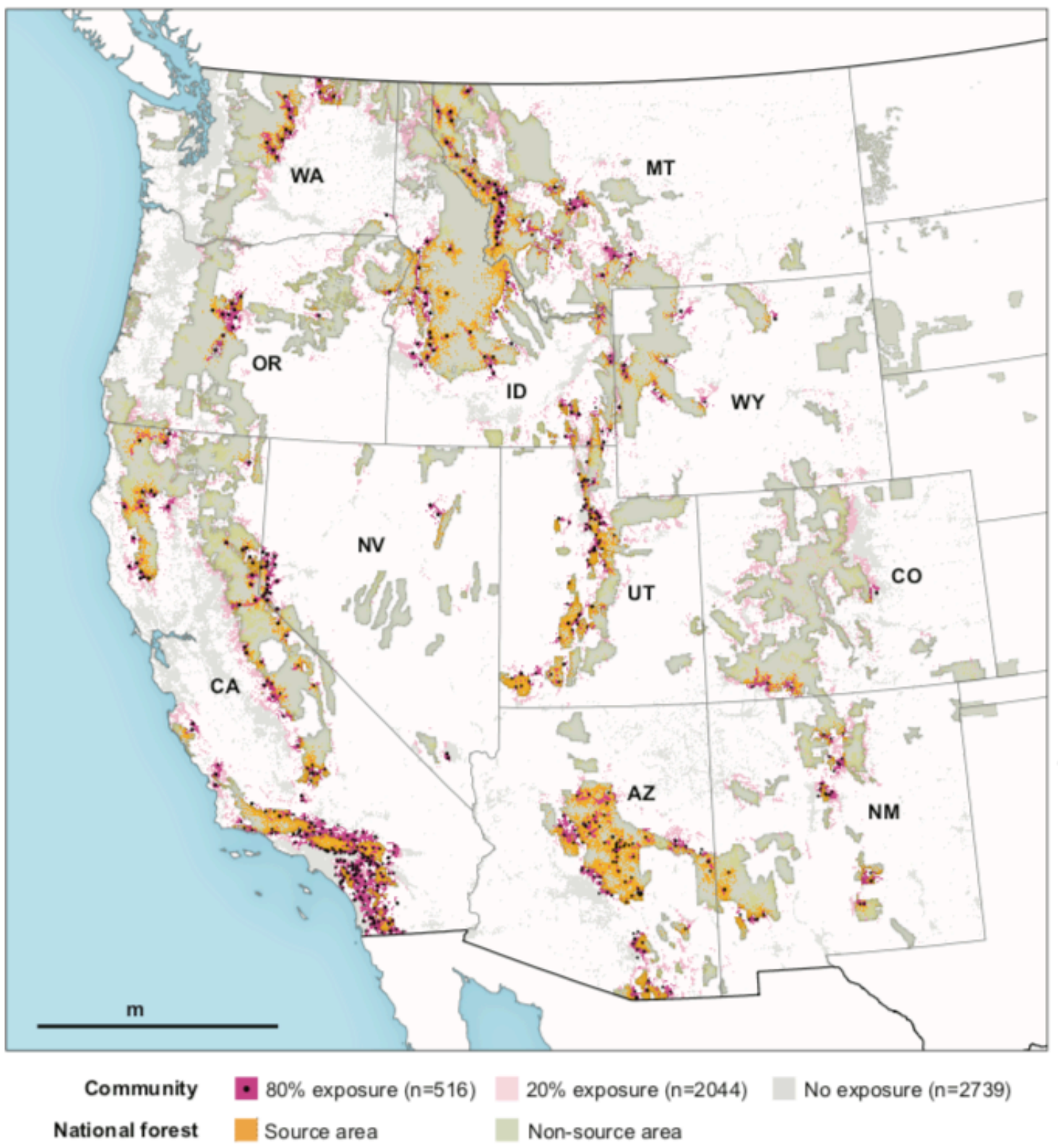

Figure 3. Map of the western US shows the 516 communities that account for $80 \%$ of the wildfire exposure originating in the national forest. Areas of the national forest that contribute the most exposure are shown in orange and the most exposed areas within communities are shown in magenta. 


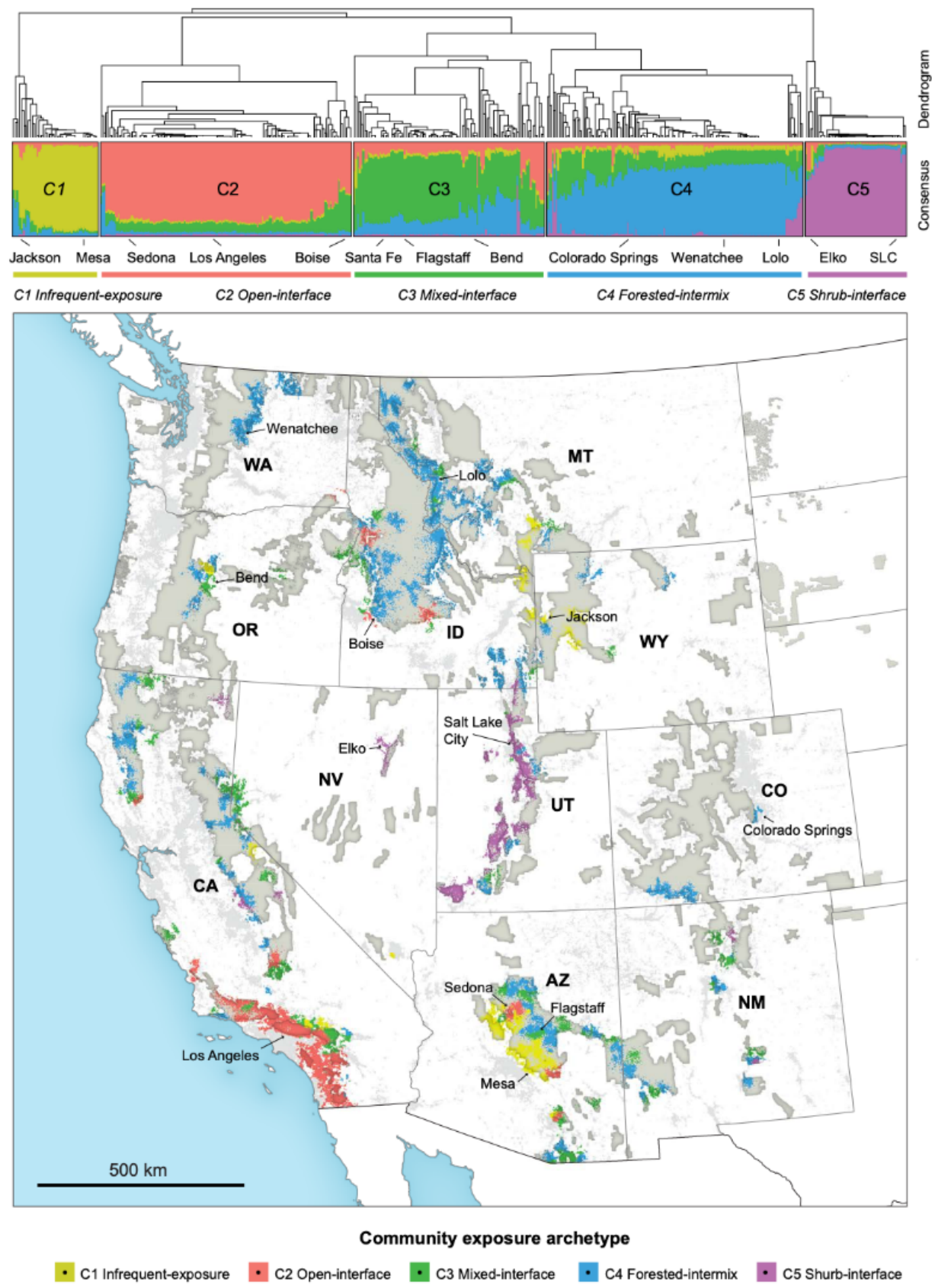

Figure 4. Exposure patterns for highly exposed communities divided into five archetypes, as shown in the dendrogram and consensus plot above and in the map below. Differences in the height of branches in the dendrogram reflect differences within and among clusters. Branches of the dendrogram dominated by a single color in the consensus plot represent greater homogeneity among communities within archetypes (e.g., C2 open-interface), while branches containing a mixture of colors represent groupings that are less distinct. 


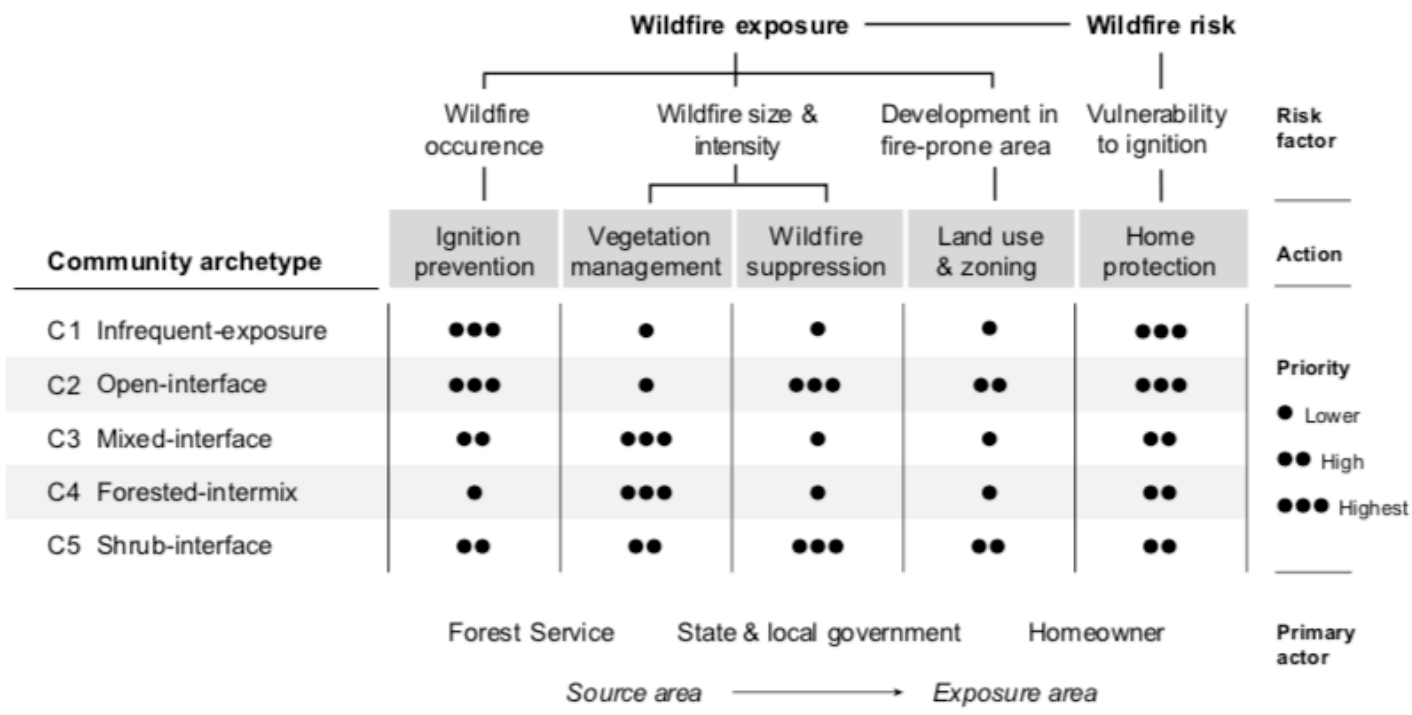

Figure 5. Community archetypes reflect different priorities for managing wildfire risk. Vegetation management, for instance, is effective in only half of highly exposed communities (i.e., C3 mixed-interface and C4 forested-intermix communities). Differences in prioritization also indicate different needs for crossboundary coordination and which actors are involved. 


\section{Tables}

Table 1. Variables used to distinguish the nature of wildfire exposure among threated communities. Variables reflect conditions found within the national forest source area (NF), exposed areas of the community $(C)$, or both $(N F / C)$.

\begin{tabular}{|c|c|c|}
\hline Variable & Zone & Description \\
\hline $\begin{array}{l}\text { Canopy cover } \\
(\%)\end{array}$ & $\mathrm{NF} / \mathrm{C}$ & $\begin{array}{l}\text { Canopy cover limits spread but can lead to crowning } \\
\text { and spotting. Source: LANDFIRE }\end{array}$ \\
\hline Flame length (m) & $\mathrm{NF} / \mathrm{C}$ & $\begin{array}{l}\text { Conditional flame length describes the intensity of the } \\
\text { fire and can limit suppression. Source: FSIM }\end{array}$ \\
\hline $\begin{array}{l}\text { Forested fuel } \\
\text { types }(\%)\end{array}$ & $\mathrm{NF} / \mathrm{C}$ & $\begin{array}{l}\text { Fuel models } 161-189 \text { contain timber-understory and } \\
\text { timber-litter fuels. Source: LANDFIRE }\end{array}$ \\
\hline $\begin{array}{l}\text { Shrub fuel types } \\
(\%)\end{array}$ & $\mathrm{NF} / \mathrm{C}$ & $\begin{array}{l}\text { Fuel models 141-149 contain woody shrubs and foliage } \\
\text { with limited herbaceous fuels. Source: LANDFIRE }\end{array}$ \\
\hline $\begin{array}{l}\text { Grass/shrub fuel } \\
\text { types }(\%)\end{array}$ & $\mathrm{NF} / \mathrm{C}$ & $\begin{array}{l}\text { Fuel models } 101-129 \text { contain mixture of grasses and } \\
\text { shrubs, including chaparral fuels in SE California. } \\
\text { Source: LANDFIRE }\end{array}$ \\
\hline $\begin{array}{l}\text { Non-burnable } \\
\text { fuel types }(\%)\end{array}$ & $\mathrm{NF} / \mathrm{C}$ & $\begin{array}{l}\text { Fuel models }<100 \text { include urban/developed, } \\
\text { agricultural, and bare lands. Source: LANDFIRE }\end{array}$ \\
\hline Slope (\%) & $\mathrm{NF} / \mathrm{C}$ & $\begin{array}{l}\text { Slope amplifies fire spread, influences local winds, and } \\
\text { limits access. Source: LANDFIRE }\end{array}$ \\
\hline Manageable (\%) & NF & $\begin{array}{l}\text { Portion of forest manageable, i.e., not a protected status } \\
\text { where mechanical thinning might be limited or } \\
\text { prohibited. Source: PAD }\end{array}$ \\
\hline $\begin{array}{l}\text { Vegetation } \\
\text { departure }(\%)\end{array}$ & NF & $\begin{array}{l}\text { Percent difference in successional class from historical } \\
\text { reference conditions. Source: LANDFIRE }\end{array}$ \\
\hline $\begin{array}{l}\text { Low-severity fire } \\
(\%)\end{array}$ & NF & $\begin{array}{l}\text { Fire regime group } 1 \text {. Fire occurred at }<35 \text {-year fire } \\
\text { return interval, low and mixed-severity. Vegetation } \\
\text { often fire-adapted. Source: LANDFIRE }\end{array}$ \\
\hline $\begin{array}{l}\text { Mixed-severity } \\
\text { fire }(\%)\end{array}$ & $\mathrm{NF}$ & $\begin{array}{l}\text { Fire regime group } 3 \text {. Fire historically occurred at } 35 \text { - } \\
200 \text {-year fire return interval, resulted in low and } \\
\text { mixed-severity. Vegetation often fire-adapted. Source: } \\
\text { LANDFIRE }\end{array}$ \\
\hline
\end{tabular}

High-severity fire NF $\quad$ Fire regime group 4. Fire historically occurred at 35$(\%)$ 200-year fire return interval, replacement severity. Source: LANDFIRE 


\begin{tabular}{|c|c|c|}
\hline Variable & Zone & Description \\
\hline $\begin{array}{l}\text { Infrequent fire } \\
(\%)\end{array}$ & NF & $\begin{array}{l}\text { Fire regime group } 5 \text {. Fire historically occurred at }> \\
\text { 200-year fire return interval, any severity. Source: } \\
\text { LANDFIRE }\end{array}$ \\
\hline $\begin{array}{l}\text { Agricultural lands } \\
(\%)\end{array}$ & $\mathrm{C}$ & $\begin{array}{l}\text { Percent of WUI classified as agriculture or pasture. } \\
\text { Agricultural lands are much less likely to carry fire due } \\
\text { to intensive management. Source: NLCD }\end{array}$ \\
\hline $\begin{array}{l}\text { Intermixed WUI } \\
(\%)\end{array}$ & $\mathrm{C}$ & $\begin{array}{l}\text { Development (density }>1 \mathrm{hu} / 6.17 \mathrm{~km} 2) \text { that intersects } \\
\text { with wildland vegetation }(>50 \% \text { cover }) \text {. Source: } \\
\text { SILVIS }\end{array}$ \\
\hline $\begin{array}{l}\text { Interface WUI } \\
(\%)\end{array}$ & $\mathrm{C}$ & $\begin{array}{l}\text { Development where wildland vegetation cover }<50 \% \\
\text { but located }<2.4 \mathrm{~km} \text { from heavily vegetated area }(> \\
75 \% \text { wildland vegetation, }>5 \mathrm{~km} 2) \text {. Source: SILVIS }\end{array}$ \\
\hline Non-WUI (\%) & $\mathrm{C}$ & $\begin{array}{l}\text { Development not classified as either interface or } \\
\text { intermix due to lack of structure density, lack of } \\
\text { wildland vegetation, or lack of proximity to wildland } \\
\text { vegetation. Source: SILVIS }\end{array}$ \\
\hline $\begin{array}{l}\text { Percent high } \\
\text { density }(\%)\end{array}$ & $\mathrm{C}$ & $\begin{array}{l}\text { Percent of community exposure from areas with } \\
\text { structure density }>741 \mathrm{hu} / \mathrm{km} 2 \text {. Source: SILVIS }\end{array}$ \\
\hline $\begin{array}{l}\text { Percent medium } \\
\text { density }(\%)\end{array}$ & $\mathrm{C}$ & $\begin{array}{l}\text { Percent of community exposure from areas with } \\
\text { structure density }>49.5 \mathrm{hu} / \mathrm{km} 2 \text {. Source: SILVIS }\end{array}$ \\
\hline $\begin{array}{l}\text { Percent low } \\
\text { density }(\%)\end{array}$ & $\mathrm{C}$ & $\begin{array}{l}\text { Percent of community exposure from areas with } \\
\text { structure density }>6.17 \mathrm{hu} / \mathrm{km} 2 \text {. Source: SILVIS }\end{array}$ \\
\hline
\end{tabular}


Table 2. Descriptive statistics of wildfire exposure among highly exposed communities $(n=516)$. The reference values represent the average conditions among western national forests and western communities (WUI and non-WUI).

\begin{tabular}{llllll} 
National forest & Mn (SD) & Ref & Community & Mn (SD) & Ref \\
\hline Canopy cover & $23(13)$ & 31 & Canopy cover & $7(9)$ & 6 \\
Forest fuels & $35(26)$ & 53 & Forest fuels & $11(16)$ & 12 \\
Shrub fuels & $13(15)$ & 7 & Shrub fuels & $9(15)$ & 3 \\
Grass fuels & $52(27)$ & 37 & Grass fuels & $54(23)$ & 23 \\
Non-burnable & $0(0)$ & 4 & Non-burnable & $26(17)$ & 62 \\
Flame length & $2(0)$ & 2 & Flame length & $2(0)$ & 1 \\
Slope & $19(6)$ & 17 & Slope & $6(4)$ & 3 \\
Manageable lands & $85(19)$ & 76 & Agricultural lands & $5(9)$ & 8 \\
Vegetation departure & $44(12)$ & 37 & Intermixed WUI & $50(27)$ & 10 \\
Low-severity fire & $40(31)$ & 30 & Interface WUI & $40(26)$ & 30 \\
Mixed-severity fire & $23(28)$ & 36 & Non-WUI & $10(15)$ & 60 \\
High-severity fire & $31(28)$ & 22 & High-density dev & $16(18)$ & 66 \\
Infrequent fire & $6(16)$ & 10 & Med-density dev & $54(21)$ & 28 \\
& & & Low-density dev & $30(25)$ & 0
\end{tabular}


Table 3. Loadings of exposure variables on the 8 components (F1-F8) used to distinguish community archetypes. Components are ordered by the variance explained. Loadings $>0.5$ are bolded; loadings $<0.1$ are omitted.

\begin{tabular}{|c|c|c|c|c|c|c|c|c|}
\hline National forest & F1 & F2 & $\mathrm{F} 3$ & F4 & F5 & F6 & F7 & F8 \\
\hline Canopy cover & 0.9 & 0.11 & & & & 0.11 & & 0.2 \\
\hline Forest fuels & $\underline{-0.8}$ & & -0.29 & & -0.13 & -0.24 & & -0.14 \\
\hline Shrub fuels & $\underline{0.84}$ & & -0.18 & & 0.1 & 0.28 & & \\
\hline Grass fuels & & -0.13 & $\underline{0.84}$ & & & & 0.27 & 0.17 \\
\hline Flame length & -0.29 & & $\underline{0.7}$ & & & & 0.18 & 0.2 \\
\hline Slope & & -0.35 & 0.15 & -0.34 & $\underline{0.53}$ & 0.27 & & 0.35 \\
\hline Manageable lands & 0.1 & & & $\underline{0.92}$ & & & & \\
\hline Vegetation departure & & & 0.11 & $\underline{0.88}$ & & & & 0.13 \\
\hline Low-severity fire & 0.36 & 0.18 & & & & -0.15 & $\underline{-0.8}$ & 0.32 \\
\hline Mixed-severity fire & 0.41 & & 0.14 & & -0.2 & 0.11 & $\overline{0.81}$ & \\
\hline High-severity fire & $\underline{-0.74}$ & -0.25 & & 0.13 & 0.38 & & & \\
\hline Infrequent fire & -0.15 & & -0.13 & -0.1 & -0.16 & & -0.12 & $\underline{-0.85}$ \\
\hline Community & $\mathrm{F} 1$ & $\mathrm{~F} 2$ & F3 & $\mathrm{F} 4$ & F5 & F6 & F7 & F8 \\
\hline Canopy cover & $\underline{0.65}$ & 0.37 & & 0.11 & 0.41 & -0.29 & & \\
\hline Forest fuels & $\underline{-\underline{0.53}}$ & 0.38 & $\underline{-0.51}$ & & -0.38 & & 0.14 & 0.17 \\
\hline Shrub fuels & $\underline{0.65}$ & 0.19 & -0.22 & 0.14 & 0.48 & -0.22 & & -0.14 \\
\hline Grass fuels & 0.16 & 0.16 & $\underline{0.84}$ & & 0.11 & & -0.12 & \\
\hline Non-burnable & & $\underline{-0.83}$ & 0.13 & & & 0.16 & & \\
\hline Flame length & & 0.2 & 0.13 & & $\underline{0.82}$ & -0.12 & & 0.14 \\
\hline Slope & & $\underline{0.61}$ & $\underline{0.57}$ & & & & -0.18 & \\
\hline Agricultural lands & 0.17 & $-\overline{0.17}$ & & & -0.11 & $\underline{0.79}$ & 0.21 & \\
\hline Intermixed WUI & -0.13 & $\underline{-0.86}$ & & & & & & \\
\hline Interface WUI & & $\underline{0.87}$ & & & & -0.26 & & \\
\hline High-density dev & & -0.7 & & & & -0.39 & -0.1 & \\
\hline Low-density dev & 0.14 & 0.61 & & & & $\underline{0.59}$ & & \\
\hline
\end{tabular}

\begin{tabular}{lrrrrrrrr} 
Statistic & F1 & F2 & F3 & F4 & F5 & F6 & F7 & F8 \\
\hline SS loadings & 4.36 & 4.10 & 2.76 & 1.83 & 1.79 & 1.62 & 1.58 & 1.21 \\
Proportional var (\%) & 0.18 & 0.17 & 0.12 & 0.08 & 0.07 & 0.07 & 0.07 & 0.05 \\
Cumulative var (\%) & 0.18 & 0.35 & 0.47 & 0.54 & 0.62 & 0.69 & 0.75 & 0.80
\end{tabular}


Table 4. Differences in the character of exposure among 5 community archetypes, represented as mean values.

\begin{tabular}{lllllll} 
National forest & $\mathrm{C} 1$ & $\mathrm{C} 2$ & $\mathrm{C} 3$ & $\mathrm{C} 4$ & $\mathrm{C} 5$ & Overall \\
\hline Canopy cover & $24(10)$ & $12(6)$ & $32(10)$ & $11(12)$ & $31(10)$ & $23(13)$ \\
Forest fuels & $36(22)$ & $19(14)$ & $53(23)$ & $22(34)$ & $36(18)$ & $35(26)$ \\
Shrub fuels & $10(11)$ & $16(12)$ & $5(8)$ & $3(5)$ & $39(15)$ & $13(15)$ \\
Grass fuels & $53(22)$ & $65(20)$ & $41(23)$ & $74(33)$ & $24(22)$ & $52(27)$ \\
Flame length & $2(0)$ & $2(0)$ & $2(0)$ & $2(0)$ & $2(0)$ & $2(0)$ \\
Slope & $17(6)$ & $22(5)$ & $17(5)$ & $14(4)$ & $21(5)$ & $19(6)$ \\
Manageable & $84(23)$ & $81(19)$ & $82(22)$ & $92(13)$ & $83(20)$ & $85(19)$ \\
Veg departure & $40(14)$ & $44(13)$ & $43(12)$ & $45(10)$ & $49(12)$ & $44(12)$ \\
Low-sev. fire & $65(22)$ & $31(20)$ & $53(32)$ & $11(17)$ & $7(15)$ & $40(31)$ \\
Mixed-sev. fire & $16(18)$ & $3(8)$ & $29(25)$ & $14(18)$ & $76(21)$ & $23(28)$ \\
High-sev. fire & $16(14)$ & $65(21)$ & $15(16)$ & $26(22)$ & $15(16)$ & $31(28)$ \\
Infrequent fire & $2(6)$ & $1(3)$ & $2(6)$ & $49(25)$ & $2(3)$ & $6(16)$ \\
& & & & & & \\
Community & $\mathrm{C} 1$ & $\mathrm{C} 2$ & $\mathrm{C} 3$ & $\mathrm{C} 4$ & $\mathrm{C} 5$ & Overall \\
\hline Canopy cover & $4(5)$ & $4(6)$ & $14(10)$ & $2(4)$ & $9(8)$ & $7(9)$ \\
Forest fuels & $6(8)$ & $7(13)$ & $23(19)$ & $6(12)$ & $6(7)$ & $11(16)$ \\
Shrub fuels & $8(14)$ & $7(11)$ & $6(14)$ & $5(14)$ & $26(21)$ & $9(15)$ \\
Grass fuels & $55(21)$ & $53(20)$ & $56(25)$ & $70(23)$ & $37(20)$ & $54(23)$ \\
Non-burnable & $31(17)$ & $33(16)$ & $15(13)$ & $19(17)$ & $30(17)$ & $26(17)$ \\
Flame length & $2(0)$ & $1(0)$ & $1(0)$ & $2(0)$ & $2(1)$ & $2(0)$ \\
Slope & $4(2)$ & $7(4)$ & $6(4)$ & $3(2)$ & $6(5)$ & $6(4)$ \\
Agricultural & $4(7)$ & $3(7)$ & $7(10)$ & $4(9)$ & $12(12)$ & $5(9)$ \\
Intermixed & $43(23)$ & $39(23)$ & $66(24)$ & $58(26)$ & $41(27)$ & $50(27)$ \\
Interface & $47(21)$ & $52(25)$ & $23(20)$ & $33(24)$ & $49(28)$ & $40(26)$ \\
Non-WUI & $10(15)$ & $8(17)$ & $11(12)$ & $9(19)$ & $10(11)$ & $10(15)$ \\
High-den dev & $22(19)$ & $24(19)$ & $6(8)$ & $16(20)$ & $11(14)$ & $16(18)$ \\
Med-den dev & $56(18)$ & $57(20)$ & $45(22)$ & $56(20)$ & $61(22)$ & $54(21)$ \\
Low-den dev & $22(16)$ & $19(20)$ & $48(24)$ & $28(21)$ & $28(23)$ & $30(25)$ \\
& & & & & & \\
Count (n) & 49 & 147 & 109 & 153 & 58 & 516
\end{tabular}




\title{
Chapter 3:
}

\section{Organizational Geography of Wildfire Risk Management}

\begin{abstract}
Organizations and agencies at multiple levels of government have needed to adapt to the increased risk from wildfire throughout the western US. These environmental changes have increasingly transformed wildfire risk management into a polycentric system defined by multiple actors whose actions are interconnected and interdependent. Since large fires rarely stop at existing boundaries, it is increasingly important to understand wildfire management in terms of the risk management tenure and not simply in terms of land ownership. This chapter describes the organizational geography of wildfire risk management in North Central Washington, USA, and uses geographic modeling to map the organizational geographies of various federal, state, and local agencies and organizations whose work involves managing wildfire risk in the region. While land ownership and management boundaries were important predictors of management tenure for some organizations, in general, wildland urban interface had an overriding influence of the overall geography of risk management activities. The diversity of overlapping management tenures influenced organizational roles in risk management in different ways, leading some organizational groups to expand the management roles they play while the roles of others became more specific. These results have broad applications for understanding how land tenure systems shift in response to environmental change.
\end{abstract}




\section{Keywords}

Land tenure; Geographic distribution models; Participatory GIS mapping; Organizational ecology; Natural hazards

\section{Research Highlights}

- Fire management involves a diverse patchwork of interests and responsibilities

- Tenure over wildfire risk management extends beyond ownership boundaries

- Past work can be used to map organizational geographies

- Organizational diversity is especially high around the wildland urban interface

- Organizations respond to diversity by generalizing or specializing 


\section{Organizational Geography of Wildfire Risk Management}

Wildfire risk management occurs against a patchwork of overlapping land interests, often requiring coordination and cooperation among stakeholders, each holding some set of privileges, interests, rights, and responsibility. In many fire-prone landscapes, land management is dominated by those groups with property interests directly threatened by wildfire, including federal and state land management agencies, individual homeowners, and institutional landowners. These groups maintain divergent land use goals, especially with regards to fire, which in turn leads to distinct views towards ideal wildfire outcomes. Homeowners, for instance, care strongly about reducing smoke around their residences, while land management agencies have increasingly looked to the beneficial use of fire to address hazardous fuel loads and restore forest health. At the same time, other organizations, such as local governments, fire districts, and NGOs, maintain significant interests in lands which they have no formal title to or authority over.

Like water and air, wildfire is a biophysical process that serves to connect or divide different areas of the landscape, including the specific interests of individuals, communities, and organizations. Fire arising under one set of social and biophysical conditions may impact a separate area where conditions, expectations, capacities, and constraints are drastically different. When fire crossed boundaries, lack of cooperation among nearby land managers and landowners can lead to uncoordinated and conflicting actions about how to prepare for and respond to fire. These risk interdependencies have been increasingly recognized in wildfire policy (McCaffery et al. 2015) as management 
initiatives increasingly promote collaborative and cross-boundary solutions to better fire management (Charnley et al. 2018).

Yet it is not always clear what boundaries are relevant, nor how the interests and responsibilities in fire often different groups vary according to these boundaries. For instance, boundaries include not only existing land ownership but the potential to manage forests and fuels and the means of access and capacities by which to manage. Existing studies of wildfire transmission have largely defined boundaries based on land ownership and management designations (Ager et al. 2017; Evers et al. 2019; Palaiologou et al. 2019). While land ownership and management designation may provide an adequate proxy for a cursory understanding of wildfire transmission and interacting interests in wildfire risk management, it is not clear how these boundaries dictate the complex set of social relationships, rules, and processes that ultimately dictate where and how organizations involve themselves in managing wildfire risk.

This chapter examines the geography of wildfire risk management through the lens of land tenure. Professionals involved wildfire risk management were surveyed and asked to report what they do and where they work. These data provide an unique opportunity to evaluate the extent to which different organizational groups involved in wildfire risk management are influenced by ownership boundaries and whether other aspects of land tenure may sometimes be more important to understanding the organizational geography of wildfire risk management. In posing these questions, this research posits that cross-boundary work is more common than often assumed, and furthermore, and that there are certain areas of the landscape, irrespective of land 
ownership, where the interests of multiple social groups coalesce. What is more, this framing suggests that organizations respond to these areas of organizational diversity, in some cases, assuming more general roles, while in other cases, more specific. In addressing these questions, the chapter introduces a novel technique for mapping organizational geographies based on the reported locations of past risk management activities. This approach provides key insights into how wildfire-related risk management activities are associated with landscape characteristics and where cross-boundary management activities are most common. Before turning to the methods employed, I briefly review two concepts central to this work: land tenure and organizational geography.

\subsection{Wildfire risk and land tenure}

Risks and responsibilities associated with wildfire risk are strongly tied to the larger land tenure system, which reflects the system of both formal (i.e., legal) and informal (i.e., customary) rules that shape the relationships among people as individuals or organizations with respect to land (FAO 2016). These rules include both associated rights (e.g., benefits) - such as rights of use, control, access, and transfer - as well as responsibilities and restraints (e.g., costs). When fires cross the social and political boundaries, land tenure dictates how and where social actors anticipate and respond to such risk. Further, because many public values impacted by fire extend beyond existing boundaries and therefore exist apart from ownership and jurisdictional maps (Williams et al. 2018). Even when communities directly escape losses, damage from a fire on public 
lands can have profound and prolonged impacts on residents and local economies (Nielsen-Pincus et al. 2013).

These examples highlight why land ownership boundaries may serve as a poor proxy for estimating who is at risk from fire and where the interests of individual stakeholders lie. Large wildfires transfer risk to neighboring landowners since those that bear losses are likely to differ from those that bear formal responsibility (Busby et al. 2012). Fuel treatments can affect how wildfire moves through a landscape (Cochran et al. 2013; Ager et al. 2017), sheltering some areas from exposure while opening other areas to increased hazard. Development patterns and building practices influence how the risk of wildfire manifests and, therefore, where responsibility for managing that risk lies. Even when fire risk is constrained to single ownership, overlapping interests in that land can produce divergent views on how that risk should be managed.

In the US and elsewhere, risk externalities and overlapping interests in wildfire risk are concentrated within the wildland-urban interface, the region where development and other human values at risk concentrate along or are interspersed within fire-prone ecosystems. Given the degree of hazard they contain, considerable work has gone into systematically mapping these regions at both national and regional scales around the world. A separate body of research on the WUI has focused on the sociology of the WUI and has sought to understand the unique social characteristics of this space, including the diversity of actors that occupy it. Yet to date, only limited work exists that attempts to bridge the geographic focus of the former with the social contextual focus of the later. Young (2002) described this distinction in research focus as 'thin' and 'thick' views of an 
institution like land tenure. Whereas a thin view of land tenure generally focuses on formal rules as written, such as property rights, nuisance laws, or legal liability, a thick view is more concerned with practice and informal understanding, which considers the vital influence of trust, identity, etc. From a thin perspective, wildfire risk is apportioned according to existing land ownerships and jurisdictions. From a thick perspective, wildfire risk is seen as a tapestry of interests and responsibilities, sometimes synergistic and sometimes antagonistic, including those that are: (1) overriding, where an individual, organization, or government have exclusive power to allocate or reallocate land through expropriation, etc.; (2) overlapping, where several parties have different rights/responsibilities to the same parcel of land, such as when one party may have lease rights, another may have the right of way, etc.; (3) complementary, where different parties share the same interest in the same parcel of land such as when members of a community share common rights to grazing land or a community forest, etc., and; (4) competing, where different parties contest the same interests in the same parcel.

\subsection{Organizational geography}

Organizational geography refers to the relationship among organizations and space, both in terms of how organizational actions are shaped by the geography in which they operate, but also in terms of how that geography becomes modeled on the structure of organizations that operate within it (Del Casino et al. 2000). Organizational geography borrows heavily from ecological concepts such as niche and diversity. From an ecological perspective, for instance, environmental factors shape organizational structure and activity at the same time that organizational activity also shapes its surrounding 
environment. Organizations, like organisms, fill functional niches, which are shaped both from environmental opportunities and constraints in addition to those created through interaction with other organizations. Organizational diversity, like biodiversity, can lead to the creation of additional niches. As the diversity of organizations increases, the functional roles of organizations may alternatively become more specific or more general. Finally, likely ecology, the interaction of organizations can be described in terms of networks, which emphasizes the structural organization of a system over its component parts.

Ecological views of interorganizational behavior have been recognized for decades (e.g., Hannan and Freeman 1997; Powell 1990), but have only recently begun to be applied to coupled social-ecological systems (e.g., Bodin et al. 2016). Hannan and Freeman (1977) focused their theory of organizational ecology on the change in populations of organizations over time. In identifying the factors that influence the life history of individual organizations, they emphasize the inertia of individual organizations. This suggests that the degree to which individual organizations can adapt to changes in the environment can actually be quite limited, especially as organizations age or grows in size. As such, adaptation is taken as a system-level attribute that results from birth and death of organizations over time. More recently, researchers began to explore how the interactions between these organizations affect strategies for survival. In a similar light, Jones et al. 1998 advanced a theory of inter-organizational network that distinct from interorganizational view of activity tied to markets or hierarchical control (Powell 2003). Compared to hierarchical or market-based inter-organizational 
relationships, they theorized that network-type interactions emerge when demand is periodic or unpredictable yet interorganizational contact is frequent and geographically concentrated. Such networked relationships are further promoted when the assets involved in production are specialized yet the tasks required to fulfill transactions complex (Jones et al. 1998).

While both theories were developed to describe organizations in decentralized markets, such factors are apt also for describing wildfire management, which requires coordinated work across multiple unrelated sectors of the economy (Steelman 2016, Nielsen-Pincus et al. 2018). Here as well, certain conditions push organizational relationships towards a distributed network structure, heterogeneous in composition, and built on informal relations and co-dependencies rather than on contractual relationships or market-based exchanges. It is worth noting, however, that this bottom-up conception of wildfire risk management differs markedly from typical emergency management structures, which tend towards vertical integration and top-down control. Thus, while some recent research has argued for a more integrated approach towards wildfire risk management (e.g., Thompson et al. 2018), others have argued that much of wildfire risk is dependent on the decentralized, often uncoordinated actions of individual homeowners and communities (e.g., Dickinson et al. 2015).

\section{Methods}

\subsection{Study area}

Like much of the western US, North Central Washington (NCWA) is notable for its mixed ownership, composed of large, contiguous public wildlands and development 
that is concentrated within relatively small geography (e.g., Evers et al. 2018). Located on the dry east side of the Cascades Mountains, this $90,000-\mathrm{km}^{2}$ region has experienced several recent mega-fires including the 2014 Carlton Complex and the 2015 Okanogan Complex (Figure 1). Precipitation ranges from 160 inches in the high Cascades to less than 10 inches annually within parts Upper Columbia Plateau. Vegetation corresponds to the precipitation gradient, with the western portion of the study area covered in forests and the arid eastern portion covered in sagebrush and grass. Nearly 283,000 people reside in the area. Of the 130,000 structures within the region, more than two-thirds are considered WUI: $23 \%$ of which are found within intermix WUI (wildland vegetation > $50 \%$ ) and $44 \%$ within the interface WUI (wildland vegetation $<50 \%$ yet adjacent to large wildland area). Wildfire in the region has increased substantially in recent decades due to the increasing length of the wildfire season, the increased frequency of synoptic fire weather conditions, and the legacies of past land use and fire suppression that has resulted in the accumulation of hazardous fuels in many of the area's extensive dry forests (Hessburg et al. 2003). Like other natural amenity locations, wildfire risk is inextricably tied to development in the region (Radeloff et al. 2018), which is driven by its proximity to the Seattle metro area.

\subsection{Data collection}

Data were collected using an online questionnaire designed and administered in the Qualtrics online survey software. I administered the questionnaire to individuals whose work involved addressing wildfire risk within North Central Washington. The survey utilized chain-referral sampling to identify the population (Erikson 1979), a 
technique that is used when populations are ill-defined or hidden (e.g., Heckathorn 2002). Respondents identified individuals with whom they had worked in the last five years. These individuals were added to the survey sample and queued for the next round of recruitment. All individuals were assigned a unique identifier for record-keeping and privacy purposes.

The questionnaire was organized into three sections. First, respondents described their work related to wildfire via a set of closed and open-ended questions, including their organizational affiliation and primary roles related to addressing wildfire risk. Second, respondents identified on a map of the NCWA up to 10 locations where they had worked to address wildfire risk in the past five years. Third, for each working relationship identified, the respondent described the frequency of contact, the degree of influence of that contact on their work to address wildfire risk, and the type(s) of that the collaboration entailed (e.g., education, research, and public awareness; planning and administrative activities; risk reduction projects; emergency response and/or recovery).

Respondents reported locations of work using a mapping application embedded within the Qualtrics questionnaire. The mapping application - built using the JavaScript library OpenLayers3 and a PostGIS online geodatabase to save data - asked respondents to mark up to 10 areas on the map where they worked on wildfire-related risk management between 2013 and 2018. Respondents could toggle visual overlays as a reference, including land ownership and the wildland urban interface. The size of the point could be varied to represent different sized projects by zooming the map in and out. While respondents were given the option to append a note to each point, most did not. 
The work locations were recorded in an online PostGIS database using Carto. Work locations were then downloaded from the online database, and the longitude and latitude of each point were appended to the resultant table. In the two cases where respondents reported more than the requested number of points, ten points were chosen at random so as not unduly to weight their responses. Locations that fell outside the study area were also removed.

Figure 1. Study area located in North Central Washington on the east side of the Cascade Mountains (50 miles east of Seattle). More than 380,000 people reside in the region. Major communities are labeled. For reference, the study area is broken into six drainages: 1) Methow, 2) Okanogan, 3) Chelan, 4) Wenatchee, 5) East of the Columbia, and 6) Yakima.

\subsection{Data analysis}

Respondent was divided into six organizational groups meant to capture wildfire risk management at the federal, state, and local levels. Each respondent reported which of the eight roles they played in addressing wildfire risk (Table 1). These roles were meant to broadly capture the various wildfire risk management activities that occur prior, during, and after wildfire events. Activities included educational services, public awareness, research on wildfire risk, planning, administration (e.g., strategic documents, grant writing, etc.), risk mitigation work (e.g., hazardous fuel removal, structure fortification, etc.), response (e.g., incident response), recovery, and research. The total number of roles was tallied for each respondent, and taken as a whole, the role diversity within each organizational group. 


\subsection{Estimating organizational geography}

Organizational geographies were constructed from the work locations reported in the survey using MAXENT, a statistical algorithm frequently used in ecological studies to estimate the range of a given species (Dorman 2011). The data used to construct the distribution models consists of a collection of observation points, a gridded landscape, and environmental covariates for each of the grid cells. The environmental covariates served as the independent predictor variables of organizational geography. Geographic covariates were assembled into a multi-layer raster stack (Table 2). Land ownership boundaries were assumed to influence the location of work for some organizations directly (e.g., federal land management agencies), while only indirectly impacting the organizational geography of other organizational groups such as NGOs. Further, land designations would influence the type of work done, particularly on public lands. For example, federal wilderness and roadless areas limit access to the heavy equipment used in large-scale fuels and restoration projects. Wildlands were classified as either forest or shrub using NLCD data. Fuel loads tend to be higher and more contiguous in wildlands, which influences wildfire spread and potential fire hazard. WUI and structure locations were estimated using SILVIS WUI data. Several environmental covariates were recorded as a distance. Distance to roads was included to capture the transportation needs of moving and operating heavy equipment requires, increased chances of ignition, use as firebreaks, and importance for emergency egress. Finally, distance to WUI was included to capture the fact that areas proximal to homes are strongly correlated with potential loss from wildfire (Radeloff et al. 2017). All data were projected at a 270-m resolution using 
UTM zone $10 \mathrm{~N}$ coordinates. All covariates were screened for correlations greater than 0.7 to guard against multicollinearity.

Table 1. Roles related to addressing wildfire risk. Roles capture roles related to wildfire risk before, during, and after wildfires.

\begin{tabular}{ll} 
Role & Description \\
\hline Education & Targeted training and general education \\
Awareness & Public awareness of wildfire ecology and wildfire risks \\
Planning & Planning activities to address wildfire risk \\
Administration & Support, coordination, and funding activities \\
Risk mitigation & Project implementation meant to reduce wildfire risk \\
Response & Standard and emergency response to wildfire events \\
Recovery & Short and long-term recovery from wildfire \\
Research & Social and ecological research related to wildfire
\end{tabular}

Using these geographic covariates, I estimated the organizational geography for each organizational group based on past locations of work, as reported by survey participants. Specifically, observation points were joined to the grid cell in which they occurred and compared to points randomly selected from the gridded landscape where work was absent. Cross-validation was used to split data into five groups, and a separate model was fit for each split. Models were fit for each split and evaluated against the data withheld. Each model was used to predict work locations, and outputs were combined together into a single map weighted by the evaluation score (see below). Finally, I defined the geography of each organizational group as those locations in the study area, where the predicted likelihood of work exceeded 0.5 in three or more of the cross- 
validated models. The resulting surfaces represented the organizational geographies of each organizational group.

Table 2. Geographic context variables used to predict the distribution of work of organizational groups, along with a brief description and source for each. All reference data were processed at a 270-m spatial resolution.

\begin{tabular}{lll} 
Variable & Description & Source \\
\hline Ownership & Owner (factor: USFS, federal, tribal, state, local) USGS \\
Designation & Special designation (factor: wilderness, roadless) PAD \\
Distance to WUI & Distance to WUI (continuous, meters) & SILVIS 2010 \\
Distance to road & Distance to major roads (continuous, meters) & Natural earth \\
Forest wildland & Deciduous, evergreen (binary; NLCD 41:43) & NLCD 2011 \\
Shrub wildland & Shrub, grassland (binary; NCLD 51:52, 71:72) & NLCD 2011 \\
Drainage & Six primary drainages within the study area & N/A \\
Elevation & Elevation (continuous, meters) & USGS
\end{tabular}

Organizational geographies were evaluated for accuracy using the Receiving Operating Characteristic (ROC) plots (Fielding and Bell 1999). The ROC plot traces the tradeoff between model specificity (e.g., false-positive rate) and sensitivity (e.g., true positive rate). The area under the ROC curve (i.e., the AUC) describes the overall discriminatory power of the model. As a rule, AUC values of $0.5-0.7$ are considered low and represent poor model performance, values of $0.7-0.9$ are considered moderate, and values above 0.9 represent excellent model performance (Hosmer et al. 2013). Modeling fitting, cross-validation, and evaluation were implemented in the sdm R package (Naimi and Araujo 2015).

Finally, organizational geographies for each of the five organization groups were combined to calculate organizational diversity, or the total number of organizational 
groups likely to work within different parts of the landscape. Thus, organizational diversity varied across the study area from a low of 0 (no work by any organizational groups) to a maximum of 6 (work predicted for all organizational groups), representing the number of institutions likely to work at each point on the map within a given year. Finally, the predicted organization diversity was extracted for each work location. The organizational diversity was then related to the number of roles that each individual reported. The overall relationship organizational geographic diversity and role diversity was then modeled as a simple linear regression, both in aggregate and within each of the six organizational groups.

\section{Results}

\subsection{Organizational groups and roles}

Mapping respondents $(\mathrm{n}=126)$ were affiliated with organizations working at a range of different operational levels. When comparing survey respondents to nonrespondents, I found that individuals that were nominated two or more times were significantly more likely to participate in the survey and that those that were nominated only once. Compared to survey respondents who did not participate in the mapping exercise, those who pointed out locations of work were much more likely to hold roles focused exclusively on addressing wildfire risk and were more likely to be focused on specific communities or jurisdictions with the region. Respondents and work locations were assigned to six organizational groups (Table 3), where state and USFS actors accounted for the majority of both responses and work. 
Table 3. Number of responses by organizational group along with the number of work locations reported in the five-year period prior to 2018.

\begin{tabular}{lrrrrrrr} 
& USFS & Federal & State & NGO & Local & Private & All \\
\hline Respondents & 27 & 15 & 31 & 18 & 28 & 7 & 126 \\
Work locations & 165 & 75 & 204 & 97 & 198 & 52 & 791 \\
Work loc/resp & 6.1 & 5 & 6.5 & 5.4 & 7.1 & 7.4 & 6.3
\end{tabular}

Most respondents reporting having multiple roles in wildfire risk management (mean $=4.4$ roles). In order of frequency, $76 \%$ of respondents reported a role in public awareness of wildfire risk, $66 \%$ in risk mitigation, $66 \%$ in education, $64 \%$ in planning, $62 \%$ in wildfire response, $49 \%$ in administration, $46 \%$ in recovery, and $24 \%$ in research. Participation in roles differed by organizational group (Table 4). The greatest range in role participation was found in planning-related activities, where both USFS and other federal organizations reported participating in planning much more than other organizations and especially compared to state-level organizations. Both NGOs were more active in awareness activities compared to other organizational groups and significantly less likely to participate in recovery and research. Finally, NGO respondents reported participating in response to a lesser degree, while local organizations were less likely to participate in risk mitigation projects.

\subsection{Locations of work}

Respondents reported 876 locations of work (Figure 2). The number of work locations reported by each respondent ranged from 1 to 20 , with a mean of 6.5 . Work locations clearly clustered within and around developed areas, specifically those found along the periphery of the national forest within the several valleys that extend westward 
into the Cascades. Slightly more locations were reported in the south of the study area than the north. The portion of the study area that people reported work varied widely, from those individuals reporting work in a single location to others whose work spanned more than half of the region. In some cases, the distance between reported locations was more than $100 \mathrm{~km}$.

Table 4. Role participation by organization type (i.e., \% of respondents that reported role). Cells marked with $+/$ - had higher/lower role participation than the average (based on $95 \%$ confidence interval).

\begin{tabular}{llllllll} 
Role & $\begin{array}{l}\text { USFS } \\
(\mathrm{n}=27)\end{array}$ & $\begin{array}{l}\text { Federal } \\
(\mathrm{n}=15)\end{array}$ & $\begin{array}{l}\text { State } \\
(\mathrm{n}=31)\end{array}$ & $\begin{array}{l}\text { NGO } \\
(\mathrm{n}=18)\end{array}$ & $\begin{array}{l}\text { Local } \\
(\mathrm{n}=28)\end{array}$ & $\begin{array}{l}\text { Private } \\
(\mathrm{n}=7)\end{array}$ & $\begin{array}{l}\text { All }(95 \% \mathrm{CI}) \\
(\mathrm{n}=126)\end{array}$ \\
\hline Education & $0.56-$ & 0.67 & 0.71 & 0.61 & 0.71 & 0.71 & $0.66(0.60-0.73)$ \\
Awareness & 0.74 & $0.67-$ & 0.74 & $0.89+$ & 0.79 & 0.71 & $0.76(0.68-0.84)$ \\
Planning & 0.78 & $0.87+$ & $0.45-$ & 0.61 & 0.64 & 0.57 & $0.64(0.50-0.81)$ \\
Admin. & 0.56 & $0.67+$ & 0.39 & 0.39 & 0.61 & $0.14-$ & $0.49(0.26-0.66)$ \\
Mitigation & 0.74 & 0.73 & 0.65 & 0.67 & $0.46-$ & $1.00+$ & $0.66(0.53-0.89)$ \\
Response & 0.78 & 0.73 & 0.68 & 0.28 & 0.68 & $0.14-$ & $0.62(0.27-0.83)$ \\
Recovery & 0.44 & 0.60 & 0.58 & $0.22-$ & 0.36 & $0.71+$ & $0.46(0.30-0.67)$ \\
Research & 0.22 & 0.27 & 0.29 & $0.17-$ & 0.21 & 0.29 & $0.24(0.19-0.29)$
\end{tabular}

Work addressing wildfire risk was disproportionately concentrated in some areas of the landscape $\left(\chi^{2}=292.41, \mathrm{df}=35, \mathrm{p}\right.$-value $<0.001$; Table 5). Work was most common on private land (43\%), followed by national forests $(33 \%)$, state $(13 \%)$, other federal (e.g., BLM, 5\%), and local land (e.g., city-owned, $<1 \%$ ). The vast majority of work (88\%) occurred outside of areas with special protection status (e.g., wilderness, roadless). Most works fell on land containing wildland vegetation (85\%). Of this, roughly 
half occurred in forested land cover and a half in non-forested land covers (e.g., grass and shrublands).

Table 5. Organizational geographies (\%) based on underlying land ownership. Cells marked with $+/-$ were more/less common than expected based on chisquared tests.

\begin{tabular}{lccccccc}
$\begin{array}{l}\text { Ownership } \\
(\% \text { study area })\end{array}$ & $\begin{array}{c}\text { USFS } \\
(\mathrm{n}=165)\end{array}$ & $\begin{array}{c}\text { Federal } \\
(\mathrm{n}=75)\end{array}$ & $\begin{array}{c}\text { State } \\
(\mathrm{n}=204)\end{array}$ & $\begin{array}{c}\text { NGO } \\
(\mathrm{n}=97)\end{array}$ & $\begin{array}{c}\text { Local } \\
(\mathrm{n}=198)\end{array}$ & $\begin{array}{c}\text { Private } \\
(\mathrm{n}=52)\end{array}$ & $\begin{array}{c}\text { All } \\
(\mathrm{n}=791)\end{array}$ \\
\hline National forest $(0.17)$ & $0.54+$ & 0.14 & $0.13-$ & 0.28 & $0.10-$ & 0.12 & 0.23 \\
Roadless NF (0.12) & $0.13+$ & 0.07 & 0.05 & 0.09 & $0.03-$ & 0.05 & 0.07 \\
Wilderness NF (0.16) & 0.05 & 0.01 & 0.02 & 0.06 & 0.02 & 0.02 & 0.03 \\
Other federal (0.06) & $0.01-$ & $0.26+$ & 0.04 & 0.00 & 0.03 & 0.00 & 0.05 \\
State (0.12) & $0.05-$ & 0.13 & $0.21+$ & 0.09 & 0.15 & 0.10 & 0.13 \\
Private (0.26) & 0.21 & 0.35 & $0.51+$ & 0.39 & $0.57+$ & $0.62+$ & 0.43 \\
Private WUI (0.06) & $0.02-$ & 0.05 & 0.05 & 0.10 & $0.11+$ & 0.10 & 0.06
\end{tabular}

Despite the limited area (6\%), one-quarter of the landscape was located within 1 mile of the WUI and nearly half of the landscape (49\%) within 2.5 miles (Table 6). Overall, $26 \%$ of reported work occurred inside of the WUI, $59 \%$ within 1 mile, and $79 \%$ within 2.5 miles. Only 7\% of the work reported was more than 5-miles from the WUI. Of the six organization types, NGOs, local and private organizations were most likely to work within the WUI and adjacent non-WUI developed areas. Of these two groups, approximately $70 \%$ of work locations occurred within one mile of the WUI. Despite being the least tied to the WUI, the majority of USFS work was within 2.5 miles of the WUI and more than $80 \%$ was within 5 miles. 
Table 6. Portion of work locations reported inside the WUI or within 1-mile, 2.5miles, or 5-miles of the WUI, grouped by primary organizational groups.

\begin{tabular}{lccccccc}
$\begin{array}{l}\text { Distance to WUI } \\
\text { (\% of study area })\end{array}$ & $\begin{array}{c}\text { USFS } \\
(\mathrm{n}=165)\end{array}$ & $\begin{array}{c}\text { Federal } \\
(\mathrm{n}=75)\end{array}$ & $\begin{array}{c}\text { State } \\
(\mathrm{n}=204)\end{array}$ & $\begin{array}{c}\text { NGO } \\
(\mathrm{n}=97)\end{array}$ & $\begin{array}{c}\text { Local } \\
(\mathrm{n}=198)\end{array}$ & $\begin{array}{c}\text { Private } \\
(\mathrm{n}=52)\end{array}$ & $\begin{array}{c}\text { All } \\
(\mathrm{n}=791)\end{array}$ \\
\hline WUI $(0.06)$ & 0.13 & 0.20 & 0.27 & 0.31 & 0.32 & 0.35 & 0.26 \\
$<1 \mathrm{mi}(0.25)$ & 0.36 & 0.52 & 0.64 & 0.68 & 0.69 & 0.73 & 0.59 \\
$<2.5 \mathrm{mi}(0.49)$ & 0.59 & 0.76 & 0.83 & 0.84 & 0.90 & 0.85 & 0.79 \\
$<5 \mathrm{mi}(0.73)$ & 0.83 & 0.91 & 0.96 & 0.93 & 0.96 & 0.96 & 0.93
\end{tabular}

\subsection{Organizational geographies}

Models of organizational geography varied in quality were good varied in quality from adequate to good (AUC $=0.72-0.87$; Table 6$)$. In general, local-level work could be predicted with greater success than federal and state organizational groups (the exception being other federal). Work reported by the USFS was the most specific to land ownership (i.e., national forests), followed by the state and private. The work of local organizations was highly specific to private ownership. NGO and other federal organizational groups, by contrast, were more diverse in terms of where they reported work. State work covered the largest portion of the study area, followed closely by USFS. The working landscapes of two federal organizational groups were most distinct. The USFS was the only organizational group with work that extended into higher elevations, while other federal work was restricted to the valley bottoms. As shown within their respective panels, state and local organizations covered almost identical geographies. Both NGO and private geographies were the most spatially clustered. 
Figure 2. Organizational geographies for six major organization groups involved in wildfire risk management. Highlighted locations represent those areas predicted by the work distribution models that had similar environmental attributes to actual work locations.

Table 7. Importance of environmental covariates in determining the working geography of each organizational group. Average AUC values reported for each organizational geography.

\begin{tabular}{lllllll} 
Variable & USFS & Federal & State & NGO & Local & Private \\
\hline Ownership & 0.31 & 0.09 & 0.12 & 0.03 & 0.04 & 0.12 \\
Designation & 0.02 & 0.00 & 0.12 & 0.04 & 0.04 & 0.01 \\
Distance to WUI & 0.25 & 0.01 & 0.54 & 0.58 & 0.53 & 0.24 \\
Distance to road & 0.02 & 0.03 & 0.02 & 0.02 & 0.09 & 0.02 \\
Wildland vegetation & 0.05 & 0.00 & 0.00 & 0.02 & 0.01 & 0.01 \\
Elevation & 0.10 & 0.67 & 0.06 & 0.01 & 0.03 & 0.02 \\
Drainage & 0.20 & 0.20 & 0.02 & 0.30 & 0.11 & 0.37 \\
\hline AUC - training & 0.83 & 0.87 & 0.83 & 0.87 & 0.87 & 0.89 \\
AUC - test & 0.75 & 0.84 & 0.82 & 0.78 & 0.79 & 0.82
\end{tabular}

\subsection{Organizational diversity and role specificity}

Organizational diversity was highest along road corridors, city centers and outlying WUI. The area with the greatest diversity occurred north of Leavenworth in the area surrounding Lake Wenatchee. Organizational diversity was also high in the Methow Valley and in the area surrounding Chelan. While there was no overall relationship between organizational diversity and role specificity, these relationships were more nuanced when individual organizational groups were considered (Figure 3). Federal actors (e.g., USFS, BLM, FWS, etc.) and state actors showed a negative relationship between organizational geography and work diversity. By contrast, non-governmental and private actors that reported work in more organizationally diverse portions of the 
landscape also reported occupying a greater diversity of wildlife management roles. Finally, local-organization respondents showed no relationship between organizational and role diversity, though the degree to which these respondents tended to work in areas of higher organizational diversity is notable.

\section{Discussion}

Land tenure extends beyond ownership boundaries and is constituted from a complex patchwork of formal and informal interests, rights, and responsibilities. Unseen at most times, the composition and structure of land tenure become more visible during times of environmental change, requiring individuals and organizations to reconsider the historical structure of their relationships in light of new environmental risks and uncertainties. This chapter demonstrated a novel approach to assessing the organizational geographies of wildfire risk management in a wildfire-prone landscape characterized by an expanding wildland urban interface, fragmented land ownership, and increasing wildfire risk. This view of organizational geographies illustrates a 'thick institutional' view of wildfire risk and has important implications for understanding how wildfire risk is shared among neighboring actors.

\subsection{Organizations involved in addressing wildfire risk}

The survey of wildfire risk managers in the NCWA revealed hundreds of actors working across multiple sectors of the economy and at multiple levels of government and non-governmental organizations. While the scope of actors and the structure of their relationships is beyond the scope of this chapter, this serves to emphasize the multifaceted nature of managing wildfire risk. Keeping this diversity in mind is key as 
individual agencies consider how to restructure their individual stances towards wildfire. For instance, Thompson et al. (2018) argue that the USFS applies system thinking and enterprise risk management to agency policy and procedures, especially regarding response and suppression strategies, yet do not consider how the USFS is situated within a larger ecosystem of actors. By contrast, this work shows that the USFS is one of several actors present in most fire-prone regions. The emergence of initiatives like collaborative forest landscape restoration and the expansion of federal good neighbor authority provide some of the tools for coordinating with other actors. Those affiliated with the Washington State Department of Natural Resources were both the most numerous actors in the region as well as the most expansive in terms of the geographic scope of their work. Finally, given the extensive tracks of Washington State forests that lie between national forests and developed private lands, effective coordination with the state is a critical buffer against unplanned ignitions on national forests.

Figure 3. Relationship between organizational diversity (derived from the overlap of all organizational geographies) and role diversity (derived from the total number of reported roles) grouped by organizational group.

\subsection{Organizational geographies of wildfire risk management}

Locations that organizations work were shaped by existing land ownership boundaries. Some organizations were tied to single ownership boundaries. For example, USFS-affiliated actors reported work primarily within the national forest while work reported by local organizations (e.g., fire districts, conservation districts) occurred primarily on privately owned lands. Locations of work for other organizational groups were more diverse. State actors were notably diverse in terms of both the extent and 
diversity of lands on which their work took place, with work occurring on both federal, state, and private ownership. These results demonstrate that land ownership may be a poor proxy for estimating where the interests of individual organizations lie, as well as a reminder that the larger institution of land tenure is more nuanced than the typically assumed in the dichotomy of public versus public land. The fact that more than half of the work reported occurred outside of associated jurisdictional boundaries demonstrates how interests in wildfire risk span boundaries and, therefore, like other public goods such as water, require collaboration in order to manage adequately. Further, more than half of worked occurred within one mile of the WUI, making it clear that WUI remains the dominant driver of risk management activities in North Central Washington. Given that more than half of the study area is located within one 1.5 kilometers of the WUI, the geographic concentration of work around the WUI reflects the fundamental way in which the WUI has reordered fire-prone landscapes.

These research support findings from several recent studies that suggest that managing wildfire risk requires considering developed areas as well as surrounding lands. It is worth emphasizing the incredible social and biophysical diversity of these lands, the degree of interacting interests, and the need for coordinated risk management. While studies have gone further by specifying the type of development (e.g., Johnson and Flannigan 2018) or specific patterns of development and wildland vegetation at fine-grain scales (e.g., Lampin-Maillet et al. 2010), only recently have researchers started to consider the functional dimensions of these areas. For example, Evers et al. 2018 developed functional definitions of the WUI that connected wildfire risk to elements of 
the larger landscape located beyond those conditions found immediately surrounding the structure. There are also important social dimensions to the WUI as well (e.g., Paveglio et al. 2015, 2018), and these include the organizational and institutional dimensions related to land tenure.

The areas where organizations operate capture at some level the specific interests of those organizations. As wildfires increase in size, organizations with interest in wildfire risk will need to expand the geographies in which they operate. In some cases, however, organizations may lack the legal access to these areas and will need to rely on cooperative agreements in order to address wildfire risk. In other cases, agreements may provide access for organizations, enabling organizations to work across boundaries. For example, the so-called 'Good Neighbor Authority' was recently expanded in the western US to allow state agencies to conduct fuel reduction projects on federal lands where state or local assets are at risk from federal fires. This research has shown how organizational diversity varies across the study area and that this may be the result of past efforts to coordinate wildfire risk management and response across a variety of institutional layers.

\subsection{Organizational diversity and role specificity}

Organizational diversity, defined as those areas in the study area where organizations at different institutional levels were likely to work, varied across the study area. The amount of overlap between different institutions appears to be a function of both ownership boundaries as well as past investments in wildfire capacity. Two areas of particular note were the area north of Leavenworth and the area northeast of Cle Elum. The former represents a densely vegetated area with a significant number of seasonal 
homes. Here, a diverse group of local residents, local fire district, county, and state government, and several conservation organizations formed shortly after the 2000 National Fire Plan and have recruited substantial resources into fire awareness and mitigation efforts, subsequently serving as a template for success for the entire region (CWSC 2019). The later received considerable investments through an agreement between the USFS and the NRCS through the Joint Chiefs' Landscape Restoration Program (USFS \& NRCS 2019). In contrast, the area affected by the 2015 Carlton Complex is notable for its lack of organizational diversity.

We found a weak relationship between organizational diversity and individual level role specificity. This finding supports the initial hypothesis that actors specialize more when a greater number of organizations are operating in the same area. I suggest that such specialization is the result of social processes that contribute to the formation of structures of networked governance, including increased asset specificity and task complexity. As actors become more specialized, they also become more dependent on others to accomplish tasks. Such reciprocity is reinforced through frequent interactions, and these interactions serve to minimize transaction costs through tacit informal agreements. Such specialization may, in turn, work towards increased collaboration in fragmented land ownership where management and planning activities need to be coordinated at several scales. This further suggests that as more and more organizations are affected by wildfire, as has occurred in dozens of wildfire hotspots around the western US, that organizations are modifying the work they do, and that this has 
profound implications in terms of changes in the capacity to address wildfire risk over time.

There are some notable exceptions to this general trend. First, as mentioned above, the Cle Elum area has been the focus of a coordinated effort to match federal and state projects, and the higher specificity may be the result of greater coordination. Further, the area is much more homogenous in terms of land ownership, and there is much less WUI. By contrast, ownership north of Leavenworth is notably fragmented among private inholdings and larger contiguous areas of national forest. Further, given its proximity to the Seattle metro area, development pressure is particularly acute in this area, which has resulted in a significant number of seasonal second homes. This suggests a more diverse social environment within which highly coordinated work is less practical (Paveglio et al. 2018). The northern Okanagan region of the study area had less organizational diversity and, as a result, less specification. The majority of the organizational geography in the northern area stated while USFS work was patchy, and local and NGO work was sparse. Notably, this was the area that was hit hardest by the devastating Carlton fire complex in 2015. The combination of limited organizational diversity and the limited number of roles suggests that this area still lacks the capacity to address wildfire risk and may be vulnerable to a similar sequence of events that hit the community in 2015. In the absence of a greater institutional presence, a greater portion of the risk is held solely by individual property owners. 


\subsection{Participatory GIS and its limitations.}

The techniques that I employed to collect spatial information have a long pedigree in the fields of participatory mapping and participatory GIS, although significant issues remain in terms of accuracy. Nonetheless, the ubiquity of online mapping services has drastically increased familiarity with this technology, which has opened up opportunities to collect spatial information as part of typical survey research. By generalizing the relationship between work locations and underlying environmental covariates, this technique could be rapidly scaled to larger landscapes, including those where a detailed survey of wildfire risk management organizations has not yet been conducted. While the organizational geography models presented in this paper could be extrapolated to the national scale, it is worth noting that the same predictors are unlikely to be the same in other fire-prone areas. Testing these models in other geographies is a future area of research.

The assumptions underlying distribution models have important implications. There remains significant debate within geographers and ecologists about the limitations of geographic distribution models. The data used in such models is inherently troublesome from a statistical point of view and violates assumptions related to normality, independence, and observation bias. Increasingly ecologists have relied on multiple models to reveal classification sensitivities and inconsistencies. Another popular approach is to combine many classification models into a single ensemble. Each distribution model can be folded into future research, with each distribution representing a hypothesis that can be judged against future observations. 
Nonetheless, inaccuracy is expected, and this explains the relative lack of discriminatory strength that the work occurrence models showed. The accuracy of the work distribution models was highest with local and state-level organizations and weakest with federal organizations. This likely reflects the fact that the stance of local and state-level organizations towards wildfire is more focused on protecting values at risk through outright suppression. By contrast, the lower AUC values for federal organizations may reflect a greater diversity of management stances regarding wildfire, including using wildfire for beneficial uses. Further, it suggests that there were additional values at risk that I did not include among the list of environmental covariates that influence where risk management activities occur. Examples of these values include imperiled habitat (e.g., spotted owl nesting locations) or watersheds that provide community drinking water.

\section{Conclusion}

Abrupt changes in the environment can disrupt established management regimes and create the need for working across boundaries. It is often assumed that land ownership and jurisdictional boundaries define where and how individuals and organizations address wildfire risk but given the ease at which wildfire risk crosses boundaries, could it be that cross-boundary work is less the exception and more the rule. This research has shown how the organizational geography of wildfire risk management is primarily determined by proximity to developing, and only secondarily by land ownership. However, narrow geographically, the wildland urban interface has become a dominant force in the geography of risk management in fire-prone landscapes. The 
resultant diversity of organizational involvement shapes the character of work, in some cases leading to more role specificity while in others more role diversity. Finally, identifying areas where organizational geography overlap may indicate where shared interests in wildfire risk management that support shared stewardship initiatives at both federal and state levels. 


\section{Figures}

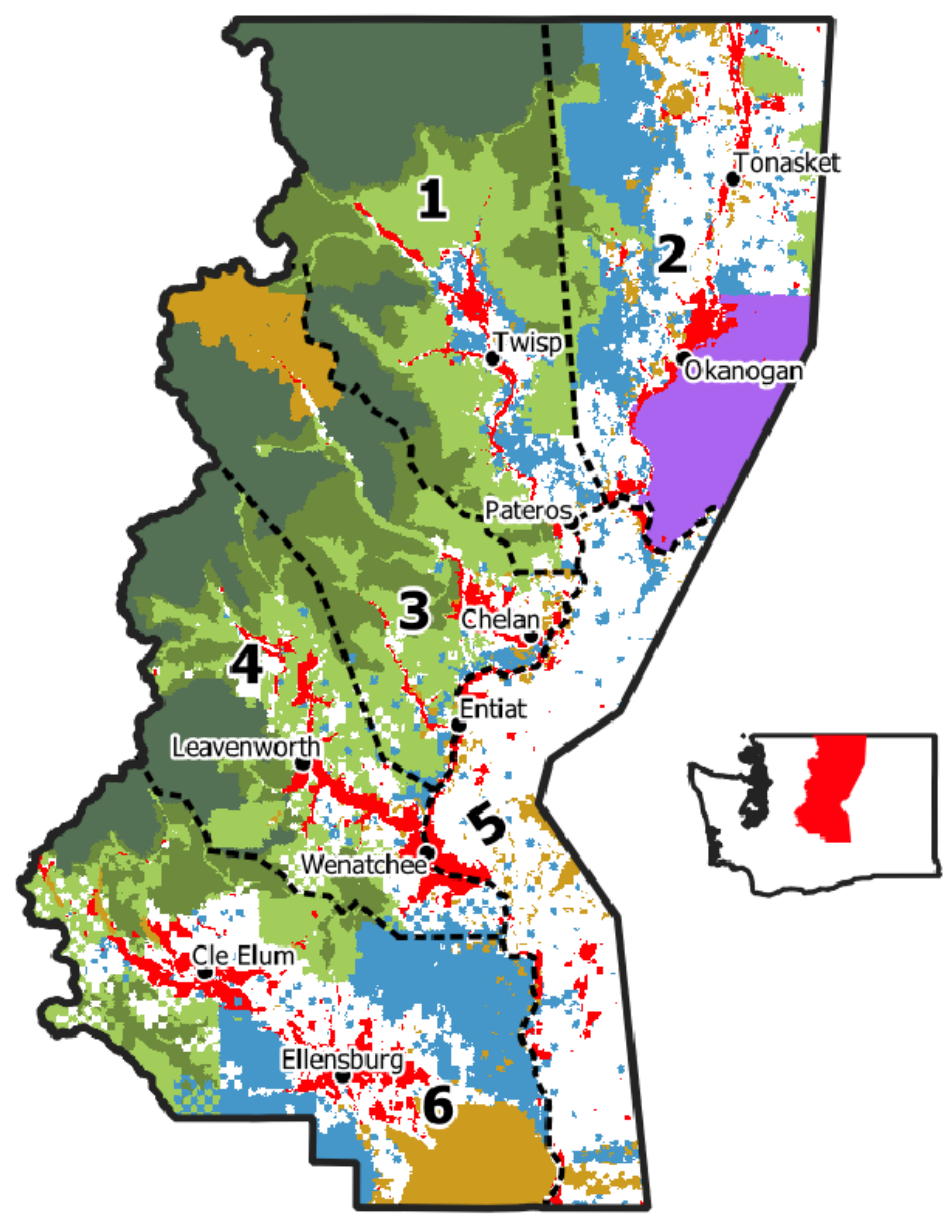

Figure 1. Study area located in North Central Washington on the east side of the Cascade Mountains (50 miles east of Seattle). More than 380,000 people reside in the region. Major communities are labeled. For reference, the study area is broken into six drainages: 1) Methow, 2) Okanogan, 3) Chelan, 4) Wenatchee, 5) East of the Columbia, and 6) Yakima. 

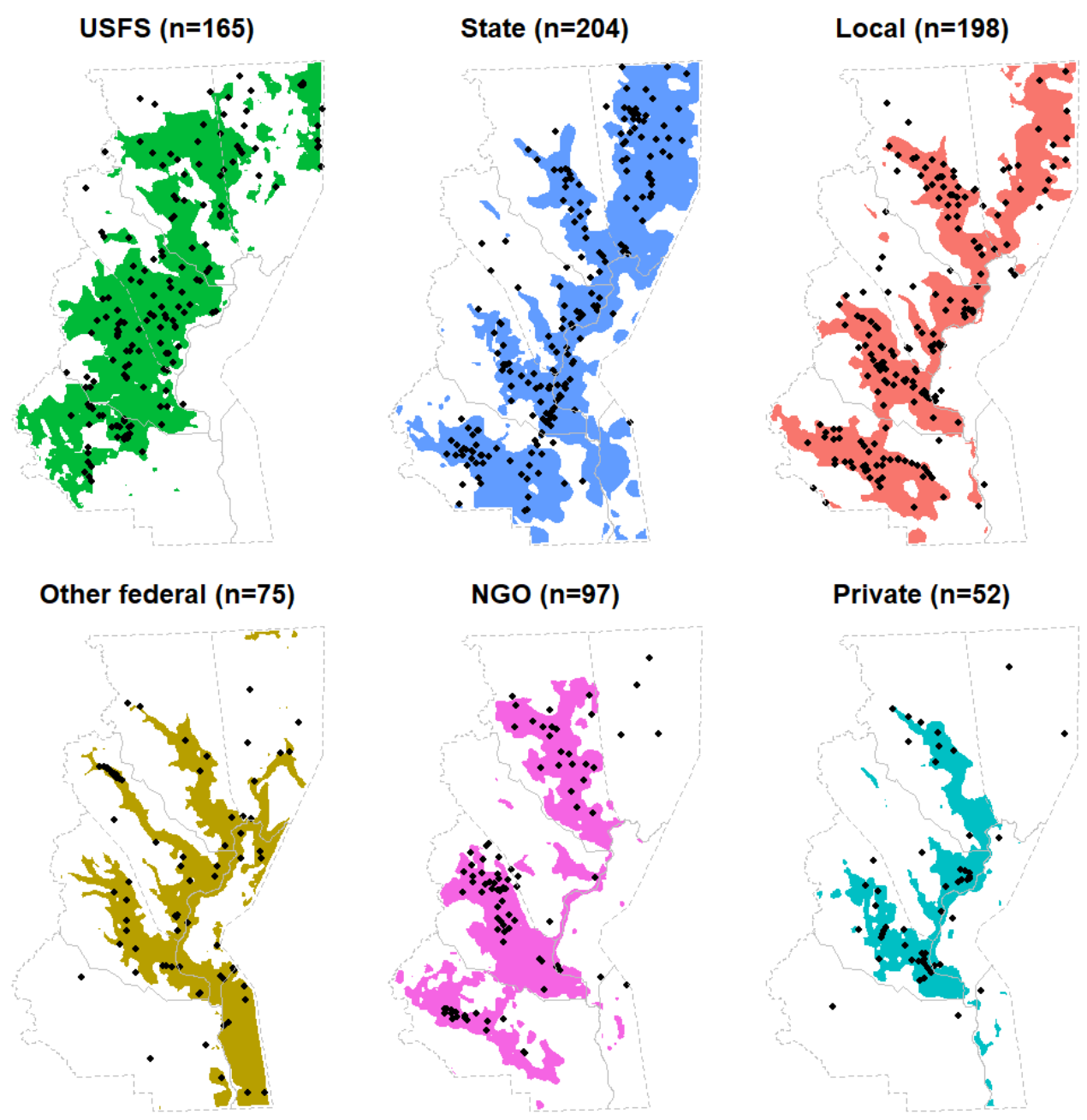

Private $(n=52)$

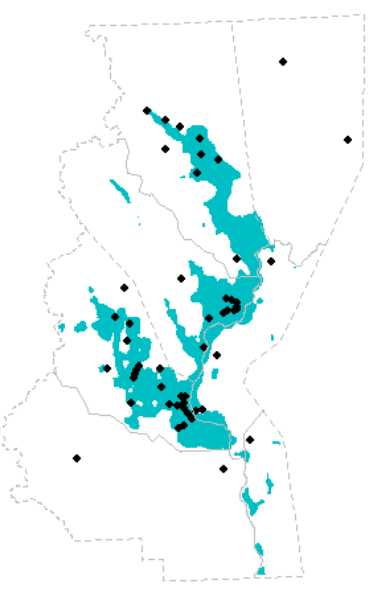

Figure 2. Organizational geographies for six major organization groups involved in wildfire risk management. Highlighted locations represent those areas predicted by the work distribution models that had similar environmental attributes to actual work locations. 


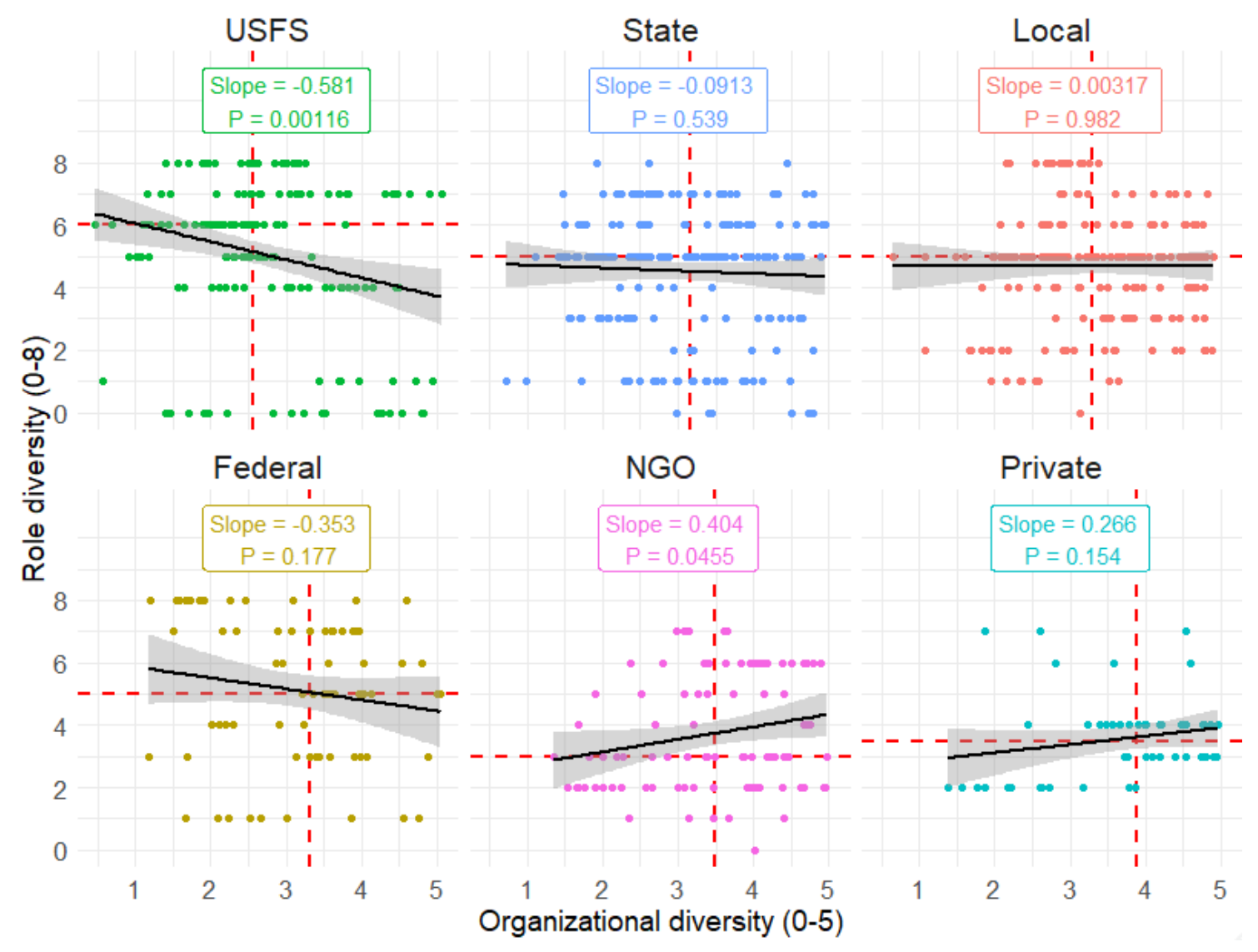

Figure 3. Relationship between organizational diversity (derived from the overlap of all organizational geographies) and role diversity (derived from the total number of reported roles) grouped by organizational group. 


\title{
Chapter 4:
}

\section{Collaboration in the Wildfire Risk Management System}

\begin{abstract}
Cross-boundary collaboration has been proposed as a solution to the problem of increased fire risk, although the promise of this approach has been hamstrung by the lack of metrics measuring the impact of investments in collaboration over time. Given that fire risk often extends beyond the resources, jurisdiction, and capacity of any one organization, assessing these investments may require less focus on the actions of specific actors involved in wildfire risk management and more attention on the how the overall management network is structured and evolving in response to increasing fire risk. This chapter looks at the network of working relationships among wildfire professionals in North Central Washington, one of nearly two dozen wildfire risk hotspots in the western US. The resulting professional networks showed that the structure of working relationships among organizations is strongly linked to the locations where they work, which is further mediated by the amount of wildfire risk shared in addition to the similarity in land ownership in which partner organizations work. Shared management tenure did not influence working relationships, indicating a need for future policy to support cross-boundary collaboration. This work presents the concept of the wildfire risk management system and provides an early view of how this multi-sector, multi-scale institution is structured in geographically contiguous areas of high wildfire risk.
\end{abstract}




\section{Keywords:}

Social network analysis; Species distribution models; Participatory GIS mapping

\section{Research Highlights:}

- Managing wildfire risk increasingly depends on cross-boundary collaboration

- Little is known about the relational structure of wildfire risk management networks

- Collaboration developed from affiliation, relational closure, and focus of work

- Relationships were associated with both geographic proximity and large scales

- Fire exchange promoted collaboration especially among similar land ownerships 


\section{Collaboration in the Wildfire Risk Management System}

A surge in wildfire risk in many fire-prone landscapes has exposed an urgent need for new forms of risk management (Moritz et al. 2014; Fischer et al. 2016; Steelman 2018; Schoennagel et al. 2018). As fires have grown in size and intensity, the need for work coordinated across both jurisdictional and organizational boundaries has been emphasized by a growing number of managers, scientists, and politicians (Charnley et al. 2018, Ager et al. 2015). This need is particularly acute where development occurs in fireprone landscapes, owing to the values at risk and the scale of coordination required to effectively mitigate fire risk (Nielsen-Pincus et al. 2019). The diversity of actors involved gives rise to substantial management challenges due to inconsistent policies, budget constraints, organizational structures, differing priorities, and differences in the operational rules and scales at which individuals and organizations have the capacity and authority to act (Abrams et al. 2015; Fischer et al. 2016; Steelman 2016). Given these structural constraints, some have argued for an expanded focus on the larger management system, although there remains a paucity of landscape-scale studies that examine these cross-boundary management regimes.

Only recently have researchers begun to systematically map community wildfire risk at the national scales (Ager et al. 2019, Evers et al. 2019, Palaiologou et al. 2020). This work has shown how wildfire risk is clustered within several dozen hotspots in the western US. Given the large geographies of these hotspots, risk management involves actors from multiple levels of government, in addition to potentially hundreds of public, nonprofit, private, and research-based actors. Despite working in the same geographic 
area, professionals involved in managing wildfire risk often face significant coordination challenges that exceed the capacity of any one organization, particularly when working across large and diverse landscapes. Informal and formal institutional structures have directly or indirectly evolved from this coordination over time. Developed over decades or longer, established patterns of interactions can be disrupted by abrupt changes in the environment, thus creating the need for new patterns of cooperation and coordination (Galaz et al. 2008).

Despite the distinct tendency in natural hazard response to view interactions from a hierarchical perspective (e.g., incident command), such command-and-control structures are neither possible or desirable on socially and ecologically diverse landscapes. Given the magnitude of risk-exposure, the breadth of drivers involved, and the degree to which management actions are interconnected, a more appropriate lens may involve a bottom-up view towards polycentric risk governance. This view assumes multiple centers of authority that organize in a relatively organic process (Chaffin and Gunderson 2016). Social change in these systems is often linked to critical events (Gunderson et al. 1995) or structural gaps that arise in complex social systems and that actors subsequently seek to address (Ostrom 1990; 2010; Lubell et al. 2002). Since these changes are often uncoordinated, progress is fragmented as different actors seek to address the specific contexts in which they operate (Folke et al. 2005; Berardo \& Lubell 2016). This chapter uses the term wildfire risk management system (WMRS) to describe this setting. 
Several recent programs and authorities to support collaborative, cross-boundary work (Charnley et al. 2017), often with a focus on wildfire risk management. For instance, the USFS has launched numerous programs and policies that rely on publicprivate partnerships, such as the Collaborative Forest Landscape Restoration Program, the Western Watershed Enhancement Partnership, the Joint Chiefs Joint Landscape Restoration Partnership, Good Neighbor Authority, and stewardship contracting. The Joint Chiefs Landscape Restoration Partnership (JCLRP) supports fuels reduction and ecological restoration on US forestlands that focuses on the challenge of planning and funding a coordinated program of work across the public-private jurisdictional divide. The Good Neighbor Authority (GNA) allows non-USFS partners to implement projects on federal forestland, emphasizing the "end result" of activities that achieve key land management goals and meet local community needs. Fire Adapted Communities (FAC) help homeowners, communities, and land managers in fire-prone areas prepare for inevitable fire and include multi-jurisdictional mitigation groups to share risk reduction responsibility in the community (Goldstein et al. 2010, Abrams et al. 2015). Despite their promise, the success of these programs is limited by the lack of appropriate metrics for systematically identifying collaboration opportunities and tracking outcomes over time, which in turn might encourage future investment in such programs.

Network-based approaches show promise for describing and thus evaluating such systems due to their focus on relational structure (Bodin et al. 2017; Sayles et al. 2019). Rather than study the individual actors of a system, network-based analyses examine how actors are bound together in light of the diversity of contexts in which they act 
(Emirbayer 1997). Traditionally conceived in social sciences, an increasing number of studies have extended network analyses to coupled social-ecological networks (SEN). SEN provides both an important conceptual model for assessing the various dependencies and feedbacks within social-ecological systems as well as an analytical framework for quantifying inferences. While the SEN framework has been applied to a broad range of conservation problems, its use in understanding wildfire management has only been recently proposed (Ager et al. 2015), and empirical studies remain few (Hamilton et al. 2018 is a notable exception).

This chapter applies the SEN framework to speculate on change within the WRMS exposed to increased wildfire risk. Figure 1 describes cross-boundary relationships in the WRMS using symbology popularized by Bodin et al. (2014). Each network motif is composed of nodes and edges. The nodes reflect discrete social actors (red) and ecological units (green). The edges, in turn, describe the structure of relationships that exist among the social and ecological nodes. An edge between two actors represents a social relationship, which represents some history of coordinated work that occurred between these individuals. In contrast, an edge between ecological nodes represents the exchange of wildfire risk; two nodes are connected if a fire that ignites in one node is able to burn into the other. Finally, an edge between a social actor and an ecological node represents some interest in a particular place, which might include a variety of responsibilities or concerns. For example, ownership would constitute a placespecific interest, as would responsibility for a specific jurisdiction. With these elements in mind, consider the simplest management case (Figure 1A). Each actor in the WRMS is 
tied to a single ecological node. While wildfire risk may be present, and even quite significant, it is nonetheless constrained to existing boundaries. Since wildfire risk is not shared between the locations, responsibility for managing wildfire risk remains tied to a single actor.

Figure 1. Transformation in the wildfire risk management system as risk moves from the simple $(A)$ to more complex $(B-D)$. Three transformations are illustrated: (B) risk interdependency; (C) spatial externalities, and; (D) coordinated management.

These relationships become more complex as fires increase in size and or as land tenure becomes more fragmented. For instance, a large wildfire is likely to burn into adjacent ecological units, thereby causing risk to spill over into adjacent lands (Ager et al. 2017). Likewise, as social interest in a particular location become more concentrated or as land becomes subdivided across multiple land uses, there is a greater likelihood that interest in a given wildfire becomes commonly held (Busby et al. 2012). Addressing these changes requires that actors shift who they engage with and where they focus their attention. Three potential responses are shown to the right of the figure. First, as interests become increasingly shared among one or more actors, classic collective-action challenges arise. This context (Figure 1B) creates a strong incentive for actors to work together, as shown by the formation of new social ties. Second, as fire increases in size and complexity, a greater portion of fire risk becomes shared across adjacent units of land (Figure 1C). This increase in connectivity, shown by the ties between the green nodes, can result in the externalization of risk. It would, therefore, be expected that organizations will expand their interests to adjacent lands in order to either address the spread of risk 
(e.g., due to potential liability) or to stem the generation of risk at its source. Nonetheless, ownership and political boundaries can often severely limit access. Thus, in this third case, actors or organizations will seek to coordinate actions with adjacent actors, in effect aligning social structures with underlying landscape processes (Figure 1D). These mechanisms drive risk interdependencies within the WRMS.

The examples above are meant to illustrate the social processes that occur in response to increased risk from wildfire. To date, little systematic research exists that document where these activities occur, among which actors, and under what conditions. This chapter addresses this gap by looking for patterns of coordination among wildfire management actors using social network analyses. These coordination motifs show where co-management is most likely to occur in addition to those conditions that challenge its formation. I ask the following questions. Q1: How are relationships structured among WRMS actors? To what extent are working relationships confined to existing organizational groups? Q2: Does the proximity of work influence the structuring of the network and are working relationships more common in areas where wildfire risk is shared?

\section{Methods}

\subsection{Study area}

North Central Washington is a fire-prone landscape notable for its drastic climate and vegetation gradients, which vary from wet subalpine forests to dry high-desert shrubland as the Cascade Range descends east into the Columbia River Basin. Lengthening fire seasons have resulted in an increased frequency of extreme fire years, 
most notably during the 2014 Carlton and 2015 Okanogan complexes that collectively burned 225,000 hectares. Owing to this risk, the region has been received tens of millions of dollars in funding to develop the capacity to anticipate, respond, and recover from such fires. The combination of exposure, experience, and investment make the area an important regional case study in wildfire management and adaptation. Development is relatively sparse in the region and is concentrated along transit corridors and valley bottoms. Nonetheless, wildfire risks to communities are acute, and the region has experienced several recent catastrophic fires. Fire return intervals vary from less than 35 years to more than 500 years. Fire activity in higher-elevation forests is strongly tied to winter precipitation, and the timing of the springtime melt while the fire at lowerelevation is shaped by past fire suppression, particularly within dry forests that are ecologically adapted to frequent low-intensity burns.

Figure 2. (A) Principal land cover North Central Washington study area shows a mixture of forest and shrubland systems. (B) Fire frequencies vary between 30 and 500 years with the most flammable areas occurring at the transition zone from dryland-forest to open desert-steppe. (C) Land ownership represents a mixture of private and public lands with developed areas occupying valley bottomlands.

\subsection{Wildfire risk management system (WRMS) survey}

WRMS data were collected via an online questionnaire designed around the concept of rapid assessments. Respondents identified their title, organizational affiliation, primary roles related to fire, and the scale of their work (local to regional). Respondents then mapped where they had worked to address wildfire risk in the past five years. Finally, respondents identified individuals whom they had worked during the same 
period, and briefly noted the focus, frequency, and influence of those relationships. The survey was administered in ten rounds between March and June 2018. Newly identified individuals were recruited to the subsequent rounds of surveying. The survey was terminated with the arrival of the 2018 fire season. While the instrument was designed to survey the wildfire management system broadly defined, here the focus is on those actors that reported specific locations of work within the study area - that is, that 'worked-onthe-ground.' Survey data were used to generate a network using the network package within R (Butts 2008). Nodes in the network represent individuals in the WRMS that were surveyed; edges represent the collaborative working relationships reported between them. Working ties were assumed to be symmetrical and therefore, the network was treated as undirected. Work locations and spatial relationships were analyzed as edge attributes saved to a separate network representing all pairwise connections between actors (see Section 2.3.3).

\subsection{Relational analysis using exponential random graph models (ERGM)}

Analyses were conducted using exponential random graph models (ERGM) as implemented in the statnet package in $\mathrm{R}$ (Handcock et al., 2003). ERGM is a rapidly evolving inferential technique that uses the network itself as the dependent variable. While interpretation is similar to standard logistic regression, the assumption of independence that underlies the models is drastically different. In fact, ERGM actually assumes dependence within the data and is, therefore, able to capture endogenous effects of network structure such as reciprocity, closure, and influence. As a result, fitting an ERGM to observed network data provides inference on the social patterns (i.e., the model 
terms) that produce the observed structure of the network. Processes not included in the proposed model are assumed to act as random noise. The ERGM model was built in a forward-stepwise fashion. For each interaction, I extracted the estimated effects (coefficients) and respective standard-errors into a single table. Overall performance was tracked using Akaike Information Criterion (AIC), which weighs information gain against model parsimony. Standard Markov Chain Monte Carlo (MCMC) diagnostics were run on the final model to ensure proper mixing and guard against possible model degeneracy. The next section describes the specific terms included in the ERGM model.

\subsubsection{Node effects (general, mixing)}

Node-matching terms within the model account for the tendency of individuals to work more closely with other individuals within the same or similar organizations. I estimate this effect separately for each group under the assumption that different organization groups exhibit different mixing behaviors. Eight dummy variables describe the wildfire management role respondents reported, including: (a) outreach and education, (b) administration; (c) planning; (d) risk mitigation; (e) incident response; (f) recovery; and (g) research. Finally, respondents describe the scale that best describes the work they conduct, from single or multiple communities, single or multiple jurisdictions, or more generally focused in the region.

\subsubsection{Structural effects}

The structure of the social network is often strongly shaped by so-called endogenous effects, such as the tendency to reciprocate, associate with popular individuals, and make connections based on mutual acquaintances (Prell 2012). These 
effects differ from exogenous effects because they depend on the existing network structure. Two endogenous, structural effects are included in the model to account for the conditional aspect of tie formation. The geometrically weighted degree distribution (gwdegree) captures the propensity for centralized network structures. Because a positive coefficient indicates a relatively homogeneous degree distribution (hence antipreferential) and a negative coefficient indicates a more skewed or "fat-tailed" distribution, the gwdegree term models, which captures the tendency for individuals to preferentially associate with others who are already well-connected (Hunter 2007). The geometrically weighted edgewise shared partners (gwesp) to capture the tendency for network closure (i.e., the formation of triangles). Both terms include a decay function, which stops the model fitting algorithm from becoming trapped within a limited set of network configurations during the fitting process (Schneider 2006). The specific decay value used was fixed during model fitting at 0.3 . The initial value was based on AIC and goodness-of-fit statistics, although in general, model fit was relatively insensitive to these changes.

\subsubsection{Geospatial effects}

Social relationships are often tied to underlying geography (Boschma 2005). To test how geographic proximity influenced the structure of the network, distances were derived among all pairs of individuals in the network using reported locations-of-work. These distances were then modeled as fixed edge covariates using the mean Euclidean distance between the two sets of work locations. Other forms of proximity were considered as well, including the likelihood that any two locations fall within the same 
burn perimeter. Relative wildfire connectivity may be especially important in landscapes that vary greatly in terms of topography, vegetation, and fire regimes. Areas of the landscape that burn more frequently and across larger distances may be more connected than a separate pair of points equally distant yet located in a less fire-prone portion of the landscape. The effect of distance was log-transformed, which allows for the formation of ties at large distances (Butts 2011).

Two metrics were developed to understand cross-boundary work. The first metric identifies specific network motifs within the model. Specifically, ties were identified between actors that were associated with a different organization and that reported work within 5-km of one-another. Visually, this is equivalent to the SEN network motif shown in Figure 1D. The second metric uses the organizational geographies that I described in Chapter 3. The former approach was based on both network and geographic proximity. Specifically, I identify those individuals who were both socially connected and who worked within the same general area. This creates the coordinated relationship shown in Figure 1D. For each work location, I identified other points within a $5 \mathrm{~km}$ radius. For those points, I then identified the associated actors and whether those actors shared a working tie. The second analytic is to look at organizational geographic diversity as a predictor within the model. The assumption here is that the likelihood of a tie is conditional on the number of times that work points for both individuals are located within the same overlapping geography. As above, this relationship was handled in the ERGM model as edge variables and thus required populating an n-by-n matrix representing all pairwise actor combinations. 


\section{Results}

\subsection{Wildfire risk management community}

Of the 295 individuals who responded to the survey, two-fifths $(\mathrm{n}=127,43 \%)$ reported 'work on the ground' between 2013 and 2018 (Figure 3). State, local, and USFS-affiliated actors accounted for the large majority of actors $(25 \%, 22 \%, 21 \%$ respectively), while other federal (e.g., BLM, FWS, NPS, Tribal), NGO, and private accounted for the remainder $(13 \%, 14 \%, 5 \%$ respectively). These 127 respondents reported 197 working ties among each other during the same period, representing $2.5 \%$ of all possible ties. On average, actors had 3 working ties. Only 13 individuals had more than 5 ties while the maximum was 14. Twelve respondents had zero ties and were socially isolated from the network. The structure of these relationships is visualized as a network graph in Fig. 3A, where actors are circular nodes and work ties are lines between those nodes. Individuals connected by working ties are 'pulled' together, which causes related actors to become visually clustered. The size of each graph node relates to the number of working ties, and owing to the number of their connections, these actors tend are pulled toward the center of the graph. As are visually apparent, NGO-affiliated actors were the most central $($ centrality $=0.211)$, followed by local $($ centrality $=0.14)$, state $($ centrality $=0.12)$, other federal $($ centrality $=0.10)$, private $($ centrality $=0.07)$, and USFS $($ centrality $=0.06)$.

\subsection{Locations of work}

Respondents reported 995 location where they had worked to address wildfire risk between 2013 and 2018 (Figure 3B). The number of work locations reported varied from 
1 to 29 locations, although most individuals reported 6 or fewer $($ mean $=7.5, \mathrm{sd}=6.1)$.

The area over which respondents reported work varied widely. Some individuals reported work across as much as half of the entire study areas, while others were confined to a specific area. The one-to-many relationships between actors in Figure 3B and work locations in Figure 3C are shown as blue lines. The divergent angles of these actor-work ties reflect differences in geographic focus among different sectors of the social network. For instance, many of the actors in the lower-left quadrant of the social network reported work in the northern part of the study area, whereas many of the actors in the top-right of the network are tied to work location found further south. Two-thirds of the study area were with $5-\mathrm{km}$ of another work location and most work (75\%) occurred within 5-km of the WUI (see Figure 2C). Relatively little work was reported on federal land designated as wilderness or roadless areas.

Figure 3. Relationship between the social network and reported work location. Actor-to-actor collaborative work-ties (A) are superimposed over ties that connect the actor to the location of work (B). Social distance in $A$ is implied by the relative distance between actor nodes.

\subsection{Predictors of work relationships}

Table 1 lists the coefficients for the complete ERGM model. The edge coefficient represents the mean likelihood of a tie-formation (i.e., the network edge density) and thus functions as the model intercept. The likelihood of a tie existing between any two nodes equals the inverse logit of the coefficient. Additional terms reflect processes that increase or decrease the likelihood of tie formation relative to the intercept. 
Structural closure was positive and significant: Two actors were more likely to share a working relationship when both actors reported working with the same third person. Closure is associated with the formation of network clusters, which suggests distinct pockets of working relationships in the WRMS. Node degree had no influence on work relationships, meaning that actors did not preferentially seek work with other actors based on the number of existing working relationships.

Actors were more likely to work with others that were affiliated with the same type of organizational group. Preferential assortment, however, varied among organizational groups. While coefficients were positive for all organization types, only 4 out of the 6 were significant. Homophily was greatest among NGOs, followed by local, then federal actors. Homophily among USFS affiliates was also significant, but less in magnitude. The combination of social closure with assortative mixing results in the social clustering evident in Figure 3A. Federal, local, and NGO actors tend to reside in specific quadrants of the network graph, while USFS, state, and private actors were more dispersed.

Certain types of work entailed more collaboration. Collaboration was more common when risk management roles included administration and risk mitigation and much less common when their work included research. Other roles did not significantly differ from the mean. Effects are additive, so if two individuals were involved in mitigation work, the likelihood of a connection between the two is double that where only one partner occupied that role. Finally, not all actors work on the same scale, and the scale they primarily work at impacted tie formation. In general, the larger the scale the 
people reported working at, the more likely they were to be involved in working partnerships. For instance, ties with actors that worked at a regional scale were 2.5 times more likely than actors that worked at a community scale. In a similar sense, working ties were more common when actors reported work over larger ranges.

Table 1. Estimated coefficients from the complete ERGM model. Positive estimates reflect factors that promote working relationships among actors while negative estimates dissuade ties. Effects are additive.

\begin{tabular}{llrrrc} 
Category & Variable & Est & SE & z value & p \\
\hline Intercept & Tie propensity & -2.641 & 0.836 & -3.16 & $0.002^{* *}$ \\
Structural & Closure & 0.753 & 0.109 & 6.900 & $<0.001^{* * *}$ \\
& Popularity & 0.429 & 0.328 & 1.305 & 0.192 \\
Homophily & Federal & 1.343 & 0.347 & 3.869 & $0.000^{* * *}$ \\
& Local & 0.611 & 0.253 & 2.411 & $0.016^{*}$ \\
& NGO & 1.521 & 0.308 & 4.931 & $<0.001^{* * *}$ \\
& Private & 1.326 & 1.124 & 1.180 & 0.238 \\
& State & 0.394 & 0.266 & 1.483 & 0.138 \\
& USFS & 0.648 & 0.297 & 2.184 & $0.029 *$ \\
Work focus & Education & 0.255 & 0.153 & 1.671 & 0.095 \\
& Awareness & -0.121 & 0.166 & -0.731 & 0.465 \\
& Planning & -0.107 & 0.119 & -0.894 & 0.371 \\
& Administration & 0.245 & 0.106 & 2.318 & $0.020^{*}$ \\
& Mitigation & 0.201 & 0.121 & 1.657 & 0.098 \\
& Response & -0.091 & 0.114 & -0.802 & 0.422 \\
Scale of & Recovery & -0.024 & 0.102 & -0.239 & 0.811 \\
work & Research & -0.244 & 0.134 & -1.818 & 0.069. \\
& Several communities & 0.407 & 0.313 & 1.301 & 0.193 \\
& Jurisdiction & 0.680 & 0.260 & 2.612 & $0.009 * *$ \\
Spatial & Several jurisdictions & 0.815 & 0.254 & 3.206 & $0.001^{* *}$ \\
effects & Regional & 1.060 & 0.324 & 3.275 & $0.001 * *$ \\
& Work proximity (mean) & -0.853 & 0.143 & -5.984 & $<0.001 * * *$ \\
& Fire exchange (mean) & 0.106 & 0.031 & 3.416 & $0.001 * * *$ \\
& Ownership similarity & 0.625 & 0.293 & 2.137 & $0.033^{*}$ \\
& Co-management score & -0.287 & 0.518 & -0.553 & 0.580
\end{tabular}




\subsection{Spatial influence on work relationships}

The effect of distance on work relationships was particularly notable. Actors that reported working in nearby locations were more likely to report shared work. For instance, people that reported work within $1 \mathrm{~km}$ were 4-times as likely to report working together than those separated by $10-\mathrm{km}$ and 10 -times as likely to work together than people whose work was 40-km (25-mi) apart. For instance, collaboration was almost 1.78-times more likely when the average distance between work locations was $5 \mathrm{~km}$ compared to when the average distance was $10 \mathrm{~km}$, and $2.5 \mathrm{x}$ more likely than compared to $15 \mathrm{~km}$. I looked at other factors that moderate the effects of distance, including the amount of fire exchange and similarity in land ownership. As the amount of shared fire increased, so too did the likelihood of shared work. No fire was shared among approximately $40 \%$ of actor pairs. Compared to this baseline, collaboration among potential actors that shared a moderate degree of fire risk (i.e., $50^{\text {th }}$ percentile) were 1.5times more likely to collaborate, while those that shared a high degree of fire risk (i.e., the 90 th-percentile) were nearly $2 \mathrm{x}$ as likely to work together. Further, the greater the similarity in ownership, the more likely that two actors worked together. If both actors worked entirely within the same land ownership, they were 1.76-times more likely to report working together than if the two actors worked in completely different ownerships. Finally, I examined the degree to which the working locations for one actor occurred within the organizational geography associated with the organizational group of their potential working partner. Here I did not find a significant relationship, the reasons for which I elaborate within the discussion. 


\section{Discussion}

Wildfire risk management reflects the actions of dozens of actors working in a diversity of contexts and scales, often working across multiple ownerships and jurisdictions within a complex institutional system (see Lubell 2015). A growing number of programs, partnerships, agreements, and authorities seek to support the cross-boundary nature of wildfire risk management in order to temper increased fire risks (Butler \& Goldstein 2010; Steelman 2016; Charnely et al. 2017). Several of these programs have been in existence for more than a decade, while others are still being actively adopted. Relatively speaking, this policy and program focus is still young. In theory, many of these relationships are motivated by circumstances where neither actor can accomplish in full what would be possible working together. Nonetheless, developing and maintaining these relationships require time, effort, and resources, so it is reasonable to assume that whatever is accomplished in collaboration goes beyond the cost entailed. Thus, the structure of the relationships that emerge over time embodies a collective investment in learning and capacity building. Cross-boundary programs seek to offset some of this cost and strengthen these collaborative structures. This chapter examined the structure of the working relationships among professionals at multiple scales of government and sectors

of society, yet whose work collectively involved the management of wildfire risk on the ground.

Working relationships depended on a variety of different factors, including network structure, organizational affiliation, the focus of work, and geography. Like many social networks, risk management networks were strongly influenced by the 
tendency for two people to connect based on their prior relationship with a third person. Closure builds capital through redundancy since the multiple ties ensure that information is able to traverse without becoming siloed within individual clusters (Burt 2005). Bonding also serves as a mechanism for monitoring and sanctioning in social settings, given that more individuals are privy to the actions of the others. Berardo \& Scholz (2010), for instance, found that closure often results in contexts where institutions are nascent or formal rules are lacking and act to hedge against risk and uncertainty. On the other hand, the WRMS in North Central Washington revealed significant selective assortment among similarly affiliated individuals. This process may occur because individuals are attracted to similar others or because interaction with similar others is easier (Prell 2012). Combined with closure, seeking out like individuals can result in segmented networks divided into distinct clusters, especially when actors preferentially search out others in similar roles or affiliated with similar organizational groups. Burt (2005) argued that certain actors seek to bridge the structural gaps resulting from social clusters, thus serving to connect different domains of practice and knowledge.

Distance played a pivotal role in the formation of work relationships among network actors. Actors working in nearby locations were much more likely to report a working relationship. Generally, partnerships were most common among actors that worked geographically close to one another, tended to work in the same land ownership, and in areas of the landscape with greater fire activity. This triad of influences reflected as much as 10-times greater likelihood of a working relationship. The importance of proximity suggests that many working relationships have emerged organically under 
circumstances that may be difficult to engineer in a top-down fashion. That this effect was strengthened in areas that were fire exchange was greatest, which may point to the emergent capacity building that comes from preparing for and responding to similar fire events. That individuals in the WMRS were able to identify prioritize these locations may also speak to extensive risk mapping products in the region, including numerous Community Wildfire Protection Plans and recent Community Wildfire Assitance and Planning reports.

Contrary to my expectations, working relationships were not influenced by the degree of overlap in the organizational geographies as developed and discussed in Chapter 3. Thus, while I assumed that areas of the landscape where interests are shared among multiple organizational groups would overcome organizational homophily and support cross-organizational work, the data did not support this, at least not in the complete model. When other geographic factors were withheld, I did find that there was a significant positive effect from the correspondence of organizational geography, but the degree of correlation between distance, ownership, fire exchange meant that the individual effect of organizational geography was difficult to isolate. Nonetheless, I take the significant positive effect of organizational overall in the reduced model to indicate that a minor influence of shared geographic interests on working relationships. This finding, in light of the findings from Chapter 3, suggests that there is an opportunity to target areas of shared geographic interest.

Scale is fundamental to many environmental governance problems (Cumming et al. 2006; Folke et al. 2007). I found evidence that organizational actors that operate at 
larger geographic scales were more likely to maintain collaborative relationships than those whose work was more geographically focused. This may suggest that actors that work at larger scales become increasingly dependent on collaborative partnerships, or alternatively, the efforts to increase cross-boundary collaboration have largely focused on regional actors. Differences in working relationships among respondents at different scales also suggest that individuals working in particular areas look to higher-scale actors to coordinate their work at a regional scale. This form of centralization is sometimes referred to as a core-periphery network (Borgatti \& Everett, 1999). Still, the limited sample of local-level actors and the relative lack of collaboration relationships at lower scales may reflect a lack of coordination or horizontal fragmentation at lower-levels that can be improved through various Fire Adapted Community coalitions operating in the area (Butler \& Goldstein 2010).

\section{Conclusion}

Adaptation emerges among multiple centers of agency and authority in society as a relatively self-organized or autonomous process marked by collaboration, social learning, and innovation. Despite historic management regimes based on centralized decision making, self-directed and emergent processes are difficult to direct in an exogenous, top-down fashion. As described in this research, regions exposed to heightened fire risk can show extensive collaboration around risk management, although the need to confirm these findings in other fire-prone hotspots is important. This study looked at the social-ecological network among professionals involved in managing wildfire and wildfire risk. Relationships were influenced by a variety of factors, including 
social context, types of work, and geography. Proximity of past work has a marked influence on collaboration, especially among those working at large scales. Potential fire exchange further encouraged these working relationships, especially when working in similar land ownership. Overlapping risk management tenure did not influence collaboration, suggesting the need for investment to encourage cross-boundary partnerships. 


\section{Figures}

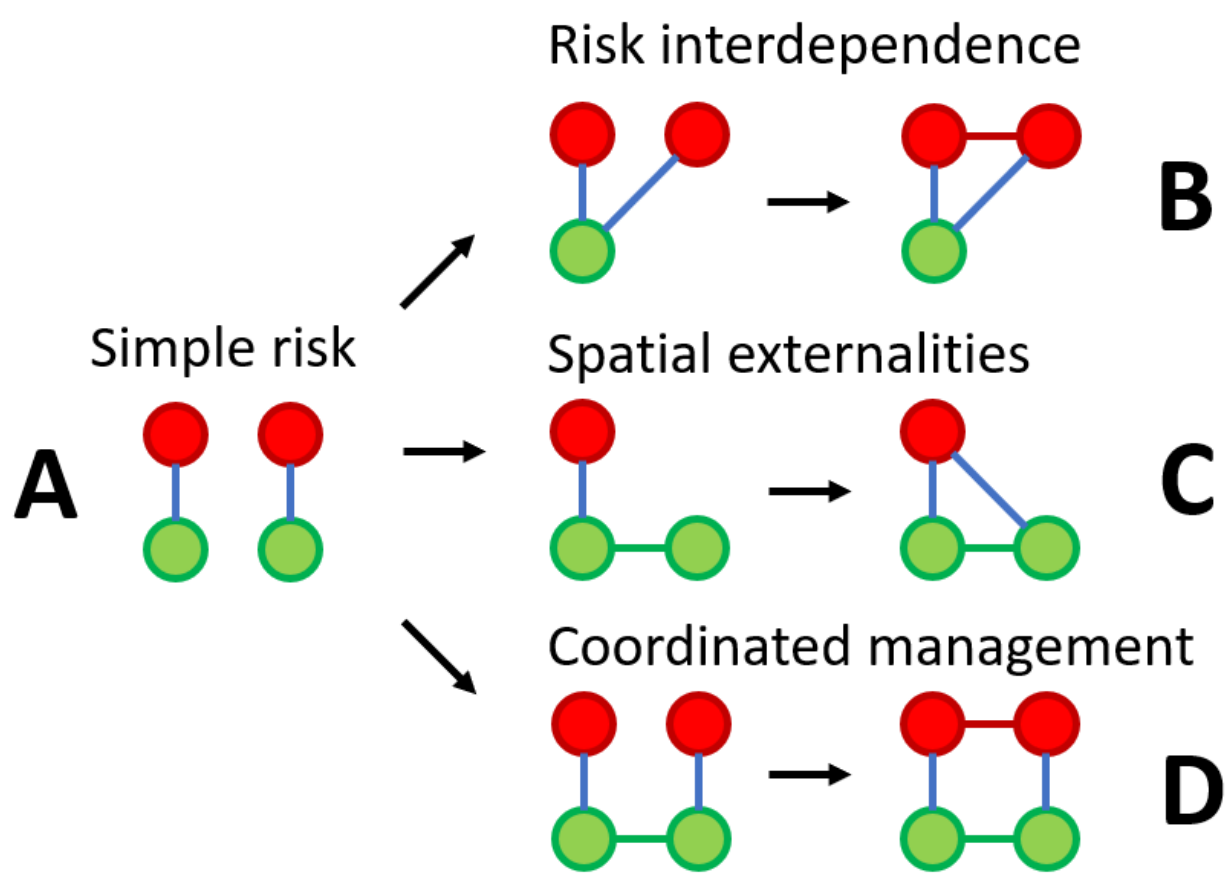

Figure 1. Transformation in the wildfire risk management system as risk moves from the simple $(A)$ to more complex $(B-D)$. Three transformations are illustrated: (B) risk interdependency; (C) spatial externalities, and; (D) coordinated management. 


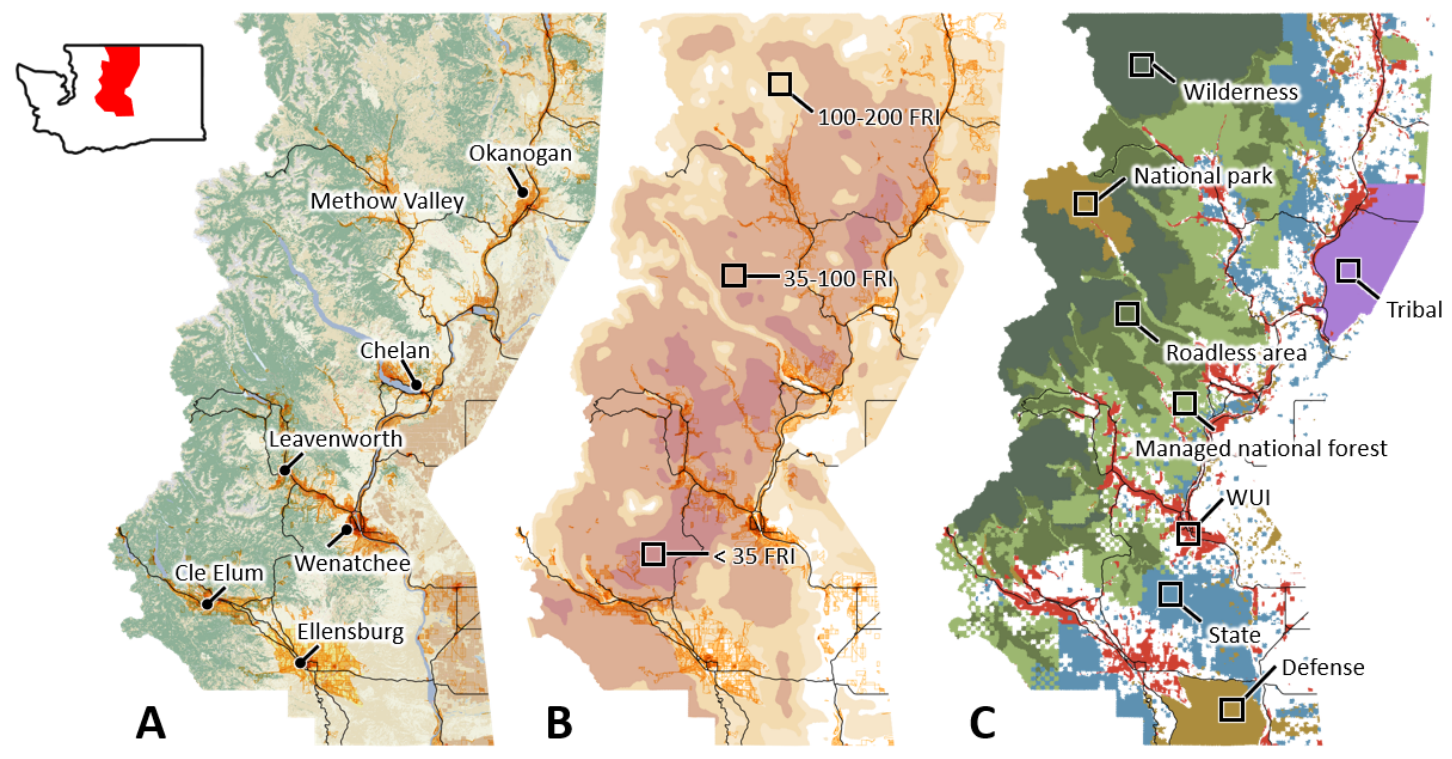

Figure 2. (A) Principal land cover North Central Washington study area shows a mixture of forest and shrubland systems. (B) Fire frequencies vary between 30 and 500 years with the most flammable areas occurring at the transition zone from dryland-forest to open desert-steppe. (C) Land ownership represents a mixture of private and public lands with developed areas occupying valley bottomlands. 


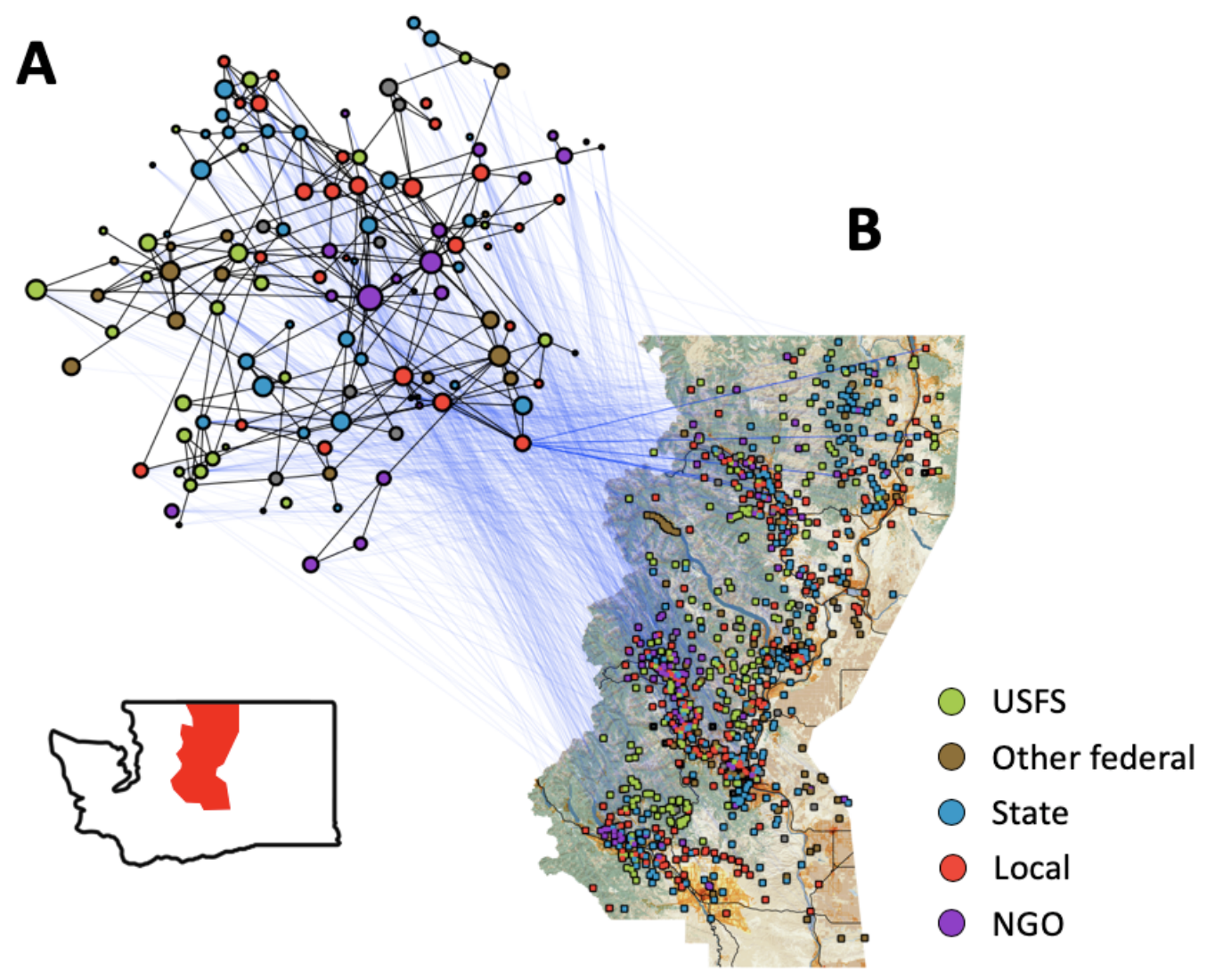

Figure 3. Relationship between the social network and reported work location. Actor-to-actor collaborative work-ties (A) are superimposed over ties that connect the actor to the location of work (B). Social distance in $A$ is implied by the relative distance between actor nodes. 


\section{Conclusion:}

\section{Wildfire Risk Management at the Interface}

This dissertation examined wildfire and wildfire risk management as several interfaces. Wildfire activity is balanced between a variety of environmental constraints, which increasingly include a host of social factors that dictate the context and impact under which fire plays out. Foremost among these contexts in the wildland-urban interface. As a society, we have reached an inflection point where all-out suppression of wildfire has stopped being a viable or even desirable long-term strategy. Increasingly, we need to ask ourselves how we will live with fire. Answers to this question are found at the interface of society and the environment. A brief summary of this research follows.

\section{Summary and contribution of research}

In Chapter 1, I showed that while wildfire activity has expanded substantially over the past quarter-century, the rate of expansion differed substantially by region and vegetation type. Notable for the period, fire activity in the western US has switched from predominantly shrubland-based to predominantly forest-based. Even within forests, the rate at which fire activity has increased varies and was most notable in those forests that historically experience wildfire at longer intervals. Still, fire activity in low-severity fire regime forests remains dominant, representing as much as half of the fire in forests in any given year. This increase is due in part to the legacy of fire suppression and the accumulation of biomass that occurred in its absence. Despite these increases, almost all forest types remain in a persistent fire deficit, and this is especially true in those forests 
where the effects of fire suppression have been greatest. A combination of accumulated fuels, drier and hotter fire seasons, and uncharacteristically intense fire patterns fire may result in a growing portion of these forests converting to shrubland states. Finally, I compared shifts in the fire activity relative to changes in the development patterns in the western US. Over this same period, the western US has nearly doubled in population, resulting in a huge increase in homes built in fire-prone landscapes. I showed how these changes in development have coincided with changes in fire activity, further accelerating the growth of risk in the western US.

Growth fire size has resulted in more fire burning across boundaries. For communities, this requires placing more attention on the surrounding landscape. For land managing agencies like the US Forest Service, reducing wildfire transmission into community is critical for addressing escalating fire suppression costs. Chapter 2 used simulations to assess wildfire exposure to communities in the Western US from wildfire originating on national forests. While the magnitude of the problem seems to defy simple solutions, I showed that community fire exposure originates from a fairly narrow zone of the national forest. Likewise, the vast majority of exposure in concentrated within only $10 \%$ of western communities. I further showed how the social and biophysical conditions within the most highly exposed communities are notably diverse. As a result, the same set of risk mitigation strategies is unlikely to work in all contexts. I identified five distinct exposure archetypes in the western US and tied each to specific national risk management strategies. 
As fire has grown in size and intensity, so too has the number of actors involved in its management. Chapter 3 looked at risk management through the lenses of wildfire risk tenure. I maintained that wildfire risk management reflects part of the larger land tenure system, which in the US is codified in terms of laws pertaining to property rights, nuisance, and liability. Yet, many individuals and organizations that maintain interest in fire risk and impacts which have no formal authority on the impacted lands, yet still maintain critical roles in terms of the work conducted and the capacity to mitigate risk. The research described in Chapter 3 quantified how different organizational groups geographically focus their work in the landscape and compared how these interests relate to ownership boundaries. Perhaps not surprisingly, I found that different organizational groups maintain different geographic ranges, although the wildland urban interface, rather than land ownership boundaries, has become the dominant influence on where most organizations work. What is more, the roles played by different organizational groups appear to differ with respect to the diversity of organizational groups working in a given area. Some organizations appear to assume more specialized roles in areas of high diversity while the roles of others more general. Explicitly mapping where different organizations work shows how ownership boundaries create an incomplete understanding of where managers of wildfire risk operate. Identifying areas of overlapping interests is particularly important in implementing a new generation of federal, state, and local policies and programs that encourage shared stewardship and cross-boundary work.

The diversity of actors involved in wildfire and the degree to which interests in wildfire spans ownership boundaries suggests an increased reliance on collaboration and 
cross-boundary work. Chapter 4 focused on working relationships within the wildfire risk management system in North Central Washington. In particular, I examined who worked with who, and how those relationships are influenced by the specific geographic context of their work. While working networks were clustered by affiliation, there was also strong evidence of cross-organizational work, especially when professionals have worked in nearby locations. This effect was even more pronounced where wildfire risk was high and ownership was less fragmented. While working in similar locations promoted collaborative partnerships, individuals whose management work was narrowly focused on specific geography were less likely to work collaboratively. This suggests a coreperiphery model where regional actors depend on individual projects to build connections with other partners. Collaboration was particularly common among actors conducting educational, administrative, and mitigation activities.

Taken together, this work contributes to our understanding of wildfire risk in a number of ways. I identified significant shifts in fire activity in the western US relative to ecological and social boundaries that continue to shape risk mitigation and forest restoration work. By examining the transmission of fire across boundaries and into communities, I provided a functional definition of the WUI, which describes the social and biophysical context under which wildfire hazards to communities unfold and future risks managed. Based on the observation that exposure is clustered into geographic hotspots, this research documented for the first time the extensive organizational network involved in managing wildfire risk within those regions. Using record of past management activities, I showed how the WUI has an overriding influence on 
management concerns which transcends ownership boundaries. Finally, this research has provided an initial look into the social mechanisms underlying collaboration in fragmented mixed-ownership landscapes.

\section{Future research directions}

Even over the short period of time spent working on this dissertation, it is impressive to see the speed at which research has developed. I am excited to see how the research contained in this dissertation contributes in some small way to that evolution. Still, there are a number of directions that seem particularly important for future work. First is the issue of replication. The second half of this dissertation focused on wildfire risk management in North Central Washington, which represents just one of several dozen hotspots in the Western US. Thus, a critical next step in this work is to replicate this research in other hotspots. The community exposure archetypes presented in Chapter 2 represent a convenient framework for sampling other regions to continue this work. Second is the issue of untangling cause and effect within coupled human-natural systems. The work in North Central Washington made clear the extent to which management capacity depends on learning from past experience. Understanding how wildfire translates into adaption is key. Last is the issue of scale. Understanding cross-scalar linkages are essential. The concept of scale is well developed in landscape ecology where the effect of disturbance at one scale is understood in terms of its impacts at scales both higher and lower. I am fascinated to see the conversation of fire as a coupled humannatural system evolve, and I am hopeful that the lessons learned with regards to fire can 
be transferred to an increasingly broad range of situations in which humans and the environment are inextricably linked.

\section{Concluding remarks}

Wildfire is a remarkably ubiquitous force throughout the globe and one that has always been closely tied to society. It was indeed one of the first and most powerful tools that humans harnessed to shape the landscape to their needs. For much of the twentieth century, wildfire was so aggressively suppressed in the US as to essentially nonexistent in many natural ecosystems and human communities. Owing to a variety of interacting factors - accumulated fuel loads resulting from an extended fire deficit, longer and drier fire seasons, and a growing number of people living in the WUI - wildfire has returned to the Western US with striking rapidity and force. This has created unsettling times, but also a moment of profound novelty and excitement. The question looking forward is: How do we live with fire?

While the research in this dissertation does not answer that question, it does point to trend new ground in directions which such answers may lie. First, for all of its ubiquity, fire is remarkably fluid in terms of conditions under which it occurs. Combined with the vast cast of people, agencies, and organizations that care deeply about fire and its impact, and the variety of forms that fire risk becomes even greater. Nonetheless, there are factors that can be identified that help clarify the specific contexts in which fire occurs and how best it can be managed for and adapted to. While the risk of wildfire is palpable to a growing number of people, the risk itself will always persist as a social construction. As a concept, risk is useful insofar as it provides clarity on decisions and 
the future, but it will always mean different things to different people in different contexts. In doing this research, I have been struck by the degree to which even objective measures of risk become intensely political. It seems increasingly apparent that the answer to living with fire will at least partially emerge through adaptive learning over time, which will inherently be a contested, emergent process. Indeed, there will probably never been a point in which we can say that we have successfully learned to live with fire; it will be a continual process of learning, sharing, and adapting. 


\section{References}

Abatzoglou, J.T. and Kolden, C.A., 2013. Relationships between climate and macroscale area burned in the western United States. International Journal of Wildland Fire, 22(7), pp.1003-1020.

Abatzoglou, J., Williams, P. 2016. Impact of anthropogenic climate change on wildfire across western US forests Proceedings of the National Academy of Sciences. 113(42), 11770-11775. https://dx.doi.org/10.1073/pnas.1607171113

Abrams, J. B., Knapp, M., Paveglio, T. B., Ellison, A., Moseley, C., and Nielsen-Pincus, M. 2015. Re-envisioning community-wildfire relations in the US West as adaptive, 20(3. http://doi.org/10.5751/ES-07848-200334

Abrams, J., Nielsen-Pincus, M., Paveglio, T., Moseley, C. 2015. Community wildfire protection planning in the American West: homogeneity within diversity? Journal of Environmental Planning and Management 59(3), 557-572.

https://dx.doi.org/10.1080/09640568.2015.1030498

Ager, A.A., Barros, A.M., Preisler, H.K., Day, M.A., Spies, T.A., Bailey, J.D. and Bolte, J.P., 2017. Effects of accelerated wildfire on future fire regimes and implications for the United States federal fire policy. Ecology and Society. 22 (4): 12., 22(4), p.12.

Ager, A. A., Evers, C. R., Day, M. A., Preisler, H. K. H. K., Barros, A. M., and NielsenPincus, M. 2017. Network analysis of wildfire transmission and implications for 
risk governance. PLoS ONE, 12(3), 1-28.

http://doi.org/10.1371/journal.pone.0172867

Ager, A. A., Kline, J. D., and Fischer, A. P. 2015. Coupling the Biophysical and Social Dimensions of Wildfire Risk to Improve Wildfire Mitigation Planning. Risk Analysis, 35(8), 1393-1406.

Ager, A.A., McMahan, A.J., Barrett, J.J. and McHugh, C.W., 2007. A simulation study of thinning and fuel treatments on a wildland-urban interface in eastern Oregon, USA. Landscape and Urban Planning, 80(3), pp.292-300.

Ager, A., Palaiologou, P., Evers, C., Day, M., Ringo, C., Short, K. 2019. Wildfire exposure to the wildland urban interface in the western US. Applied Geography. https://doi.org/10.1016/j.apgeog.2019.102059

Alcasena, F. J., Evers, C. R., and Vega-Garcia, C. 2018. The wildland-urban interface raster dataset of Catalonia. Data in Brief, 17. http://doi.org/10.1016/j.dib.2017.12.066

Alexandre, P.M., Stewart, S.I., Keuler, N.S., Clayton, M.K., Mockrin, M.H., BarMassada, A., Syphard, A.D. and Radeloff, V.C., 2016. Factors related to building loss due to wildfires in the conterminous United States. Ecological applications, 26(7), pp.2323-2338.

Alexandre, P.M., Stewart, S.I., Mockrin, M.H., Keuler, N.S., Syphard, A.D., BarMassada, A., Clayton, M.K. and Radeloff, V.C., 2016. The relative impacts of vegetation, topography and spatial arrangement on building loss to wildfires in case studies of California and Colorado. Landscape Ecology, 31(2), pp.415-430. 
Ansell, C. and Gash, A., 2008. Collaborative governance in theory and practice. Journal of public administration research and theory, 18(4), pp.543-571.

Argañaraz, J. P., Radeloff, V. C., Bar-Massada, A., Gavier-Pizarro, G. I., Scavuzzo, C. M., and Bellis, L. M. 2017. Assessing wildfire exposure in the Wildland-Urban Interface area of the mountains of central Argentina. Journal of Environmental Management, 196, 499-510. http://doi.org/10.1016/j.jenvman.2017.03.058

Bar-Massada, A., Stewart, S. I., Hammer, R. B., Mockrin, M. H., and Radeloff, V. C. 2013. Using structure locations as a basis for mapping the wildland urban interface. Journal of Environmental Management. http://doi.org/10.1016/j.jenvman.2013.06.021

Barnett, K.; Parks, S.A.; Miller, C.; Naughton, H.T. Beyond fuel treatment effectiveness: Characterizing interactions between fire and treatments in the US. Forests 2016, $7,237$.

Barrett, S., Havlina, D., Jones, J., Hann, W.J., Frame, C., Hamilton, D., Schon, K., DeMeo, T., Hutter, L., Menakis, J., 2010. Interagency Fire Regime Condition Class (FRCC) Guidebook, version 3.0. In: USDA Forest Service, US Department of the Interior, and The Nature Conservancy.

Baum, J., Shipilov, A. 2006. The SAGE Handbook of Organization Studies https://dx.doi.org/10.4135/9781848608030.n3

Berardo, Ramiro, and John T. Scholz. 2010. Self-Organizing Policy Networks: Risk, Partner Selection, and Cooperation in Estuaries. American Journal of Political Science 54(3): 632-49. 
Bodin, O., 2017. Collaborative environmental governance: Achieving collective action in social-ecological systems. Science (New York, N.Y.) 357.

https://doi.org/10.1126/science.aan1114

Bodin, O., Crona, B., Thyresson, M., Golz, A.-L.L., Tengö, M., 2014. Conservation success as a function of good alignment of social and ecological structures and processes. Conservation biology : the journal of the Society for Conservation Biology 28, 1371-9. https://doi.org/10.1111/cobi.12306

Bodin, Ö., Robins, G., McAllister, R., Guerrero, A., Crona, B., Tengö, M., Lubell, M. 2016. Theorizing benefits and constraints in collaborative environmental governance: a transdisciplinary social-ecological network approach for empirical investigations Ecology and Society 21(1) https://dx.doi.org/10.5751/ES-08368210140

Borgatti, S.P., Everett, M.G., 1999. Models of core/periphery structures. Social Networks 21, 375-395.

Bowman, D., Balch, J., Artaxo, P., Bond, W., Cochrane, M., D'Antonio, C., Defries, R., Johnston, F., Keeley, J., Krawchuk, M., Kull, C., Mack, M., Moritz, M., Pyne, S., Roos, C., Scott, A., Sodhi, N., Swetnam, T., Whittaker, R. 2011. The human dimension of fire regimes on Earth Journal of Biogeography 38(12), 2223-2236. https://dx.doi.org/10.1111/j.1365-2699.2011.02595.x

Bradshaw, K.M., 2010. A modern overview of wildfire law. Fordham Environmental Law Review, 21, p.445. 
Burby, R. J. 2006. Katrina and the Government Disaster Policy: The Annals of the American Academy of Political and Social Science, (March), 171-191. http://doi.org/10.1177/0002716205284676

Bureau of the Census. 2008. Federal Register: Census Designated Place (CDP) Program for the 2010 Census-Final Criteria. Retrieved from https://www.federalregister.gov/documents/2008/02/13/E8-2667/censusdesignated-place-cdp-program-for-the-2010-census-final-criteria

Burt, Ronald. 2005. Brokerage and Closure: An Introduction to Social Capital. New York: Oxford University Press.

Busby, G.M., Albers, H.J. and Montgomery, C.A., 2012. Wildfire risk management in a landscape with fragmented ownership and spatial interactions. Land Economics, 88(3), pp.496-517.

Butler, W., Goldstein, B. 2010. The US Fire Learning Network: springing a rigidity trap through multiscalar collaborative networks

Butts, C.T., 2012. Space and Structure: Methods and Models for Large-Scale Interpersonal Networks.

Calkin, D. E., Cohen, J. D., Finney, M. A., and Thompson, M. P. 2014. How risk management can prevent future wildfire disasters in the wildland-urban interface. Proceedings of the National Academy of Sciences, 111(2), 746-751. http://doi.org/10.1073/pnas.1315088111 
Calkin, D. E., Thompson, M. P., and Finney, M. A. 2015. Negative consequences of positive feedbacks in US wildfire management. Forest Ecosystems, $2(9$. http://doi.org/10.1186/s40663-015-0033-8

Carto (2019), GitHub repository, https://github.com/CartoDB/cartodb

Champ, P. 2017. Adapting to wildfire: Moving beyond homeowner risk perceptions to taking action. In: Laney, Kara N. A century of wildland fire research: Contributions to long-term approaches for wildland fire management: Proceedings of a workshop. Washington, DC: The National Academies Press. p. 67-72. pp. 67-72).

Chas-Amil, M. L., Touza, J., and García-Martínez, E. 2013. Forest fires in the wildlandurban interface: A spatial analysis of forest fragmentation and human impacts. Applied Geography, 43, 127-137. http://doi.org/10.1016/j.apgeog.2013.06.010

Chumstick Wildfire Stewardship Coalition (CWSC. 2019. Website accessed on Nov 1, 2019. https://www.chumstickcoalition.org/about-us

Cohen, J. D. 2000. Preventing Disaster: Home Ignitability in the Wildland-Urban Interface. Journal of Forestry, 98(3), 15-21. Retrieved from https://academic.oup.com/jof/article/98/3/15/4614212

Cohen, J. D. 2010. The Wildland-Urban Interface Fire Problem. Fremontia, 38, 16-20. Retrieved from https://www.fs.fed.us/rm/pubs_other/rmrs_2010_cohen_j002.pdf Cumming, G. S., Cumming, D. H. M., and Redman, C. L. 2006. Scale Mismatches in Social-Ecological Systems: Causes, Consequences, and Solutions. Ecology and Society, 11(1). 
Cumming, G.S., Olsson, P., Chapin, F.S. and Holling, C.S., 2013. Resilience, experimentation, and scale mismatches in social-ecological landscapes. Landscape Ecology, 28(6), pp.1139-1150.

DeCaro, D.A., Chaffin, B.C., Schlager, E., Garmestani, A.S. and Ruhl, J.B., 2017. Legal and institutional foundations of adaptive environmental governance. Ecology and society: A journal of integrative science for resilience and sustainability, 22(1), p.1.

Del Casino Jr, V.J., Grimes, A.J., Hanna, S.P. and Jones Iii, J.P., 2000. Methodological frameworks for the geography of organizations. Geoforum, 31(4), pp.523-538.

Dennison, P., Brewer, S., Arnold, J., Moritz, M. 2014. Large wildfire trends in the western United States, 1984-2011 Geophysical Research Letters. 41(8), 29282933. https://dx.doi.org/10.1002/2014GL059576

Dickinson, K., Brenkert-Smith, H., Champ, P. and Flores, N., 2015. Catching fire? Social interactions, beliefs, and wildfire risk mitigation behaviors. Society and Natural Resources, 28(8), pp.807-824.

Dormann, C. F. 2011. Modeling species' distributions. - In: Jopp, F. et al. eds), Modelling complex ecological dynamics. Springer, pp. 179-196.

Duit, A. and Galaz, V., 2008. Governance and complexity-emerging issues for governance theory. Governance, 21(3), pp.311-335.

Emirbayer, M. 1997. Manifesto for a Relational Sociology American Journal of Sociology. 103 (2), 281-317. https://dx.doi.org/10.1086/231209 
Enright, N.J., Fontaine, J.B., Bowman, D.M., Bradstock, R.A. and Williams, R.J., 2015. Interval squeeze: altered fire regimes and demographic responses interact to threaten woody species persistence as climate changes. Frontiers in Ecology and the Environment, 13(5), pp.265-272.

Epstein, G., J. Pittman, S. M. Alexander, S. Berdej, T. Dyck, U. Kreitmair, K. J. Raithwell, S. Villamayor-Tomas, J. Vogt, and D. Armitage. 2015. Institutional fit and the sustainability of social-ecological systems. Current Opinion in Environmental Sustainability 14:34-40.

http://dx.doi.org/10.1016/j.cosust.2015.03.005

Erickson, Bonnie H. 1979 "Some problems of inference from chain data." Sociological Methodology 10:276-302.

ESRI. 2012. North America Detailed Streets. Retrieved June 14, 2018, from https://www.arcgis.com/home/item.html?id=f38b87cc295541fb88513d1ed7cec9f d

Evers, C.R., Ager, A.A., Nielsen-Pincus, M., Palaiologou, P. and Bunzel, K., 2019. Archetypes of community wildfire exposure from national forests of the western US. Landscape and urban planning, 182, pp.55-66.

Fielding, A. H., Bell, J. F. 1997. A review of methods for the assessment of prediction errors in conservation presence/absence models. Environ. Conserv.

Finco, M., Quayle, B., Zhang, Y., Lecker, J., Megown, K. A., and Brewer, C. K. 2012. Monitoring trends and burn severity (MTBS): monitoring wildfire activity for the past quarter-century using Landsat data: Morin, Randall S.; Liknes, Greg C., 
comps. Moving from status to trends: Forest Inventory and Analysis (FIA) symposium 2012; 2012 December 4-6; Baltimore, MD. Gen. Tech. Rep. NRS-P105. Newtown Square, PA: U.S. Department of Agriculture, Forest Service, Northern Research Station. pp. 222-228.

Finney, M. A., Grenfell, I. C., McHugh, C. W., Seli, R. C., Trethewey, D., Stratton, R. D., and Brittain, S. 2011. A Method for Ensemble Wildland Fire Simulation. Environmental Modeling and Assessment, 16(2), 153-167. http://doi.org/10.1007/s10666-010-9241-3

Finney, M. A., McHugh, C. W., Grenfell, I. C., Riley, K. L., and Short, K. C. 2011. A simulation of probabilistic wildfire risk components for the continental United States. Stochastic Environmental Research and Risk Assessment, 25(7), 9731000. http://doi.org/10.1007/s00477-011-0462-z

Fire Adapted Communities Coalition. Guide to Fire Adapted Communities (2014. Retrieved from http://www.forestinfo.org/land_use_pdfs/fac-reference-guide2014-final.pdf

Fischer, A.P. and Charnley, S., 2012. Risk and cooperation: managing hazardous fuel in mixed ownership landscapes. Environmental Management, 49(6), pp.1192-1207.

Fischer, A. P., and Jasny, L. 2017. Capacity to adapt to environmental change: Evidence from a network of organizations concerned with increasing wildfire risk. Ecology and Society, 22(1. http://doi.org/10.5751/ES-08867-220123

Fischer, P., Spies, T., Steelman, T., Moseley, C., Johnson, B., Bailey, J., Ager, A., Bourgeron, P., Charnley, S., Collins, B., Kline, J., Leahy, J., Littell, J., Millington, 
J., Nielsen-Pincus, M., Olsen, C., Paveglio, T., Roos, C., Steen-Adams, M., Stevens, F., Vukomanovic, J., White, E., Bowman, D. 2016. Wildfire risk as a socioecological pathology. Frontiers in Ecology and the Environment. 14(5), 276284. https://dx.doi.org/10.1002/fee. 1283

Fischer, A. P., Vance-Borland, K., Jasny, L., Grimm, K. E., and Charnley, S. 2016. A network approach to assessing social capacity for landscape planning: The case of fire-prone forests in Oregon, USA. Landscape and Urban Planning, 147, 18-27. http://doi.org/10.1016/j.landurbplan.2015.10.006

Folke, C., Pritchard Jr, L., Berkes, F., Colding, J. and Svedin, U., 2007. The problem of fit between ecosystems and institutions: ten years later. Ecology and Society, 12(1).

Gibbons, P., Linda van Bommel, A., Cary, G.J., Driscoll, D.A., Bradstock, R.A., Knight, E., Moritz, M.A., Stephens, S.L. and Lindenmayer, D.B., 2012. Land management practices associated with house loss in wildfires. PloS one, 7(1).

Gill, A. M., Stephens, S. L., and Cary, G. J. 2013. The worldwide "wildfire" problem. Ecological Applications, 23(2. http://doi.org/10.1890/10-2213.1

Goldstein, B. E., Butler, W. H., and Hull, R. B. 2010. The fire learning network: A promising conservation strategy for forestry. Journal of Forestry, 108(3), 120-125. Retrieved from http://www.scopus.com/inward/record.url?eid=2-s2.077951895729andpartnerID=40andmd5=597bfb43c7be $17 f f 6 c 9 c 6 e 4 e a 40 b 08 d 0$ 
Halofsky, J.S., Donato, D.C., Franklin, J.F., Halofsky, J.E., Peterson, D.L. and Harvey, B.J., 2018. The nature of the beast: examining climate adaptation options in forests with stand-replacing fire regimes. Ecosphere, 9(3), p.e02140.

Hamilton, M., Fischer, A., Ager, A. 2019. A social-ecological network approach for understanding wildfire risk governance Global Environmental Change. 54, 113123. https://dx.doi.org/10.1016/j.gloenvcha.2018.11.007

Hammer, R. B., Stewart, S. I., and Radeloff, V. C. 2009. Demographic Trends, the Wildland-Urban Interface, and Wildfire Management. Society and Natural Resources, 22(8), 777-782. http://doi.org/10.1080/08941920802714042

Handcock MS, Hunter DR, Butts CT, Goodreau SM, Morris M (2003b. statnet: Software Tools for the Statistical Modeling of Network Data. Statnet Project, Seattle, WA. Version 2, http://www.statnetproject.org.

Hannan, M., Freeman, J. 1977. The Population Ecology of Organizations American Journal of Sociology 82(5), 929-964. https://dx.doi.org/10.1086/226424

Haugo, R., Kellogg, B., Cansler, A., Kolden, C., Kemp, K., Robertson, J., Metlen, K., Vaillant, N., Restaino, C. 2019. The missing fire: quantifying human exclusion of wildfire in Pacific Northwest forests, USA Ecosphere. 10(4), e02702. https://dx.doi.org/10.1002/ecs2.2702

Headwaters Economics. 2016. Land use planning to reduce wildfire risk: lessons from five western cities. 
Heckathorn, D.D., 2002. Respondent-driven sampling II: deriving valid population estimates from chain-referral samples of hidden populations. Social problems, 49(1), pp.11-34.

Hessburg, P.F. and Agee, J.K., 2003. An environmental narrative of inland northwest United States forests, 1800-2000. Forest Ecology and Management, 178(1-2), pp.23-59.

Hessburg, P.F., Miller, C.L., Povak, N.A., Taylor, A.H., Higuera, P.E., Prichard, S.J., North, M.P., Collins, B.M., Hurteau, M.D., Larson, A.J. and Allen, C.D., 2019. Climate, Environment, and Disturbance History Govern Resilience of Western North American Forests. Frontiers in Ecology and Evolution, 7, p.239.

Hessburg, P.F., Spies, T.A., Perry, D.A., Skinner, C.N., Taylor, A.H., Brown, P.M., Stephens, S.L., Larson, A.J., Churchill, D.J., Povak, N.A. and Singleton, P.H., 2016. Tamm review: management of mixed-severity fire regime forests in Oregon, Washington, and Northern California. Forest Ecology and Management, 366, pp.221-250.

Heyerdahl, E.K., McKenzie, D., Daniels, L.D., Hessl, A.E., Littell, J.S. and Mantua, N.J., 2008. Climate drivers of regionally synchronous fires in the inland Northwest (1651-1900. International Journal of Wildland Fire, 17(1), pp.40-49.

Holsinger L, Keane RE, Parsons RA, Karau E. 2006. Development of biophysical gradient layers for the LANDFIRE prototype project. In 'The LANDFIRE Prototype Project: Nationally Consistent and Locally Relevant Geospatial Data for Wildland Fire Management'. Eds MG Rollins, CK Frame) USDA Forest 
Service, Rocky Moun-tain Research Station, General Technical Report RMRSGTR-175, pp. 99-122. Fort Collins, CO) Available at http://www.fs.fed.us/rm/pubs/rmrs_gtr175/rmrs_gtr175_099_122.pdf [Verified April 2008]

Hosmer Jr, D.W., Lemeshow, S. and Sturdivant, R.X., 2013. Applied logistic regression (Vol. 398. John Wiley and Sons. Pp. 160-164

Hulse, D., Branscomb, A., Enright, C., Johnson, B., Evers, C., Bolte, J. and Ager, A., 2016. Anticipating surprise: Using agent-based alternative futures simulation modeling to identify and map surprising fires in the Willamette Valley, Oregon USA. Landscape and Urban Planning, 156, pp.26-43.

Imperial, M.T., 2005. Using collaboration as a governance strategy: Lessons from six watershed management programs. Administration and Society, 37(3), pp.281-320.

Jakes, P. J., Nelson, K. C., Enzler, S. A., Burns, S., Cheng, A. S., Sturtevant, V., ... Staychock, E. 2011. Community wildfire protection planning: Is the Healthy Forests Restoration Act's vagueness genius? International Journal of Wildland Fire, 20(3), 350-363. http://doi.org/10.1071/WF10038

Johnston, L. M., and Flannigan, M. D. 2018. Mapping Canadian wildland fire interface areas. International Journal of Wildland Fire, 27(1), 1-14. http://doi.org/10.1071/WF16221

Johnstone, J. F., Allen, C. D., Franklin, J. F., Frelich, L. E., Harvey, B. J., Higuera, P. E., Mack, M. C., Meentemeyer, R. K., Metz, M. R., Perry, G. L. and Schoennagel, T., 
2016. Changing disturbance regimes, ecological memory, and forest resilience. Frontiers in Ecology and the Environment, 14(7), pp.369-378.

Jolliffe, I. T. 2002. Principal Component Analysis, Second Edition. Springer. Retrieved from http://cda.psych.uiuc.edu/statistical_learning_course/Jolliffe I. Principal Component Analysis (2ed., Springer, 2002) (518s)

Jones, C., Hesterly, W.S. and Borgatti, S.P., 1997. A general theory of network governance: Exchange conditions and social mechanisms. Academy of management review, 22(4), pp.911-945.

Kaufman, L., and Rousseeuw, P. J. Eds. 1990. Finding Groups in Data. Hoboken, NJ, USA: John Wiley and Sons, Inc. http://doi.org/10.1002/9780470316801

Keane RE, Hessburg PF, Landres PB, Swanson FJ (2009) The use of historical range and variability (HRV) in landscape management. Forest Ecology and Management 258:1025-1037.

Keeley, J. E., Syphard, A. D., and Fotheringham, C. J. 2008. The 2003 and 2007 wildfires in Southern California. Natural Disasters and Adaptation to Climate Change. http://doi.org/10.1017/CBO9780511845710.007

Krawchuk, M.A., and Moritz, M.A., 2011. Constraints on global fire activity vary across a resource gradient. Ecology, 92(1), pp.121-132.

Krawchuk, M., Moritz, M., Parisien, M., Dorn, J., Hayhoe, K. 2009. Global Pyrogeography: The Current and Future Distribution of Wildfire. PLoS ONE 4(4), e5102. https://dx.doi.org/10.1371/journal.pone.0005102 
Lampin-Maillet, C., Jappiot, M., Long, M., Bouillon, C., Morge, D., and Ferrier, J. P. 2010. Mapping wildland-urban interfaces at large scales integrating housing density and vegetation aggregation for fire prevention in the South of France. Journal of Environmental Management, 91(3), 732-741. http://doi.org/10.1016/j.jenvman.2009.10.001

Landres, P.B., Morgan, P. and Swanson, F.J., 1999. Overview of the use of natural variability concepts in managing ecological systems. Ecological Applications, 9(4), pp.1179-1188.

Lidskog, R., Soneryd, L., and Uggla, Y. 2010. Transboundary Risk Governance. Earthscan.

Littell, J. 2018. Drought and Fire in the Western USA: Is Climate Attribution Enough? Current Climate Change Reports. 4(4), 396-406. https://dx.doi.org/10.1007/s40641-018-0109-y

Littell, J., McKenzie, D., Peterson, D., Westerling, A. 2009. Climate and wildfire area burned in western US ecoprovinces, 1916-2003 Ecological Applications https://dx.doi.org/10.1890/07-1183.1

Liu, Z., Wimberly, M. 2015. Climatic and Landscape Influences on Fire Regimes from 1984 to 2010 in the Western United States PLOS ONE 10(10), e0140839. https://dx.doi.org/10.1371/journal.pone.0140839

Maechler, M., Rousseeuw, P., Struyf, A., Hubert, M., Hornik, K., Studer, M., and Roudier, P. 2015. cluster: Finding Groups in Data: Cluster Analysis Extended. 
Partitioning Around Medoids. R Package Version 2.0.3. Retrieved from https://stat.ethz.ch/R-manual/R-devel/library/cluster/html/pam.html

McCaffrey, S. 2004. Thinking of Wildfire as a Natural Hazard. Society and Natural

Resources, 17(6), 509-516. http://doi.org/10.1080/08941920490452445

McCaffrey, S. 2008. Understanding public perspectives of wildfire risk. Wildfire Risk, Human Perceptions and Management Implications, 11-22. http://doi.org/10.4324/9781936331611

McKenzie, D., Littell, J. 2017. Climate change and the eco-hydrology of fire: Will area burned increase in a warming western USA? Ecological Applications. 27(1), 2636. https://dx.doi.org/10.1002/eap.1420

Mileti, D. 1999. Disasters by Design: A Reassessment of Natural Hazards in the United States. Natural Hazards. Washington, DC: John Henry Press. http://doi.org/ISBN: $0-309-51849-0$

Modugno, S., Balzter, H., Cole, B., and Borrelli, P. 2016. Mapping regional patterns of large forest fires in Wildland-Urban Interface areas in Europe. Journal of Environmental Management, 172, 112-126. http://doi.org/10.1016/j.jenvman.2016.02.013

Monti, S., Tamayo, P., Mesirov, J., and Golub, T. 2003. Consensus clustering: A resampling-based method for class discovery and visualization of gene expression microarray data. Machine Learning, 52(1-2), 91-118. http://doi.org/10.1023/A:1023949509487 
Moritz, M., Batllori, E., Bradstock, R., Gill, M., Handmer, J., Hessburg, P., Leonard, J., McCaffrey, S., Odion, D., Schoennagel, T., Syphard, A. 2014. Learning to coexist with wildfire. Nature. 515(7525). p.58. https://dx.doi.org/10.1038/nature13946

Moritz, M. A., and Knowles, S. G. 2016. Coexisting with Wildfire. American Scientist, 104(4), 220. http://doi.org/10.1511/2016.121.220

Moritz, M.A, Hurteau, M.D., Suding, K.N. and D'Antonio, C.M., 2013. Bounded ranges of variation as a framework for future conservation and fire management. Annals of the New York Academy of Sciences, 1286(1), pp.92-107.

MTBS Fire Level Geospatial Data. 2018, Aug - last revised. MTBS Project (USDA Forest Service/U.S. Geological Survey. Available online: http://mtbs.gov/directdownload [2018, Oct 1st].

Nielsen-Pincus, M., Evers, C., Moseley, C., Huber-Stearns, H. and Bixler, R.P., 2018. Local capacity to engage in federal wildfire suppression efforts: An explanation of variability in local capture of suppression contracts. Forest Science, 64(5), pp.480-490.

Nielsen-Pincus, M., Goldberg, C. S., Pocewicz, A., Force, J. E., Waits, L. P., Morgan, P., and Vierling, L. 2010. Predicted effects of residential development on a northern Idaho landscape under alternative growth management and land protection policies. Landscape and Urban Planning, 94(3-4), 255-263.

http://doi.org/10.1016/J.LANDURBPLAN.2009.10.011 
Nielsen-Pincus, M., Moseley, C. and Gebert, K., 2013. The effects of large wildfires on employment and wage growth and volatility in the western United States. Journal of Forestry, 111(6), pp.404-411.

Nielsen-Pincus, M., Ribe, R. G., and Johnson, B. R. 2015. Spatially and socially segmenting private landowner motivations, properties, and management: A typology for the wildland urban interface. Landscape and Urban Planning, 137, 112. http://doi.org/10.1016/j.landurbplan.2014.11.020

North, M. P., Brough, A., Long, J., Collins, B., Bowden, P., Yasuda, D., ... Sugihara, N. 2015. Constraints on Mechanized Treatment Significantly Limit Mechanical Fuels Reduction Extent in the Sierra Nevada. Journal of Forestry, 113(January. http://doi.org/10.5849/jof.14-058

North, M. P., Stephens, S. L., Collins, B. M., Agee, J. K., Aplet, G., Franklin, J. F., and Fulé, P. Z. 2015. Reform forest fire management: Agency incentives undermine policy effectiveness. Science, 349(6254).

Nowell, B. L., Steelman, T. A., Velez, A. L. K., and Godette, S. K. 2017. Perspective Matters: The Challenges of Performance Measurement in Wildfire Response Networks. In Social Network Analysis of Disaster Response, Recovery, and Adaptation (pp. 59-73. Butterworth-Heinemann.

O'Connor, B. P. 2000. SPSS and SAS programs for determining the number of components using parallel analysis and Velicer's MAP test. Behavior Research Methods, Instruments, and Computers, 32(3), 396-402. http://doi.org/10.3758/BF03200807 
OIG. 2016. Forest Service Wildland Fire Activities - Hazardous Fuels Reduction.

Retrieved from https:/www.usda.gov/oig/webdocs/08601-0004-41.pdf

Palaiologou, P., Ager, A., Evers, C., Nielsen-Pincus, M., Day, M., Ringo, C., Preisler, K. 2019. Natural Hazards Earth Systems Science (19). 1755-1777.

https://doi.org/10.5194/nhess-19-1755-2019

Palaiologou, P., Ager, A.A., Evers, C.R., Nielsen-Pincus, M., Day, M.A. and Preisler, H.K., 2019. Fine-scale assessment of cross-boundary wildfire events in the western United States.

Parks, S., Miller, C., Parisien, M., Holsinger, L., Dobrowski, S., Abatzoglou, J. 2015. Wildland fire deficit and surplus in the western United States, 1984-2012 Ecosphere 6(12). 1-13. https://dx.doi.org/10.1890/ES15-00294.1

Parks, S., Miller, C., Holsinger, L.M., Baggett, L.S. and Bird, B.J., 2016. Wildland fire limits subsequent fire occurrence. International Journal of Wildland Fire, 25(2), pp.182-190.

Paveglio, T. B., Carroll, M. S., Stasiewicz, A. M., Williams, D. R., and Becker, D. R. 2018. Incorporating Social Diversity into Wildfire Management: Proposing "Pathways" for Fire Adaptation. Forest Science. http://doi.org/10.1093/forsci/fxy005

Paveglio, T. B., Moseley, C., Carroll, M. S., Williams, D. R., Davis, E. J., and Fischer, A. P. 2015. Categorizing the social context of the wildland urban interface: Adaptive capacity for wildfire and community "Archetypes." Forest Science, 61(2). 
Price, O., and Bradstock, R. 2014. Countervailing effects of urbanization and vegetation extent on fire frequency on the Wildland urban interface: Disentangling fuel and ignition effects. Landscape and Urban Planning.

http://doi.org/10.1016/j.landurbplan.2014.06.013

Perry, D.A., Hessburg, P.F., Skinner, C.N., Spies, T.A., Stephens, S.L., Taylor, A.H., Franklin, J.F., McComb, B. and Riegel, G., 2011. The ecology of mixed severity fire regimes in Washington, Oregon, and Northern California. Forest Ecology and Management, 262(5), pp.703-717.

Picotte, J., Peterson, B., Meier, G., Howard, S. 2016. 1984-2010 trends in fire burn severity and area for the conterminous US International Journal of Wildland Fire. 25(4), 413-420. https://dx.doi.org/10.1071/wf15039

Pilliod, D.S., Welty, J.L. and Arkle, R.S., 2017. Refining the cheatgrass-fire cycle in the Great Basin: Precipitation timing and fine fuel composition predict wildfire trends. Ecology and Evolution, 7(19), pp.8126-8151.

Powell, W., 2003. Neither market nor hierarchy. The sociology of organizations: classic, contemporary, and critical readings, 315, pp.104-117.

Prell, C., 2012. Social network analysis: History, theory and methodology. Sage.

Radeloff, V. C., Hammer, R. B., Stewart, S. I., Fried, J. S., Holcomb, S. S., and Mckeefry, J. F. 2005. The wildland-urban interface in the United States. Ecological Applications, 15(3), 799-805. http://doi.org/10.1890/04-1413 Radeloff, V., Helmers, D., Kramer, A., Mockrin, M., Alexandre, P., Bar-Massada, A., Butsic, V., Hawbaker, T., Martinuzzi, S., Syphard, A., Stewart, S. 2018. Rapid 
growth of the US wildland-urban interface raises wildfire risk Proceedings of the National Academy of Sciences. 115(13), 201718850.

https://dx.doi.org/10.1073/pnas.1718850115

Radeloff, Volker C.; Helmers, David P.; Kramer, H. Anu; Mockrin, Miranda H.; Alexandre, Patricia M.; Bar Massada, Avi; Butsic, Van; Hawbaker, Todd J.; Martinuzzi, Sebastián; Syphard, Alexandra D.; Stewart, Susan I. 2017. The 19902010 wildland-urban interface of the conterminous United States - geospatial data. 2nd Edition. Fort Collins, CO: Forest Service Research Data Archive. https://doi.org/10.2737/RDS-2015-0012-2

Reilly, M., Dunn, C., Meigs, G., Spies, T., Kennedy, R., Bailey, J., Briggs, K. 2017. Contemporary patterns of fire extent and severity in forests of the Pacific Northwest, USA (1985-2010) Ecosphere 8(3), e01695. https://dx.doi.org/10.1002/ecs2.1695

Revelle, W. 2016. psych: Procedures for Personality and Psychological Research. R Package, 1-358. Retrieved from http://personality-project.org/r/psych-manual.pdf Rollins, M. G. 2009. LANDFIRE: A nationally consistent vegetation, wildland fire, and fuel assessment. International Journal of Wildland Fire, 18(3), 235-249. http://doi.org/10.1071/WF08088

Sayles, J.S., Baggio, J.A., 2017. Social-ecological network analysis of scale mismatches in estuary watershed restoration. Proceedings of the National Academy of Sciences 114, E1776-E1785. https://doi.org/10.1073/pnas.1604405114 
Schoennagel, T., Balch, J. K., Brenkert-Smith, H., Dennison, P. E., Harvey, B. J., Krawchuk, M. A., ... Whitlock, C. 2017. Adapt to more wildfire in western North American forests as climate changes. Proceedings of the National Academy of Sciences, 114(18), 4582-4590. http://doi.org/10.1073/pnas.1617464114

Schoennagel, T., Nelson, C. 2011. Restoration relevance of recent National Fire Plan treatments in forests of the western United States Frontiers in Ecology and the Environment. 9(5), 271-277. https://dx.doi.org/10.1890/090199

Schoennagel, T., Nelson, C. R., Theobald, D. M., Carnwath, G. C., and Chapman, T. B. 2009. Implementation of National Fire Plan treatments near the wildland-urban interface in the western United States. Proceedings of the National Academy of Sciences of the United States of America, 106(26), 10706-10711. http://doi.org/10.1073/pnas.0900991106

Schoennagel, T., Veblen, T. T., and Romme, W. H. 2004. The Interaction of Fire, Fuels, and Climate across Rocky Mountain Forests. BioScience, 54(7), 661. http://doi.org/10.1641/0006-3568(2004)054[0661:TIOFFA]2.0.CO;2

Scott, J. H., and Burgan, R. E. 2005. Standard Fire Behavior Fuel Models: A Comprehensive Set for Use with Rothermel' s Surface Fire Spread Model. General Technical Report RMRS-GTR-153, (June), 1-80. http://doi.org/U.S Forest Service General Technical Report RMRS-GTR-153

Seidl, R., Spies, T.A., Peterson, D.L., Stephens, S.L. and Hicke, J.A., 2016. Searching for resilience: addressing the impacts of changing disturbance regimes on forest ecosystem services. Journal of applied ecology, 53(1), pp.120-129. 
Short, K. C., Finney, M. A., Scott, J. H., Gilbertson-Day, J. W., and Grenfell, I. C. 2016. Spatial dataset of probabilistic wildfire risk components for the conterminous United States. http://doi.org/https://doi.org/10.2737/RDS-2016-0034

Singh, J., Lumsden, C. 1990. Theory and Research in Organizational Ecology Annual Review of Sociology. 16(1), 161-195. https://dx.doi.org/10.1146/annurev.so.16.080190.001113

Sjostedt, G., and Linnerooth-Bayer, J. 2001, March 1. Transboundary Risk Management. Routledge. http://doi.org/doi:10.4324/9781849776271

Smith, A. M. S., Kolden, C. A., Paveglio, T. B., Cochrane, M. A., Bowman, D. M., Moritz, M. A., ... Abatzoglou, J. T. 2016. The Science of Firescapes: Achieving Fire-Resilient Communities. BioScience, 66(2), 130-146. http://doi.org/10.1093/biosci/biv182

Snijders, T.A., Pattison, P.E., Robins, G.L. and Handcock, M.S., 2006. New specifications for exponential random graph models. Sociological Methodology, 36(1), pp.99-153.

Spies, T. A., White, E. M., Kline, J. D., Fischer, A. P., Ager, A. A., Bailey, J., ... Koch, J. 2014. Examining fire-prone forest landscapes as coupled human and natural systems Examining fire-prone forest landscapes as coupled human and natural systems. Ecology and Society, 19(3. http://doi.org/10.5751/ES-06584-190309

Steelman, T. 2008. Addressing the Mitigation Paradox at the Community Level. In W. E. Martin, C. Raish, and B. Kent (Eds.), Wildfire Risk (pp. 64-80. Resources for the Future. 
Steelman, T. 2016. U.S. wildfire governance as social-ecological problem. Ecology and Society, 21(4. http://doi.org/10.5751/ES-08681-210403

Steelman, T., and Burke, C. A. 2007. Is wildfire policy in the United States sustainable? Journal of Forestry, 105(2), 67-72. http://doi.org/10.2139/ssrn.1931057

Stephens, S. L., Iver, J. D. M., Boerner, R. E. J., Fettig, C. J., Joseph, B., Hartsough, B. R., ... Schwilk, D. W. 2012. The Effects of Forest Fuel-Reduction Treatments in the United States. BioScience, 62(6), 549-560. http://doi.org/10.1525/bio.2012.62.6.6

Stephens, S., Burrows, N., Buyantuyev, A., Gray, R., Keane, R., Kubian, R., Liu, S., Seijo, F., Shu, L., Tolhurst, K., Wagtendonk, J. 2014. Temperate and boreal forest mega-fires: characteristics and challenges Frontiers in Ecology and the Environment 12(2), 115-122. https://dx.doi.org/10.1890/120332

Syphard, A. D., Bar Massada, A., Butsic, V., and Keeley, J. E. 2013. Land Use Planning and Wildfire: Development Policies Influence Future Probability of Housing Loss. PLoS ONE, 8(8), 1-12. http://doi.org/10.1371/journal.pone.0071708

Syphard, A. D., Brennan, T. J., and Keeley, J. E. 2014. The role of defensible space for residential structure protection during wildfires. International Journal of Wildland Fire, 23(8), 1165-1175. http://doi.org/10.1071/WF13158

Syphard, A. D., Keeley, J. E., Massada, A. B., Brennan, T. J., and Radeloff, V. C. 2012. Housing arrangement and location determine the likelihood of housing loss due to wildfire. PLoS ONE, 7(3. http://doi.org/10.1371/journal.pone.0033954 
Taylor, P.B., 2019. The Good, the Bad, and the Unnecessary: Forest Fire Suppression Funding and Forest Management Provisions of the Consolidated Appropriations Act of 2018. Public Land and Resources Law Review, 41(1), p.7.

Thompson, M.P., MacGregor, D.G., Dunn, C.J., Calkin, D.E. and Phipps, J., 2018. Rethinking the Wildland Fire Management System. Journal of Forestry.

U.S. Congress. 2018. Agricultural Act of 2018. Washington DC: U.S. Government Printing Office.

U.S. Forest Service (USFS. 2003b. Healthy Forests Restoration Act of 2003: summary of implementation actions. U.S. Department of Agriculture, Washington, D.C., USA. [online] URL: http://

www.forestsandrangelands.gov/resources/overview/hfraimplementation122004.shtml

U.S. Geological Survey, Gap Analysis Program (GAP. May 2016. Protected Areas Database of the United States (PAD-US), version 1.4 Combined Feature Class. USDA and USDI. 2001. Urban Wildland Interface Communities Within the Vicinity of Federal Lands That Are at High Risk From Wildfire. Federal Register, 66, 751777. Retrieved from https://www.federalregister.gov/documents/2001/01/04/0152/urban-wildland-interface-communities-within-the-vicinity-of-federal-landsthat-are-at-high-risk-from

USDA and USDI. 2018. The National Cohesive Wildland Fire Management Strategy. Retrieved May 1, 2018, from https://www.forestsandrangelands.gov/strategy/thestrategy.shtml 
USDA. 2018. Towards Shared Stewardship Across Landscapes: An Outcome-Based Investment Strategy. https://www.fs.fed.us/sites/default/files/toward-sharedstewardship.pdf

USGS Gap Analysis Program. 2016. Protected Areas Database of the United States. Retrieved June 20, 2010, from http://gapanalysis.usgs.gov.

Vaillant, N.M. and Reinhardt, E.D., 2017. An evaluation of the Forest Service Hazardous Fuels Treatment Program-Are we treating enough to promote resiliency or reduce hazard? Journal of Forestry, 115(4), pp.300-308.

Westerling, A.L., 2016. Increasing western US forest wildfire activity: sensitivity to changes in the timing of spring. Philosophical Transactions of the Royal Society B: Biological Sciences, 371(1696), p.20150178.

Wildland Fire Leadership Council. 2014. The National Strategy. Retrieved from https://www.forestsandrangelands.gov/strategy/index.shtml

Williams, D. R., Jakes, P. J., Burns, S., Cheng, A. S., Nelson, K. C., Sturtevant, V., ... Souter, S. G. 2012. Community Wildfire Protection Planning: The Importance of Framing, Scale, and Building Sustainable Capacity. Journal of Forestry, 110(8), 415-420. http://doi.org/10.5849/jof.12-00.?

Williams, J. 2013. Exploring the onset of high-impact mega-fires through a forest land management prism Forest Ecology and Management 294(), 4-10. https://dx.doi.org/10.1016/j.foreco.2012.06.030

Williams, K.J., Ford, R.M. and Rawluk, A., 2018. Values of the public at risk of wildfire and its management. International Journal of Wildland Fire, 27(10), pp.665-676. 